Cochrane Database of Systematic Reviews

\title{
Exercise-based cardiac rehabilitation in heart transplant recipients
} (Review)

Anderson L, Nguyen TT, Dall CH, Burgess L, Bridges C, Taylor RS

Anderson L, Nguyen TT, Dall CH, Burgess L, Bridges C, Taylor RS.

Exercise-based cardiac rehabilitation in heart transplant recipients.

Cochrane Database of Systematic Reviews 2017, Issue 4. Art. No.: CD012264.

DOI: 10.1002/14651858.CD012264.pub2.

www.cochranelibrary.com 
TABLE OF CONTENTS

HEADER 1

ABSTRACT

PLAIN LANGUAGE SUMMARY

SUMMARY OF FINDINGS

BACKGROUND

OBJECTIVES

METHODS

Figure 1.

RESULTS

Figure 2.

Figure 3.

Figure 4.

DISCUSSION

AUTHORS' CONCLUSIONS

ACKNOWLEDGEMENTS

REFERENCES

CHARACTERISTICS OF STUDIES

DATA AND ANALYSES

Analysis 1.1. Comparison 1 Exercise versus no-exercise, Outcome 1 Exercise capacity (VO2peak).

Analysis 1.2. Comparison 1 Exercise versus no-exercise, Outcome 2 Sensitivity analysis (excluding Kobashigawa 1999). ......

Analysis 1.3. Comparison 1 Exercise versus no-exercise, Outcome 3 Sensitivity analysis (excluding Wu 2008).

Analysis 1.4. Comparison 1 Exercise versus no-exercise, Outcome 4 Sensitivity analysis (excluding Kobashigawa 1999 and Wu 2008).

Analysis 2.1. Comparison 2 High-intensity interval training versus continued moderate-intensity exercise, Outcome 1 Exercise capacity (VO2peak).

ADDITIONAL TABLES

APPENDICES

CONTRIBUTIONS OF AUTHORS

DECLARATIONS OF INTEREST

SOURCES OF SUPPORT

DIFFERENCES BETWEEN PROTOCOL AND REVIEW

INDEX TERMS 
[Intervention Review]

\section{Exercise-based cardiac rehabilitation in heart transplant recipients}

Lindsey Anderson ${ }^{1}$, Tricia T Nguyen 1 , Christian H Dall2 ${ }^{2}$ Laura Burgess ${ }^{3}$, Charlene Bridges ${ }^{4}$, Rod S Taylor ${ }^{1}$

1 Institute of Health Research, University of Exeter Medical School, Exeter, UK. 2Dept. of Cardiology, Dept. of Physical Therapy and IOC Sports Institute Copenhagen, Bispebjerg Hospital, University of Copenhagen, Copenhagen, Denmark. ${ }^{3}$ Cardiac Rehabilitation, Wythenshawe Hospital, University Hospital of South Manchester NHS Foundation Trust, Manchester, UK. ${ }^{4}$ Farr Institute of Health Informatics Research, University College London, London, UK

Contact address: Rod S Taylor, Institute of Health Research, University of Exeter Medical School, Veysey Building, Salmon Pool Lane, Exeter, EX2 4SG, UK. r.taylor@exeter.ac.uk.

Editorial group: Cochrane Heart Group.

Publication status and date: New, published in Issue 4, 2017.

Citation: Anderson L, Nguyen TT, Dall CH, Burgess L, Bridges C, Taylor RS. Exercise-based cardiac rehabilitation in heart transplant recipients. Cochrane Database of Systematic Reviews 2017, Issue 4. Art. No.: CD012264. DOI: 10.1002/14651858.CD012264.pub2.

Copyright @ 2017 The Cochrane Collaboration. Published by John Wiley \& Sons, Ltd.

\section{A B S T R A C T}

\section{Background}

Heart transplantation is considered to be the gold standard treatment for selected patients with end-stage heart disease when medical therapy has been unable to halt progression of the underlying pathology. Evidence suggests that aerobic exercise training may be effective in reversing the pathophysiological consequences associated with cardiac denervation and prevent immunosuppression-induced adverse effects in heart transplant recipients.

\section{Objectives}

To determine the effectiveness and safety of exercise-based rehabilitation on the mortality, hospital admissions, adverse events, exercise capacity, health-related quality of life, return to work and costs for people after heart transplantation.

\section{Search methods}

We searched the Cochrane Central Register of Controlled Trials (CENTRAL) in the Cochrane Library, MEDLINE (Ovid), Embase (Ovid), CINAHL (EBSCO) and Web of Science Core Collection (Thomson Reuters) to June 2016. We also searched two clinical trials registers and handsearched the reference lists of included studies.

\section{Selection criteria}

We included randomised controlled trials (RCTs) of parallel group, cross-over or cluster design, which compared exercise-based interventions with (i) no exercise control (ii) a different dose of exercise training (e.g. low-versus high-intensity exercise training); or (iii) an active intervention (i.e. education, psychological intervention). The study population comprised adults aged 18 years or over who had received a heart transplant.

\section{Data collection and analysis}

Two review authors independently screened all identified references for inclusion based on pre-specified inclusion criteria. Disagreements were resolved by consensus or by involving a third person. Two review authors extracted outcome data from the included trials and assessed their risk of bias. One review author extracted study characteristics from included studies and a second author checked them against the trial report for accuracy.

\section{Main results}

We included 10 RCTs that involved a total of 300 participants whose mean age was 54.4 years. Women accounted for fewer than $25 \%$ of all study participants. Nine trials which randomised 284 participants to receive exercise-based rehabilitation (151 participants) or no 
exercise (133 participants) were included in the main analysis. One cross-over RCT compared high-intensity interval training with continued moderate-intensity training in 16 participants. We reported findings for all trials at their longest follow-up (median 12 weeks).

Exercise-based cardiac rehabilitation increased exercise capacity $\left(\mathrm{VO}_{2 \text { peak }}\right)$ compared with no exercise control ( $\mathrm{MD} 2.49 \mathrm{~mL} / \mathrm{kg} / \mathrm{min}, 95 \%$ $\mathrm{Cl} 1.63$ to 3.36; $\mathrm{N}=284$; studies = 9; moderate quality evidence). There was evidence from one trial that high-intensity interval exercise training was more effective in improving exercise capacity than continuous moderate-intensity exercise $(\mathrm{MD} 2.30 \mathrm{~mL} / \mathrm{kg} / \mathrm{min}, 95 \% \mathrm{Cl} 0.59$ to 4.01; N = 16; 1 study). Four studies reported health-related quality of life (HRQoL) measured using SF-36, Profile of Quality of Life in the Chronically III (PLC) and the World Health Organization Quality Of Life (WHOQOL) - BREF. Due to the variation in HRQoL outcomes and methods of reporting we were unable to meta-analyse results across studies, but there was no evidence of a difference between exercisebased cardiac rehabilitation and control in 18 of $21 \mathrm{HRQoL}$ domains reported, or between high and moderate intensity exercise in any of the $10 \mathrm{HRQ}$ oL domains reported. One adverse event was reported by one study.

Exercise-based cardiac rehabilitation improves exercise capacity, but exercise was found to have no impact on health-related quality of life in the short-term (median 12 weeks follow-up), in heart transplant recipients whose health is stable.

There was no evidence of statistical heterogeneity across trials for exercise capacity and no evidence of small study bias. The overall risk of bias in included studies was judged as low or unclear; more than $50 \%$ of included studies were assessed at unclear risk of bias with respect to allocation concealment, blinding of outcome assessors and declaration of conflicts of interest. Evidence quality was assessed as moderate according to GRADE criteria.

\section{Authors' conclusions}

We found moderate quality evidence suggesting that exercise-based cardiac rehabilitation improves exercise capacity, and that exercise has no impact on health-related quality of life in the short-term (median 12 weeks follow-up), in heart transplant recipients. Cardiac rehabilitation appears to be safe in this population, but long-term follow-up data are incomplete and further good quality and adequatelypowered trials are needed to demonstrate the longer-term benefits of exercise on safety and impact on both clinical and patient-related outcomes, such as health-related quality of life, and healthcare costs.

\section{PLAIN LANGUAGE SUMMARY}

\section{Exercise-based cardiac rehabilitation for patients following a heart transplantation}

\section{Review question}

We wanted to find out if exercise training versus no exercise training following heart transplant effects numbers of deaths, hospital admissions, harms, exercise capacity, health-related quality of life, return to work and costs.

\section{Background}

Heart transplantation is considered to be the best treatment for some people with heart disease whose medical therapy cannot stop progression of their illness. Clinical practice guidelines recommend exercise training for people who receive heart transplants, despite limited information on the long-term benefits or harms.

\section{Search date}

We searched up to June 2016.

\section{Study characteristics}

We searched for randomised controlled trials (experiments that randomly allocate participants to one of two or more treatment groups) looking at the effectiveness of exercise-based rehabilitation programmes compared with no exercise, or a different type or intensity of exercise, in people aged 18 years or over, who were heart transplant recipients.

\section{Key results}

We included 10 trials that studied 300 people who were heart transplant recipients. Nine studies compared exercise with no exercise; one study compared high-intensity interval training with continuous moderate-intensity exercise.

We found that exercise-based cardiac rehabilitation led to an increase in the exercise capacity of heart transplant recipients compared to not undertaking exercise. There was evidence of better exercise capacity following high-intensity interval training compared to continuous moderate-intensity exercise. Four studies reported health-related quality of life, but there was no evidence of differences between exercise training and no exercise training in most (18/21) aspects reported, or between high- and moderate-intensity exercise.

One adverse event was reported in one study. 
Risk of bias in the included studies was assessed as low or unclear; lack of reporting made assessment for more than half of included studies challenging.

\section{Study funding sources}

Six (of 10) trials reported sources of funding. None reported funding from agencies with commercial interests in the results.

\section{Quality of the evidence}

Poor reporting or few participants in the analyses led to evidence quality being judged as moderate for both exercise capacity and healthrelated quality of life. Evidence suggested that exercise-based cardiac rehabilitation improves exercise capacity, and that exercise has no impact on health-related quality of life in the short-term (median 12 weeks follow-up), in heart transplant recipients whose health is stable. Further research is needed to establish long-term impacts of exercise-based rehabilitation on important aspects such as risk of death and hospital admission. 
SUMMARY OF FINDINGS

\section{Summary of findings for the main comparison. Exercise versus no exercise for post-heart transplant recipients}

\section{Exercise versus no exercise for post-heart transplant recipients}

Patient or population: Post-heart transplant recipients

Settings: Home and centre (hospital, cardiac rehabilitation clinic or physiotherapy department)

Intervention: Exercise versus no exercise

\begin{tabular}{|c|c|c|c|c|c|}
\hline \multirow[t]{3}{*}{ Outcomes } & \multicolumn{2}{|c|}{ Illustrative comparative risks ${ }^{\star}(95 \% \mathrm{Cl})$} & \multirow{3}{*}{$\begin{array}{l}\text { Relative effect } \\
(95 \% \mathrm{Cl})\end{array}$} & \multirow{3}{*}{$\begin{array}{l}\text { No of Participants } \\
\text { (studies) }\end{array}$} & \multirow{3}{*}{$\begin{array}{l}\text { Quality of the evi- } \\
\text { dence } \\
\text { (GRADE) }\end{array}$} \\
\hline & Assumed risk & Corresponding risk & & & \\
\hline & Control & Exercise versus no exercise & & & \\
\hline $\begin{array}{l}\text { Exercise capacity } \\
\left(\mathrm{VO}_{2 \text { peak }}\right) \\
\text { Follow-up: median } 9 \text { months }\end{array}$ & & $\begin{array}{l}\text { The mean exercise capacity in the interven- } \\
\text { tion groups was } \\
\mathbf{2 . 4 9} \text { higher ( } 1.63 \text { to } 3.36 \text { higher) }\end{array}$ & & $\begin{array}{l}284 \\
\text { (9 studies) }\end{array}$ & $\begin{array}{l}\oplus \oplus \oplus \ominus \\
\text { moderate } 1\end{array}$ \\
\hline $\begin{array}{l}\text { Health-related quality of } \\
\text { life } \\
\text { Various HRQoL measures } \\
\text { Follow-up: median } 12 \\
\text { months }\end{array}$ & $\begin{array}{l}\text { HRQoL in compara- } \\
\text { tor }>\text { HRQoL in inter- } \\
\text { vention, in } 16 / 19 \text { do- } \\
\text { mains }\end{array}$ & $\begin{array}{l}\text { HRQoL in intervention }>H R Q o L \text { in compara- } \\
\text { tor, in } 3 / 19 \text { domains }\end{array}$ & & $\begin{array}{l}120 \\
\text { (3 studies) }\end{array}$ & $\begin{array}{l}\oplus \oplus \oplus \ominus \\
\text { moderate } 1\end{array}$ \\
\hline
\end{tabular}

*The basis for the assumed risk (e.g. the median control group risk across studies) is provided in footnotes. The corresponding risk (and its $95 \%$ confidence interval) is based on the assumed risk in the comparison group and the relative effect of the intervention (and its $95 \% \mathrm{Cl}$ ).

Cl: Confidence interval; RR: Risk ratio;

GRADE Working Group grades of evidence

High quality: Further research is very unlikely to change our confidence in the estimate of effect.

Moderate quality: Further research is likely to have an important impact on our confidence in the estimate of effect and may change the estimate.

Low quality: Further research is very likely to have an important impact on our confidence in the estimate of effect and is likely to change the estimate.

Very low quality: We are very uncertain about the estimate.

1 Random sequence generation, allocation concealment or blinding of outcome assessors were poorly described in 50\% or more of included studies.

\section{Summary of findings 2 . High-intensity versus moderate-intensity exercise}

High-intensity versus moderate intensity exercise 
Patient or population: Post-heart transplant recipients

Settings: Physiotherapy Department

Intervention: High-intensity interval training

Comparison: Continued moderate-intensity exercise

\begin{tabular}{|c|c|c|c|c|c|}
\hline \multirow[t]{3}{*}{ Outcomes } & \multicolumn{2}{|c|}{ Illustrative comparative risks* $(95 \% \mathrm{CI})$} & \multirow{3}{*}{$\begin{array}{l}\text { Relative effect } \\
(95 \% \mathrm{Cl})\end{array}$} & \multirow{3}{*}{$\begin{array}{l}\text { No of Participants } \\
\text { (studies) }\end{array}$} & \multirow{3}{*}{$\begin{array}{l}\text { Quality of the evi- } \\
\text { dence } \\
\text { (GRADE) }\end{array}$} \\
\hline & Assumed risk & Corresponding risk & & & \\
\hline & $\begin{array}{l}\text { Moderate intensity exer- } \\
\text { cise }\end{array}$ & High-intensity exercise & & & \\
\hline $\begin{array}{l}\text { Exercise capacity } \\
\left(\mathrm{VO}_{2 \text { peak }}\right) \\
\text { Follow-up: } 12 \\
\text { weeks }\end{array}$ & $\begin{array}{l}\text { The mean exercise capac- } \\
\text { ity in the control group } \\
\text { was } 2.6 \mathrm{mg} / \mathrm{kg} / \mathrm{min} \text { (SD } \\
2.2 \text { ) }\end{array}$ & $\begin{array}{l}\text { The mean exercise capacity in the intervention } \\
\text { group was } 4.9 \mathrm{mg} / \mathrm{kg} / \mathrm{min} \text { (SD 2.7) } \\
\text { The mean exercise capacity in the intervention } \\
\text { groups was } 2.30 \text { higher ( } 0.59 \text { to } 4.01 \text { higher) }\end{array}$ & & $\begin{array}{l}16 \\
\text { (1 study) }\end{array}$ & $\begin{array}{l}\oplus \oplus \oplus \ominus \\
\text { moderate } 1\end{array}$ \\
\hline $\begin{array}{l}\text { Health-related } \\
\text { quality of life } \\
\text { Follow-up: } 12 \\
\text { weeks }\end{array}$ & $\begin{array}{l}\text { Mental component score = } \\
89.3(7.4) \\
\text { Physical component score } \\
=76.4(11.8)\end{array}$ & $\begin{array}{l}\text { Mental component score }=90.0(6.6) \\
\text { Physical component score }=77.5(8.9) \\
\text { HRQoL of patients receiving high-intensity interval } \\
\text { training = HRQoL of patients receiving continued } \\
\text { moderate-intensity exercise }\end{array}$ & & $\begin{array}{l}16 \\
\text { (1 study) }\end{array}$ & $\begin{array}{l}\oplus \oplus \oplus \ominus \\
\text { moderate } 1\end{array}$ \\
\hline
\end{tabular}

*The basis for the assumed risk (e.g. the median control group risk across studies) is provided in footnotes. The corresponding risk (and its $95 \%$ confidence interval) is based on the assumed risk in the comparison group and the relative effect of the intervention (and its $95 \% \mathrm{Cl}$ ).

Cl: Confidence interval; RR: risk ratio; RR; HRQoL: health-related quality of life

GRADE Working Group grades of evidence

High quality: Further research is very unlikely to change our confidence in the estimate of effect.

Moderate quality: Further research is likely to have an important impact on our confidence in the estimate of effect and may change the estimate.

Low quality: Further research is very likely to have an important impact on our confidence in the estimate of effect and is likely to change the estimate.

Very low quality: We are very uncertain about the estimate.

1 This evidence is based on the result of only one cross-over study with just 16 participants, resulting in a lack of precision 


\section{B A C K G R O U N D}

\section{Description of the condition}

Despite modern advances in medical treatment, heart transplantation is considered to be the gold standard treatment modality for selected people with end-stage heart disease (Yancy 2013). In general, people with advanced heart disease should be considered for heart transplantation if optimal medical therapy and cardiac resynchronisation therapy have not improved symptoms or halted progression of the underlying pathology (Shah 2012; Yancy 2013). The American College of Cardiology Foundation/ American Heart Association (ACCF/AHA) guidelines presents a description of optimal medical therapy (Yancy 2013). About 3800 heart transplants are currently performed annually worldwide (ISHLT 2015). Most heart transplants are performed in the US (2000 to 2300 annually), where in 2013 , over $50 \%$ were performed in people with cardiomyopathy, about a third in people with coronary heart disease, and fewer than 5\% in people with congenital heart disease (Colvin-Adams 2015).

Since the first heart transplantation over 45 years ago, there has been significant progress in the field. Survival and quality of life are now generally considered to be excellent, with many heart transplant recipients now being able to return to work (Hollenberg 2004; Lund 2013). Since the 1970s, one-year post-transplantation survival rates have improved from 30\% to almost 90\% (ColvinAdams 2015; Stehlik 2012), and three- and five-year survival rates are now approximately $80 \%$ and $75 \%$, respectively (Colvin-Adams 2015).

Although advances in transplant candidate selection, surgical techniques, immunosuppressive modalities, and postoperative care have led to improved long-term outcomes after transplantation (Butler 2004; Lietz 2007), long-term survival remains limited, and exercise capacity and health-related quality of life (HRQoL) of heart transplant recipients remain inferior to age-matched healthy people. Pre-operatively, most heart transplant candidates have chronic debilitating cardiac illness, with concomitant poor exercise capacity and cardiac cachexia. Post-transplantation, exercise capacity remains diminished due to decreased chronotropic competence associated with cardiac allograft denervation (Bengel 2001; Kao 1994; Kao 1995), diastolic dysfunction (Kao 1994; Kao 1995; Paulus 1992), impaired peripheral vascular function (Haykowsky 2005; Jendzjowsky 2007), as well as changes in skeletal muscle strength and biochemistry due to post-transplant deconditioning or treatment with highdose immunosuppressive therapy (Braith 2000; Lampert 1996). Maximum exercise capacity is markedly improved after heart transplantation, with patients achieving their maximal exercise capacity by one to two years' post-transplantation (Kobashigawa 1999; Mandak 1995). However, exercise capacity remains impaired compared with healthy people, and decreases thereafter at a mean rate of approximately 5\% per year (Douard 1997; Mandak 1995). This compares with a rate of decline of approximately $3 \%$ to $6 \%$ per decade in younger healthy people (aged in their 20s and 30s) which is believed to accelerate to more than $20 \%$ per decade in older people aged over 70 years (Fleg 2005).

Recent US data shows that $36 \%$ of heart recipients are hospitalised during the first year post-transplantation, and $61 \%$ are hospitalised within four years (Colvin-Adams 2014; Colvin-Adams 2015). The most common reasons for hospitalisation are transplant complications and infections. Acute rejection, which used to be one of the main causes of mortality in transplant recipients, now has relatively low incidence due to modern drug therapies, although post-transplant acute rejection still occurs in $24 \%$ of heart recipients in the first year post-transplantation and $45 \%$ of heart recipients within five years. The most common causes of early mortality during the first three months after transplant are infection, cardiovascular and cerebrovascular events, and graft failure (Colvin-Adams 2015). In the long term, mortality is most often the result of cardiovascular and cerebrovascular events, with coronary allograft vasculopathy are the main causes of death in heart transplant recipients after five years (Taylor 2007; Tjang 2008).

New challenges to heart transplantation have recently arisen. In the last decade, antibody-mediated rejection has been recognised as a particularly challenging form of rejection in heart transplant recipients, which is a major cause of allograft failure and is associated with a greater risk of coronary allograft vasculopathy and death (Colvin 2015; Nair 2011). The demographics of heart transplant recipients are also changing, with a greater number of more complicated, older recipients aged in their $60 \mathrm{~s}$ and $70 \mathrm{~s}$, who tend to have higher risks of infection, coronary allograft vasculopathy, and malignancy, which compromise their longterm survival (Kobashigawa 2012). In the US, the proportion of candidates for heart transplantation aged 65 years or older increased from 13\% in 2002 to 20\% in 2012 (Colvin-Adams 2014). Advances in heart surgery have also led to a greater proportion of younger people with congenital heart disease who are surviving past childhood and later develop heart failure. These people can have complex cardiopulmonary anatomy and most have undergone multiple median sternotomies, which increases the risk of postoperative bleeding and mortality (Tonsho 2014). The candidacy for heart transplant has also been altered in recent years by the increase in the management of candidates with mechanical ventricular assist devices prior to transplantation, with almost $40 \%$ of all adult heart transplant recipients now bridged to transplant with a durable device (Stehlik 2014).

\section{Description of the intervention}

Based on current evidence, national and international guidelines on the management of coronary heart disease and heart failure, consistently recommend cardiac rehabilitation as an effective and safe intervention (McMurray 2012; NICE 2013; Yancy 2013). Many definitions of cardiac rehabilitation have been proposed, but the following definition encompasses the key concepts of cardiac rehabilitation: "The coordinated sum of activities required to influence favourably the underlying cause of cardiovascular disease, as well as to provide the best possible physical, mental and social conditions, so that the patients may, by their own efforts, preserve or resume optimal functioning in their community and through improved health behaviour, slow or reverse progression of disease" (BACPR 2012).

Cardiac rehabilitation is a complex intervention that may involve a variety of therapies, including exercise, risk factor management and lifestyle education, behaviour change, psychological support, and strategies that are aimed at targeting traditional risk factors for cardiovascular disease, that is 'comprehensive cardiac rehabilitation' (Corra 2005). The patient groups routinely recommended for cardiac rehabilitation include people with post-myocardial infarction, post-revascularisation and valvular procedure or both, heart failure and heart surgery (i.e. bypass 
surgery or valvular surgery, or both). Cardiac rehabilitation programmes have traditionally been offered in a supervised, centre-based setting. However, many people do not receive rehabilitation (Bethell 2008), and with uptake of cardiac rehabilitation for both coronary heart disease and heart failure currently at sub optimal levels (Dalal 2012; NICE 2013; Tierney 2011), home-based cardiac rehabilitation programmes are increasingly being introduced to widen access and participation.

\section{How the intervention might work}

Recent Cochrane reviews of exercise-based cardiac rehabilitation in coronary heart disease and heart failure populations have shown cardiac rehabilitation to be a safe and effective intervention in reducing the risk of hospital admissions and conferring important improvements in health-related quality of life in these patient groups (Anderson 2016; Taylor 2014).

For decades, exercise restrictions were applied to heart transplant recipients, as it was believed that the transplanted heart remained denervated, with a higher resting heart rate and a reduced heart rate response (chronotropic incompetence). However, there is now ample evidence that both endurance and resistance training are well tolerated in heart transplant recipients, and it is widely believed that re-innervation and autonomic nervous control can be improved by physical training (Bernardi 2007), although it is unclear whether time alone may result in the normalisation of chronotropic responses, or if this occurs in combination with exercise and other factors or both (Nytrøen 2013c).

There is evidence from small, non-randomised studies that aerobic exercise training is an effective intervention to reverse the pathophysiological consequences associated with cardiac denervation and preventing immunosuppression-induced adverse effects (Braith 2005; Braith 2008; Haykowsky 2005; Keteyian 1991; Kobashigawa 1999a; Marconi 2003). In an assessment of the time course of physical reconditioning and skeletal muscle adaptation by exercise training in people five years' post-transplantation, a persistent improvement in exercise capacity was reported, indicating that exercise training could counteract the negative side effects of immunosuppressive treatment on skeletal muscles (Tegtbur 2005). In a more recent randomised controlled trial (RCT), supervised exercise training was reported to improve peak oxygen uptake in clinically stable heart recipients. This improvement was thought to be as a function of favourable skeletal muscle adaptations that result in increased oxygen utilisation by the active muscles (Haykowsky 2009). Furthermore, results from several randomised trials suggest that high-intensity interval training is safe in heart transplant recipients (Haykowsky 2009; Hermann 2011; Nytrøen 2012), and leads to superior improvements in peak oxygen uptake compared with moderate exercise (Dall 2014).

Large epidemiological studies have demonstrated the existence of an inverse and independent association between exercise capacity and mortality in apparently healthy participants (Kokkinos 2008), older men (Kokkinos 2010b), and people with documented cardiovascular disease (Kokkinos 2008; Myers 2002). Indeed, a 1.0 metabolic equivalent (MET; 1 MET $=3.5 \mathrm{~mL} / \mathrm{kg} / \mathrm{min}$ ) increase in exercise capacity has been shown to translate into a $12 \%$ improvement in survival in people with existing cardiovascular disease (Kokkinos 2010a). However, uncertainty remains regarding the precise role that exercise may play in reversing the abnormal cardiovascular and skeletal muscle function that remains after heart transplantation, and whether such an exercise-based intervention has an effect on long-term survival of transplant recipients.

\section{Why it is important to do this review}

A 2010 position paper from the Cardiac Rehabilitation Section of the European Association of Cardiovascular Prevention and Rehabilitation, in reference to post-cardiac transplantation, stated: "Early training programme can be beneficial in the early postoperative period as well as in the long-term. Although exercise training would theoretically delay or prevent CAD progression in the transplanted heart, this still has to be studied" (Piepoli 2010). Nonetheless, despite this apparent lack of evidence, clinical practice guidelines recommend exercise training as standard care for heart transplant recipients. The 2010 guidelines from the International Society of Heart and Lung Transplantation for the care of heart transplant recipients gave a Class 1 recommendation for the routine use of cardiac rehabilitation with aerobic exercise training and resistance exercise after heart transplantation. This was based on a level B rating of the evidence (that is RCT), although "there is currently no information on potential long-term benefits" (Costanzo 2010).

A recent systematic review and meta-analysis identified 9 RCTs of exercise training in 250 participants, 1 month to 7 years following heart, lung, kidney, or liver transplantation (Didsbury 2013). This review concluded that "exercise training is a promising but unproven intervention for improving cardiovascular outcomes of solid organ transplant recipients". Studies of exercise in cardiac transplant recipients have generally been performed early after transplantation using moderate exercise training (Bernardi 2007; Karapolat 2008; Kobashigawa 1999a). While several of these studies have reported that aerobic exercise leads to improved exercise capacity after heart transplantation, the results are not entirely consistent, and little is known about the type, frequency, or intensity of exercise that provides the greatest health benefits for heart transplant recipients. Moreover, little is known about the impact of exercise-based cardiac rehabilitation on health-related quality of life or long-term mortality and morbidity (Hsieh 2011).

Our scoping searches have identified additional RCTs that have been published since the June 2012 search cutoff date for of the systematic review by Didsbury 2013.

\section{O B JECTIVES}

To determine the effectiveness and safety of exercise-based rehabilitation on the mortality, hospital admissions, adverse events, exercise capacity, health-related quality of life, return to work and costs for people after heart transplantation.

\section{METHODS}

\section{Criteria for considering studies for this review \\ Types of studies}

We included parallel-group, cross-over or cluster design randomised controlled trials (RCTs).

\section{Types of participants}

We included adults aged 18 years or older who had received a heart transplant. 
We planned that if studies were identified that met all of our inclusion criteria but included a mixed population of participants, every effort was to be made to obtain outcome data for the subset of relevant participants, by contacting the study authors. If this approach was not viable, then data from the study was to be included in the meta-analysis if the subset of relevant participants comprised $50 \%$ or more of the total included participants, and sensitivity analyses were to be performed with and without data from these studies.

If considerable heterogeneity of the severity of the health status of participants was detected among the included studies, then outcome data would be stratified accordingly.

\section{Types of interventions}

Exercise-based interventions either alone or where exercise training was a component of comprehensive cardiac rehabilitation programme (defined as programmes including such components as health education and psychological interventions in addition to exercise interventions) were sought. For the purposes of this review, exercise included any structured or taught programmes provided in addition to usual medical care, with the aim of improving functional ability and quality of life.

The comparator group could include standard medical care, such as drug therapy, and participants may have received (i) no exercise training; (ii) a different dose of exercise training (for example low- versus high-intensity exercise training); or (iii) an active intervention (that is, education or psychological intervention).

\section{Types of outcome measures}

\section{Primary outcomes}

- Cardiovascular mortality.

- Hospital admissions (all-cause and cardiovascular related).

- Reported adverse events (including those related to (i) exercise and (ii) transplantation treatments or drugs).

\section{Secondary outcomes}

- All-cause mortality.

- Non-cardiovascular mortality (including chronic allograft vasculopathy, acute rejection, malignancy and infection).

- Return to work (including return to either full- or part-time employment, to the same or a reduced role, and to either the previous job or any new employment).

- Exercise capacity assessed by validated outcome measure (e.g. $\mathrm{VO}_{2}$ peak, 6-minute walk test).

- Health-related quality of life assessed using validated instruments (e.g. 36-Item Short Form Health Survey (SF-36), EQ-5D).

- Costs.

- Adherence to the exercise programme.

Reporting of outcomes was not an inclusion or exclusion criterion for the review.

\section{Search methods for identification of studies}

\section{Electronic searches}

We searched the following databases on 27 June 2016:
- Cochrane Central Register of Controlled Trials (CENTRAL) in the Cochrane Library: Issue 5, June 2016;

- Database of Abstracts of Reviews of Effects (DARE) in the Cochrane Library: Issue 2, June 2015;

- Health Technology Assessment (HTA) in the Cochrane Library: Issue 2, June 2016;

- MEDLINE Epub Ahead of Print, In-Process \& Other Non-Indexed Citations, MEDLINE daily and MEDLINE (Ovid): 1946 to 27 June 2016;

- Embase Classic and Embase (Ovid): 1947 to Week 26 2016;

- CINAHL Plus (EBSCO): 1937 to 27 June 2016; and

- Web of Science Core Collection (Thomson Reuters): 1970 to 27 June 2016.

We designed the search strategies with reference to those used for a previous, related systematic review of exercise-based cardiac rehabilitation (Heran 2011). We searched databases using a strategy combining selected MeSH terms and free-text terms relating to exercise-based rehabilitation and heart transplantation, with filters applied to limit to randomised controlled trials (RCTs). We used the Cochrane sensitivity-maximising RCT filter for MEDLINE, and applied terms recommended in the Cochrane Handbook for Systematic Reviews of Interventions for Embase (Lefebvre 2011). We applied adaptations of this filter to CINAHL and Web of Science. We translated the MEDLINE search strategy for use with the other databases using the appropriate controlled vocabulary as applicable. We applied no date limits. We imposed no language or other limitations and gave consideration to variations in terms used and spellings of terms in different countries so that the search strategy did not miss studies because of such variations. See Appendix 1 for details of the search strategies.

\section{Searching other resources}

We handsearched reference lists of retrieved articles and systematic reviews for any studies not identified by the electronic searches. We also searched clinical trial registers on 29 June 2016: World Health Organization International Clinical Trials Registry Platform (WHO ICTRP; http://www.who.int/ictrp/en) and ClinicalTrials.gov (https://clinicaltrials.gov) for ongoing clinical trials and sought expert advice.

\section{Data collection and analysis}

\section{Selection of studies}

Two review authors (TN and LA) independently screened titles and abstracts of all records identified as a result of the search for inclusion and coded them as 'retrieve' (eligible or potentially eligible/unclear) or 'do not retrieve'. In case of disagreement, a third review author was asked to arbitrate (RST). We retrieved the fulltext study reports/publication, and two review authors (TN and LA) independently screened the full text and identified studies for inclusion, and identified and recorded reasons for exclusion of the ineligible studies. Any disagreements were resolved through discussion or, if required, by consulting a third person (RST). We identified and excluded duplicates and collated multiple reports of the same study so that each study rather than each report was the unit of interest in the review. We recorded the selection process in sufficient detail to complete a PRISMA flow diagram (Figure 1) and Characteristics of excluded studies table. 
Figure 1. Summary of selection process

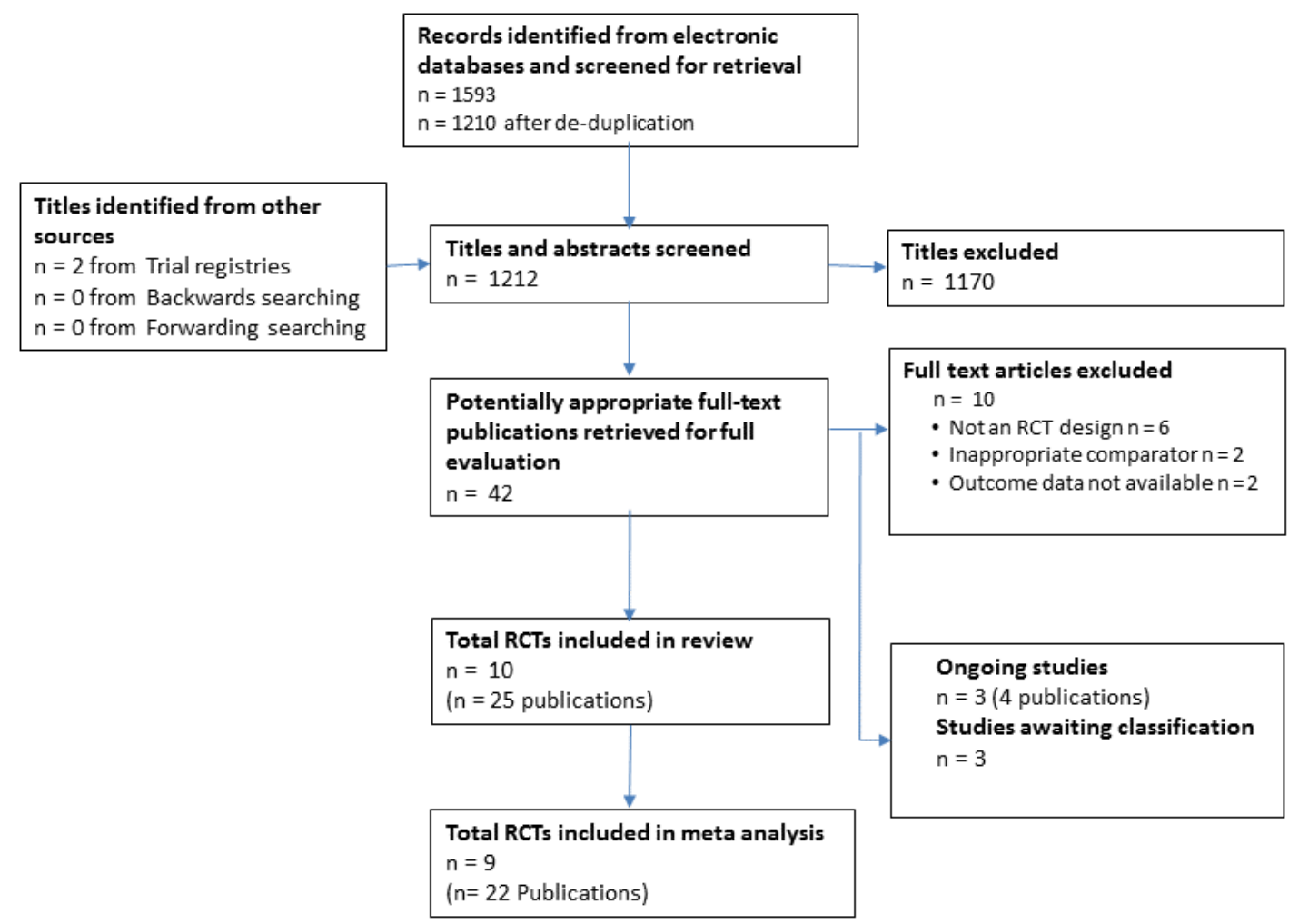

\section{Data extraction and management}

We used a data collection form that had been piloted on one study in the review to extract study characteristics and outcome data. One review author (TN) extracted study characteristics from included studies, and a second review author (LA) checked against the trial report for accuracy. We extracted the following study characteristics.

1. Methods: study design, total duration of study, details of any 'run in' period, number of study centres and location, study setting, withdrawals, and date of study.

2. Participants: $\mathrm{N}$, mean age, age range, gender, time since transplant, inclusion criteria, and exclusion criteria.

3. Interventions: intervention (including mode of exercise, duration, frequency, and intensity), description of usual care, and length of follow-up

Two review authors (TN and LA) independently extracted outcome data from included studies. Any disagreements were resolved by discussion or by involving a third review author (RST). One review author (TN) transferred data into the Review Manager file (RevMan 2014). We double-checked that data were entered correctly by comparing the data presented in the systematic review with the study reports. A second review author (LA) spot-checked study characteristics for accuracy against the trial report. If we found multiple reports of the same study, we assessed the duplicate publications for additional data. We contacted study authors where necessary to provide additional information.

\section{Assessment of risk of bias in included studies}

Two review authors (TN and LA) independently assessed risk of bias for each study using the criteria outlined in the Cochrane Handbook for Systematic Reviews of Interventions (Higgins 2011). We assessed the risk of bias according to the following domains.

1. Random sequence generation.

2. Allocation concealment.

3. Blinding of outcome assessment.

4. Incomplete outcome data.

5. Selective outcome reporting.

6. Other (specifically sources of funding and notable conflicts of interest of trial authors).

We also assessed two further quality criteria: whether the study groups were balanced at baseline, and if the study groups received comparable care (apart from the exercise component of the intervention). These criteria, agreed upon in advance by the review authors, have not been validated but were used to assess quality 
in previous cardiac rehabilitation reviews (Anderson 2016; Brown 2011; Sibilitz 2016; Taylor 2014; Taylor 2015). We assessed these two further quality criteria as follows.

\section{Groups balanced at baseline}

- Low risk of bias: The characteristics of the participants in the intervention and control groups at baseline were reported to be comparable or could be judged to be comparable (e.g. baseline data reported in Table 1 ) in terms of likely main prognostic factors.

- Unclear risk of bias: Whether characteristics of the participants in the intervention and control groups are balanced at baseline is not reported, and reported information was inadequate to assess this aspect (e.g. no table describing baseline characteristics)

- High risk of bias: There is evidence of substantive imbalance in the baseline characteristics of the intervention and control groups with regard to likely major prognostic factors.

\section{Groups received comparable treatment (except exercise)}

- Low risk of bias: All co-interventions were delivered equally across intervention and control groups.

- Unclear risk of bias: Information to assess whether cointerventions were delivered equally across groups was insufficient.

- High risk of bias: The co-interventions were not delivered equally across intervention and control groups.

We graded each potential source of bias as high, low, or unclear and provided a quote from the study report together with a justification for our judgement in the 'Risk of bias' table. We summarised the 'Risk of bias' judgements across different studies for each of the domains listed. Where information on risk of bias related to unpublished data or correspondence with a trialist, this was noted in the 'Risk of bias' table.

When considering treatment effects, we took into account the risk of bias for the studies that contributed to that outcome.

\section{Assessment of bias in conducting the systematic review}

We conducted the review according to the published protocol and reported any deviations in the Differences between protocol and review section of the systematic review.

\section{Unit of analysis issues}

We identified one cross-over trial that met our inclusion criteria (Dall 2014). In accordance with Section 16.4 of the Cochrane Handbook for Systematic Reviews of Intervention (Higgins 2011), we included data from both periods of this cross-over trial because each of the following conditions defined in our protocol were met: (i) the five month washout period was considered long enough to prevent carry-over (generally considered to be $>1$ month following an exercise intervention); (ii) no irreversible events such as mortality occurred; and (iii) an appropriate statistical approach had been used by the authors (the pkcross command in STATA).

\section{Dealing with missing data}

Kugler 2008 was identified as a conference abstract, so the authors were contacted and study data were requested. The authors replied that the full paper was not published and that they were not able to provide any further data. This study was therefore excluded.

The author of Pierce 2008 was contacted to request mean and SD values for exercise capacity. While an initial positive reply was received, no data were received. This study was therefore excluded.

The study by Kobashigawa 1999 reported mean exercise capacity values, but did not report standard deviation (SD) values. The author was contacted and SD values were requested, but the author was unable to provide the requested data. A median SD calculated from all of the other included studies, was imputed into the meta-analysis for this study and we explored the impact of including Kobashigawa 1999 on the overall assessment of results in sensitivity analyses (Analysis 1.2; Analysis 1.4).

\section{Assessment of heterogeneity}

We explored heterogeneity amongst included studies qualitatively (by comparing the characteristics of included studies) and quantitatively (using the $\mathrm{Chi}^{2}$ test of heterogeneity and $\mathrm{I}^{2}$ statistic). We used a threshold of $\mathrm{I}^{2}$ greater than $50 \%$ for both dichotomous and continuous outcomes to determine the statistical model to be used for meta-analysis.

\section{Assessment of reporting biases}

Where more than 10 trials could be pooled, we created and examined a funnel plot to explore possible small-study biases for the primary outcomes.

\section{Data synthesis}

Because only continuous data were extracted, data were expressed as mean difference with $95 \%$ confidence intervals. We entered data presented as a scale with a consistent direction of effect.

Where appropriate, and in the absence of substantial statistical heterogeneity ( $\left.P<0.10, \leq I^{2} 50 \%\right)$ associated with an effect estimate, we pooled data from each study using a fixed-effect model.

We used the funnel plot and the Egger test to examine smallstudy bias (Egger 1997). We processed data in accordance with the Cochrane Handbook for Systematic Reviews of Interventions (Higgins 2011). We completed data synthesis and analyses using Review Manager 5.3 software and Stata version 13.0 (RevMan 2014; StataCorp 2013).

\section{Summary of findings table}

Two independent review authors (LA, RST) employed the Grading of Recommendations Assessment, Development and Evaluation (GRADE) approach to interpret result findings and used GRADEpro GDT 2015 to import data from Review Manager to create a 'Summary of findings table'. We aimed to create a 'Summary of findings' table using the following outcomes: all-cause mortality, cardiovascular mortality, non-cardiovascular mortality (including chronic allograft vasculopathy, acute rejection, malignancy, and infection), hospital admissions, adverse events, exercise capacity, and return to work. However, due to lack of data, we were only able to include exercise capacity and health-related quality of life in the GRADE assessment. We used the five GRADE considerations (study limitations, consistency of effect, imprecision, indirectness, and publication bias) to assess the quality of a body of evidence as it relates to the studies that contribute data to the meta- 
analyses for the prespecified outcomes. We used methods and recommendations described in Section 8.5 and Chapter 12 of the Cochrane Handbook for Systematic Reviews of Interventions using GRADEpro software (Higgins 2011). We justified all decisions to down- or up-grade the quality of studies using footnotes, and made comments to aid readers' understanding of the review where necessary.

\section{Subgroup analysis and investigation of heterogeneity}

We anticipated length of follow-up to be a driver of intervention effect, and therefore sought to stratify meta-analysis of each outcome according to the length of trial duration, that is, shortterm follow-up (6 to 12 months), medium-term follow-up (13 to 36 months), and long-term follow-up (more than 36 months). We also aimed to undertake univariate meta-regression to explore heterogeneity and examine potential treatment effect modifiers. We sought to test eight a priori hypotheses that there may be differences in the effect of exercise-based cardiac rehabilitation on total mortality, cardiovascular mortality, and hospitalisations and exercise capacity across particular subgroups:

1. type of cardiac rehabilitation (exercise-only cardiac rehabilitation versus comprehensive cardiac rehabilitation);

2. dose of exercise intervention (dose $=$ number of weeks of exercise training $x$ average number of sessions/week $x$ average duration of session in minutes) (dose $\geq 1000$ units versus dose $<$ 1000 units);

3. follow-up period;

4. year of publication;

5. sample size;

6. setting (home- or centre-based cardiac rehabilitation);

7. study location (continent).

Given the anticipated small ratio of trials to covariates, metaregression would be limited to univariate analysis (Higgins 2011). However, given the small number of included studies, neither metaregression nor stratified meta-analysis were possible.

We aimed to extract results of subgroup analyses, including participant-level subgroup analyses, if reported by individual included studies, for example if a trial reported whether there was a difference in the effectiveness of cardiac rehabilitation between males and females.

\section{Reaching conclusions}

We based our conclusions only on findings from the quantitative or narrative synthesis of included studies for this review. We avoided making recommendations for practice, and our implications for research suggest priorities for future research and outline what the remaining uncertainties are in the area.

\section{Sensitivity analysis}

A sensitivity analysis was conducted to assess the robustness of the findings of the meta-analysis to the inclusion of two studies considered to be at high risk of bias. One study reported exercise capacity as $\mathrm{VO}_{2 \text { Peak }}$ without the standard deviation (SD) (Kobashigawa 1999). The author was contacted, but was unable to provide the required SD values, and therefore a median SD calculated from the other studies, was imputed into the metaanalysis for this study. In a second study, four participants "chose" to move from the intervention group to the comparator group following randomisation, leading to a high risk of selection bias ( $\mathrm{Wu}$ 2008). Results of sensitivity analyses are reported in Analysis 1.2; Analysis 1.3; Analysis 1.4.

\section{RES U L T S}

\section{Description of studies}

\section{Results of the search}

We identified 1593 records through our electronic database search and two records from searching the clinical trials registries. After de-duplication, 1212 abstracts were screened for inclusion, of which 1170 were excluded. The full-text of 42 publications were retrieved, after which 10 studies (25 publications) were identified as meeting our inclusion criteria. We excluded 10 publications (see Characteristics of excluded studies); three studies (four publications) were identified as ongoing (Nytrøen 2016; NCT01760538; NCT02602834); and three studies await classification (Braith 2008; Emmanuel 2015; Tegtbur 2005). No additional publications were identified from reviewing the reference lists of included publications or from forward citation searching. Details of the selection process and reasons for exclusion are summarised in a PRISMA flow diagram (Figure 1) and in the Characteristics of excluded studies table.

\section{Included studies}

Of the 10 included studies, eight compared an exercise-only intervention study with a no exercise comparator, while one compared an exercise plus education programme with a noexercise comparator (Hermann 2011) and one compared highintensity interval training with continued moderate-intensity training (Dall 2014). Details of included studies are listed in the Characteristics of included studies tables.

Five studies were undertaken in Europe (Bernardi 2007; Dall 2014; Hermann 2011; Nytrøen 2012; Tegtbur 2005), two in the USA (Braith 2008; Kobashigawa 1999a) and one each in Canada (Haykowsky 2009), Brazil (Pascoalino 2015) and Taiwan (Wu 2008). All studies were relatively small in sample size (median: $\mathrm{N}=30.5$, range: 16 to 52); the median length of follow up was 12 (range 8 to 52) weeks. Included study participants were generally described as clinically stable and were excluded from the study if they had signs or symptoms of cardiorespiratory disease (Bernardi 2007), tissue rejection (Bernardi 2007; Dall 2014; Hermann 2011; Pascoalino 2015), severe coronary allograft vasculopathy (Dall 2014; Hermann 2011), or the need for revascularisation or other intervention (Nytrøen 2012). The median age of study participants was 54.4 years (range 45 years to 60.6 years). When reported, all studies recruited mostly males (median: $78.4 \%$, range: $69 \%$ to $92.7 \%$ ). Ethnicity was very poorly reported; in the only study that reported participants' ethnicity, most $(77.8 \%)$ were described as white (Kobashigawa 1999). Participants in the exercise programmes were a median of 12 (range 0.5 to 61 ) months post-transplant. Six studies reported sources of study funding; four did not report funding. None of the studies reported receiving funding from an agency with commercial interest in the results.

The exercise programmes were mostly delivered in centre-based settings, two studies included a combination of home- and centrebased exercise sessions (Nytrøen 2012; Pascoalino 2015). Three studies were directed in home-based settings (Bernardi 2007; 
Tegtbur 2003; Wu 2008). In all the included studies, the mode of exercise training used in the programmes was aerobic and were most commonly in the form of static walking, running or cycling. Two studies also reported the inclusion of resistance training in the intervention (Haykowsky 2009; Kobashigawa 1999). The dose of the exercise given varied considerably across the different trials, in overall duration (range 8 to 52 weeks), frequency ( 1 to 5 days/ week), session length (28 to 50 minutes/session) and intensity (reported using different measurements: $85 \%$ to $95 \%$ of maximal heart rate; $60 \%$ to $80 \%$ of maximal oxygen uptake $\left(\mathrm{VO}_{2 \mathrm{max}}\right)$; Borg rating of 11 to 14; Raw Power in Motion (RPM) of $50 \mathrm{rpm}$ to 70 rpm; respiratory compensation point (RCP) of $80 \%$ ). Adherence and fidelity were poorly and inconsistently reported in the included studies; therefore, we were unable to analyse the actual amounts of exercise received or performed by the participants for this review.

\section{Excluded studies}

We excluded 10 studies (see Characteristics of excluded studies). Six studies were not RCTs (Anonymous 2014; Belardinelli 2006; Christensen 2012; Stevinson 1999; Nytrøen 2014; Pokan 2004), two studies had inappropriate comparators (Karapolat 2007; Kawauchi 2013), and outcome data were not available for two studies (Kugler 2008; Pierce 2008).

\section{Studies awaiting classification}

Three studies were identified that await classification (Braith 2005; Emmanuel 2015; Tegtbur 2005). One study aimed to determine the efficacy of resistance exercise in reversing skeletal muscle myopathy in heart transplant recipients, but was not included in the meta analysis as mean $\mathrm{VO}_{2 \text { peak }}$ and standard deviations were not available (Braith 2005). A second study aimed to analyse the effect of exercise on heart rate response in heart transplant recipients (Emmanuel 2015). Unfortunately, we were unable to trace the authors or find the full text of this study. A final study aimed to determine the time course of physical reconditioning and skeletal muscle adaptation late after transplantation (Tegtbur 2005). We were unable to contact the author to confirm if this study was a randomised controlled trial.

We propose that further attempts should be made to obtain required data from the authors of these studies before excluding them from future updates.

\section{Ongoing studies}

Details of ongoing studies are presented in the Characteristics of ongoing studies table. Although two ongoing studies (NCT01760538; NCT02602834) are small in size (randomising 30 and 19 participants respectively), Nytrøen 2016 is a large multicentre collaborative study which aims to enrol 120 participants. However, this study could potentially contribute no data to the analysis because it aims to explore acute response (biomarkers) after a single boost of exercise training; $\mathrm{VO}_{2 \text { peak }}$ and $\mathrm{HRQ}$ oL are measured at baseline only.

\section{Risk of bias in included studies}

Overall, the risk of bias was assessed as low or unclear. Several studies did not report sufficient methodological detail to enable assessment of potential risk of bias. Details of concealment of random allocation, blinding of outcome assessors and declaration of conflicts of interest were the most frequent poorly reported parameters. Risk of bias results are summarised in Figure 2 and Figure 3.

\section{Figure 2. Risk of bias graph: review authors' judgements about each risk of bias item presented as percentages across all included studies}

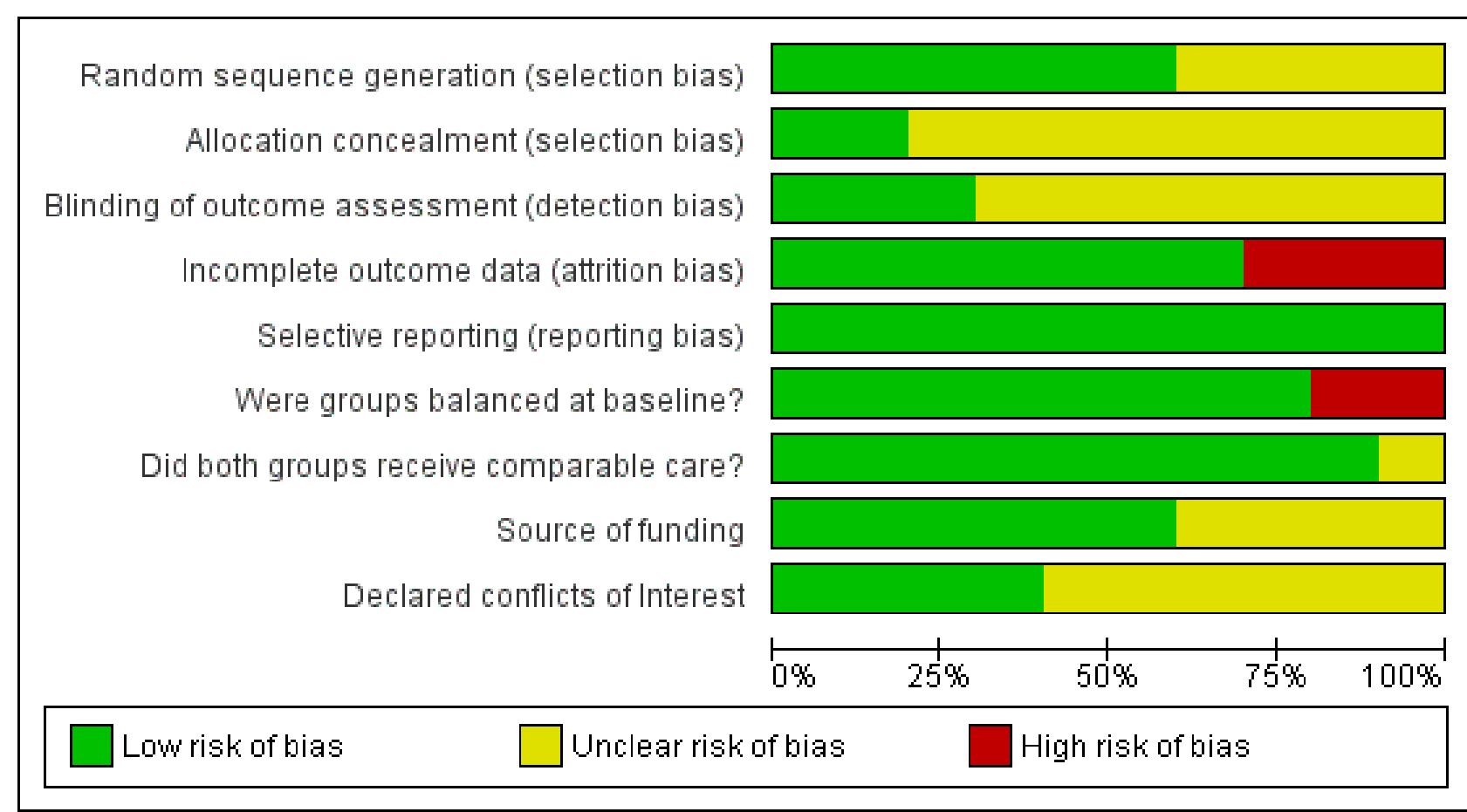


Figure 3. Risk of bias summary: review authors' judgements about each risk of bias item for each included study

\begin{tabular}{|c|c|c|c|c|c|c|c|c|c|}
\hline & 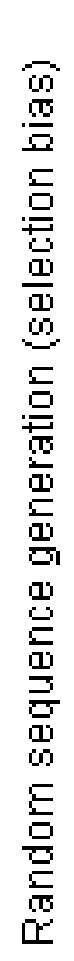 & 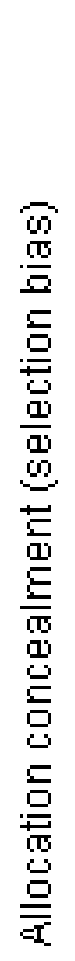 & 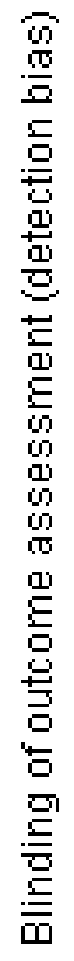 & 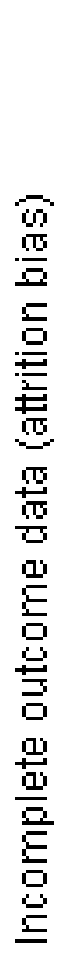 & 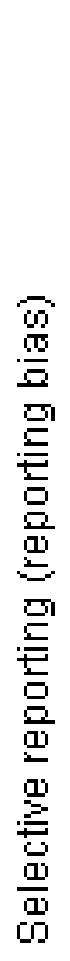 & 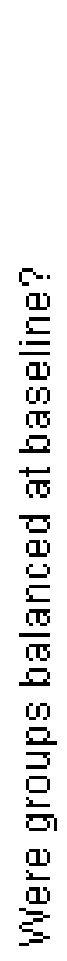 & 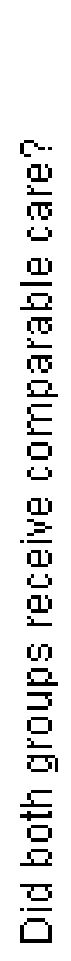 & 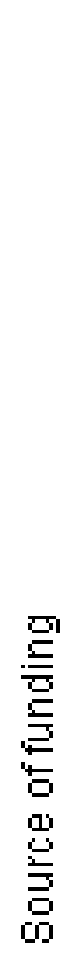 & 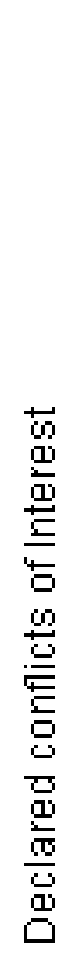 \\
\hline Bernardi 2007 & $?$ & $?$ & $?$ & & & & & $?$ & $?$ \\
\hline Braith 2008 & $?$ & $?$ & $?$ & & & & & & $?$ \\
\hline Dall 2014 & & + & + & & & & & & \\
\hline Haykowsky 2009 & + & $?$ & $?$ & & & & & & $?$ \\
\hline Hermann 2011 & + & + & + & & & & $?$ & & + \\
\hline Kobashigawa 1999 & + & $?$ & $?$ & & & & 0 & $?$ & $?$ \\
\hline Nytrgen 2012 & + & $?$ & $?$ & & & & & + & + \\
\hline Pascoalino 2015 & 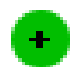 & $?$ & + & & & & & $P$ & \\
\hline Tegtbur 2003 & $?$ & $?$ & $?$ & & & & & $?$ & $?$ \\
\hline Wu 2008 & $?$ & $?$ & $?$ & & & & & $?$ & $?$ \\
\hline
\end{tabular}




\section{Allocation}

Six studies $(60 \%)$ were judged to provide evidence of adequate random sequence generation (Dall 2014; Haykowsky 2009; Hermann 2011; Kobashigawa 1999; Nytrøen 2012; Pascoalino 2015); only two studies (20\%) reported appropriate concealment of allocation methods (Dall 2014; Hermann 2011).

\section{Blinding}

Due to the nature of the intervention, it was not possible to blind those providing the intervention or study participants. Instead we investigated whether those collecting, assessing or analysing outcome data were blinded to group allocation. Blinding of this nature was reported in three studies (30\%) (Dall 2014; Hermann 2011; Pascoalino 2015).

\section{Incomplete outcome data}

All studies clearly stated withdrawal or numbers lost to followup, with the exception of Bernardi 2007 and Kobashigawa 1999. Details of withdrawals are reported in Table 1 . Overall $10.0 \%$ in the intervention group and $10.6 \%$ in the control group were lost to follow-up. None of the studies assessed participants lost to followup for systematic differences compared to those who completed the study. Three studies (30\%) were judged at high risk of bias; these studies reported losses to follow-up greater than 20\% (Braith 2008; Tegtbur 2003; Wu 2008). The remaining studies reported a relatively few losses to follow-up, with a follow-up of $80 \%$ or more reported, and were therefore judged at low risk of bias.

\section{Selective reporting}

We compared the reported outcomes in the results sections to the outcomes described in the methods of the published papers, and where possible, with the prospective clinical trial registry entry. Trial registrations were found for Hermann 2011, Dall 2014 and Nytrøen 2012, but no other published protocols or clinical trial registry entries were found for the other studies. All of the included studies fully reported on all the specified outcomes listed in study reports' methods sections.

\section{Other potential sources of bias}

\section{Groups balanced at baseline}

Eight studies had good balance of participants' baseline characteristics between intervention and control groups. One study demonstrated a statistically significant imbalance between groups at baseline with between-group differences in age (Wu 2008); another reported statistically significant between-group differences in pretransplant diagnosis of Ischaemic heart failure and body mass (Haykowsky 2009).

\section{Groups received comparable treatment}

We sought to specifically investigate the impact of exercise on heart transplant recipients. Most studies compared an exerciseonly intervention with a non-exercise comparator, with all co-interventions (medication and immunosuppressive therapy) delivered equally across intervention and comparator groups. However, in one study, in addition to exercise (the primary intervention), participants also received education (Hermann 2011). As it was unclear whether the comparator group also received education in addition to exercise, this study was judged as being of unclear risk of bias for this category.

\section{Source of funding}

Six included studies declared sources of trial funding and were assessed at low risk of bias for this domain(Braith 2008; Dall 2014; Haykowsky 2009; Hermann 2011; Nytrøen 2012; Pascoalino 2015). Four studies did not report sources of funding and were assessed at unclear risk of bias for this domain (Bernardi 2007; Kobashigawa 1999; Tegtbur 2003; Wu 2008).

\section{Declared conflicts of interest}

Four studies declared no conflicts of interest (Dall 2014; Hermann 2011; Nytrøen 2012; Pascoalino 2015). Conflicts of interest were not reported in six studies, which were assessed at unclear risk of bias (Bernardi 2007; Braith 2008; Haykowsky 2009; Kobashigawa 1999; Tegtbur 2003; Wu 2008).

\section{Effects of interventions}

See: Summary of findings for the main comparison Exercise versus no exercise for post-heart transplant recipients; Summary of findings 2 High-intensity versus moderate-intensity exercise

Nine included studies compared an exercise intervention with a no exercise usual care comparator. Dall 2014 compared high-intensity interval training with continued moderate-intensity training and was reported separately.

\section{Exercise versus no exercise comparator}

Nine studies compared an exercise-only intervention with a no exercise comparator and were included in this main comparison (Bernardi 2007; Braith 2008; Haykowsky 2009; Hermann 2011; Kobashigawa 1999; Nytrøen 2012; Pascoalino 2015; Tegtbur 2003; Wu 2008).

\section{Primary outcomes}

\section{Cardiovascular mortality}

Six studies reported no cardiovascular-related deaths in either the intervention or the comparator groups during the follow-up period (Bernardi 2007; Braith 2008; Haykowsky 2009; Kobashigawa 1999; Pascoalino 2015; Wu 2008). The remaining studies did not report on this outcome (Hermann 2011; Nytrøen 2012; Tegtbur 2003).

\section{Hospital admissions (all-cause and cardiovascular-related)}

Six studies did not report data on hospital admissions. Two studies reported one cardiovascular-related hospital admission in the intervention group, and no admissions in the comparator group (Haykowsky 2009; Nytrøen 2012). One study (Wu 2008) reported that there were no hospital admissions of participants from either group during the follow-up period. Due to the low number of events, we were unable to meta-analyse these data.

\section{Reported adverse events}

Six studies reported no adverse events (including those related to (i) exercise or (ii) transplantation treatments or drugs) in either intervention or comparator group participants during the follow-up period (Braith 2008; Haykowsky 2009; Hermann 2011; Kobashigawa 1999; Pascoalino 2015; Wu 2008). Nytrøen 2012 reported one adverse event in the comparator group (a myocardial infarction resulting in heart failure) and none in the intervention group. Two studies (Bernardi 2007; Tegtbur 2003) did not report if any adverse events occurred during the study follow-up. 


\section{Secondary outcomes}

Of the secondary outcome measures, the only outcome that was consistently reported by all studies was exercise capacity. Three studies reported health-related quality of life (Nytrøen 2012; Tegtbur 2003; Wu 2008). None of the studies reported all-cause mortality, non-cardiovascular mortality, return to work, healthcare costs, or adherence to the exercise programme.

\section{All-cause mortality}

Six studies reported that there were no deaths in either the intervention or the comparator groups, during the follow-up period (Bernardi 2007; Braith 2008; Haykowsky 2009; Kobashigawa 1999; Pascoalino 2015; Wu 2008. Three studies did not report on this outcome (Hermann 2011; Nytrøen 2012; Tegtbur 2003).

\section{Non-cardiovascular mortality}

No included study reported on non-cardiovascular mortality.

\section{Return to work}

No included study reported on return to work.

\section{Exercise capacity}

All included studies in this comparison (9 studies) measured exercise capacity which was reported as peak or maximum oxygen uptake $\left(\mathrm{VO}_{2 \text { Peak }}\right)$. In the pooled analysis, there was evidence of an improvement in the $\mathrm{VO}_{2 \text { peak }}$ in participants undertaking an exercise programme compared to those receiving no exercise (fixed-effect: $\mathrm{MD} 2.49 \mathrm{~mL} / \mathrm{kg} / \mathrm{min}, 95 \% \mathrm{Cl} 1.63$ to 3.36 , participants = 284; studies $=9$; moderate quality of evidence; Analysis 1.1). There was no evidence of statistical heterogeneity $\left(I^{2} 0 \%\right.$; $\left.\mathrm{Chi}^{2} 5.56\right)$.

\section{Sensitivity analyses}

Sensitivity analyses were conducted by repeating the metaanalysis for exercise capacity, in the presence and absence of two studies considered to be of high risk of bias, and therefore likely to be a potential risk to the robustness of the analysis. One study reported exercise capacity as $\mathrm{VO}_{2 \text { Peak }}$ without the standard deviation (SD) (Kobashigawa 1999). The author was contacted, but was unable to provide the required SD values. Therefore a median $\mathrm{SD}$, calculated from the other studies, was imputed into the metaanalysis for this study. In a second study, four participants "chose" to move from the intervention group to the comparator group following randomisation, leading to a high risk of selection bias ( Wu 2008).

Excluding Kobashigawa 1999 or Wu 2008 from meta-analyses did not impact the treatment effect of participants in the intervention group compared to the comparator group (fixed-effect: MD $2.59 \mathrm{~mL}$ / $\mathrm{kg} / \mathrm{min}, 95 \% \mathrm{Cl} 1.69$ to 3.49; participants $=257$; studies $=8$; Analysis 1.2 ; and $\mathrm{MD} 2.99 \mathrm{~mL} / \mathrm{kg} / \mathrm{min}, 95 \% \mathrm{Cl} 1.93$ to 4.05 ; participants $=247$; studies = 8; Analysis 1.3)). However, excluding both Kobashigawa 1999 and Wu 2008 from the meta-analysis increased the treatment effect (fixed-effect: MD $3.20 \mathrm{~mL} / \mathrm{kg} / \mathrm{min}, 95 \% \mathrm{Cl} 2.08$ to 4.33; participants $=220$; studies $=7$; Analysis 1.4$)$. There was no evidence of heterogeneity in any of these analyses $\left(I^{2}=0 \%\right)$.

\section{Health-related quality of life (HRQOL)}

Three studies reported HRQoL data (Nytrøen 2012; Tegtbur 2003; Wu 2008). Due to the variation in HRQoL outcomes and methods of reporting we were unable to meta-analyse results across studies; instead, we tabulated overall details and domain HRQoL scores from each of the trials with particular focus on intervention-control differences at follow-up. To provide some level of overall synthesis, for each study we assessed if total and domain HRQoL betweengroup differences were statistically different and, if so, the direction of effect (Table 2).

HRQoL was poorly reported in two trials; outcome scores for individual domains were reported in only one trial (Wu 2008). Wu 2008 reported no statistically significant difference between groups for any of the four domains of the WHOQoL-BREF. Nytrøen 2012 reported exercise to be superior to no exercise in $1 / 8$ domains of the SF-36 (general health, $\mathrm{P}<0.05$ ); Tegtbur 2003 reported higher levels of quality of life in the physical function $(P<0.05)$ and physical well-being $(P<0.01)$ sub scales of the Profile of Quality of Life in the chronically III (PLC). There were no other statistically significant differences reported between groups at follow-up.

\section{Costs}

No included study reported on cost data.

\section{Adherence}

No data were reported on adherence to the exercise programme by any included study.

\section{High-intensity exercise versus moderate exercise}

Dall 2014 compared the effects of high-intensity interval training with continued moderate-intensity training on vascular function and $\mathrm{HRQOL}$ in stable heart transplant recipients $(\mathrm{N}=16)$ in a randomised cross-over trial. Dall 2014 included a five month washout period. All measures were performed at baseline, 12 weeks, after five month washout, and again after the second 12week intervention period.

\section{Primary outcomes}

\section{Cardiovascular mortality}

No cardiovascular-related deaths were reported in either the intervention or comparator groups during the follow-up period.

\section{Hospital admissions}

Dall 2014 did not report hospital admissions during the follow-up period.

\section{Reported adverse events}

Dall 2014 reported that there were no adverse events (including those related to (i) exercise or (ii) transplantation treatments or drugs) in either the intervention or comparator groups during the follow-up period.

\section{Secondary outcomes}

\section{All-cause mortality}

Dall 2014 reported no deaths during the follow-up period.

Non-cardiovascular mortality

Dall 2014 did not report on non-cardiovascular mortality.

\section{Return to work}

Dall 2014 did not report on return to work. 


\section{Exercise capacity}

Dall 2014 reported a comparison of change from baseline for $\mathrm{VO}_{2 \text { peak }}$ for participants receiving high-intensity interval training versus continued moderate-intensity training, with a five month washout period between cross-over phases. There was evidence of superior exercise capacity following high-intensity interval training compared to continued moderate-intensity training in the 16 participants (fixed-effect: MD $2.30 \mathrm{~mL} / \mathrm{kg} / \mathrm{min}, 95 \% \mathrm{Cl} 0.59$ to 4.01 ; $\mathrm{P}<0.001$; Analysis 2.1).

\section{Health-related quality of life}

Dall 2014 reported HRQoL using SF-36 (Table 2). While there were significant improvements after both moderate exercise and high- intensity interval training on several sub scales, no significant between-group differences were reported.

Costs

Dall 2014 did not report any cost data.

\section{Adherence}

Dall 2014 did not report adherence to the exercise programme.

\section{Small study bias}

With the exception of exercise capacity, there was an insufficient number of studies and outcome data to assess small study bias by means of funnel plots or Egger test. There was no evidence of funnel plot asymmetry or statistically significant Egger tests for exercise capacity (Figure 4; $\mathrm{P}=0.36$ ).

Figure 4. Funnel plot of comparison: 1 Exercise versus no-exercise, outcome: 1.1 Exercise capacity $\left(\mathrm{VO}_{2 \text { peak }}\right)$

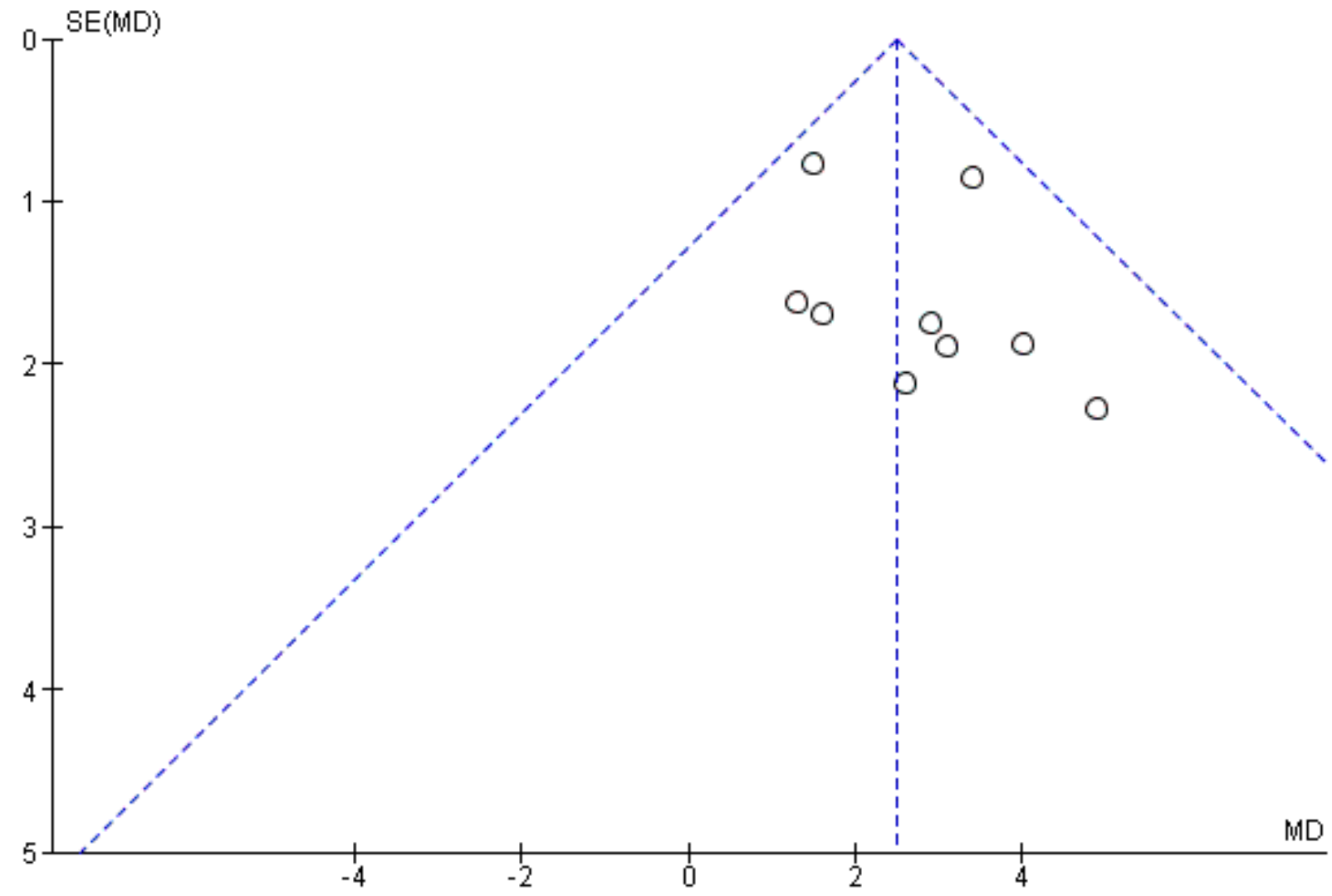

\section{DISCUSSION}

\section{Summary of main results}

The main analysis in this review found moderate quality evidence that heart transplant recipients can benefit from exercise-based rehabilitation programmes in terms of enhanced exercise capacity in the short-term (median follow-up of 12 weeks) compared with study participants who received no exercise training. There was inadequate evidence to assess the efficacy or safety of exercise in terms of cardiovascular mortality, hospital admissions or adverse events in this patient population. Exercise training did not appear to be consistently associated with improvements in health-related quality of life (HRQoL) compared with no exercise training. However, all studies that reported HRQoL used generic measures that are known to lack sensitivity with cardiac treatment, particularly in comparison with disease-specific measures. None of the included studies reported data on return to work, costs or adherence to exercise programmes.

Dall 2014 compared high-intensity interval training with continued moderate-intensity exercise in a cross-over study with 16 participants. Dall 2014 reported statistically significant evidence that high-intensity interval training resulted in a greater exercise capacity than continued moderate-intensity training in the 
immediate follow-up period (12 weeks). The limitations of crossover studies must be taken into consideration when interpreting these results. Dall 2014 included a five month washout period, during which time the effect of intervention was lost. Equally, it must also be considered that participants' health may also have deteriorated to a lower state during this period, compared to before the washout period.

\section{Overall completeness and applicability of evidence}

Study participants in this review had a median age of 54.4 years (range 45 years to 60.6 years) and were a median of 12 months (range 0.5 months to 61 months) post-transplantation. Where participants' sex was reported, most $(77.6 \%)$ were male. Ethnicity was very poorly reported; most $(77.8 \%)$ participants were described as white in the only study that reported this characteristic. The International Society for Heart and Lung Transplantation (ISHLT) statistics show that the median age of adults receiving a heart transplant has not changed since 1992 (ISHLT 2015). During the period 2009 to 2014 the mean age of heart recipients was 54 years (range 25 years to 68 years) of whom $74.9 \%$ were male and $66.2 \%$ were white. Included study participants are therefore representative of the general heart transplant population with regard to age and gender, but less so with respect to ethnicity. This is notable, because ISHLT data show that by year 5, posttransplant survival for blacks was $68.8 \%$ compared with $77.0 \%$ for whites (Colvin-Adams 2015). Moreover, participants were a median of 12 months (range 0.5 months to 61 months) post-transplant, and many of the studies defined participants as stable and healthy. They may therefore have had a higher baseline quality of life and enhanced motivation for exercise than the general population of heart transplant recipients, making it difficult to confer any additional measurable advantage. Caution should therefore be taken when translating these data to the wider heart transplant population and to de novo transplant recipients in particular. In general, the duration of follow-up in included studies was short, with a median of 12 weeks (range 8 weeks to 52 weeks). It was therefore not practical to measure most review outcomes set out in our protocol. Mortality, morbidity, hospital admissions nor return to work were reported by any of the included studies; the only outcome that could be meta-analysed was exercise capacity. As anticipated, we were unable to use meta-regression to explore predictors of treatment effect.

The pooled improvement in exercise capacity with exercisebased cardiac rehabilitation compared to no exercise in this review approached the value of one metabolic equivalent (MET) (i.e. oxygen consumption of $3.5 \mathrm{~mL} / \mathrm{kg} / \mathrm{min}$ (ACSM 2017). Epidemiological studies show that such an improvement in exercise capacity can have important prognostic benefits. Data from long-term observational studies support an inverse relationship between fitness status and overall and cardiovascular mortality risk in apparently healthy people (Blair 1996; Manson 2002; Paffenbarger 1993; Sandvik 1993) and in those with documented cardiovascular disease (CVD) (Myers 2002). Even after adjusting for potential confounding factors, reductions in mortality risk of between $8 \%$ and $20 \%$ per MET increase in exercise capacity have been observed in men and women, with and without CVD (Gulati 2003; Kokkinos 2008; Kokkinos 2010b; Myers 2002).

\section{Quality of the evidence}

In general, the methods of the included RCTs were reported in enough detail to enable assessment of the quality of the methods and risk of bias. Six (of 10) included studies adequately reported random sequence generation (Dall 2014; Haykowsky 2009; Hermann 2011; Kobashigawa 1999; Nytrøen 2012; Pascoalino 2015); only two studies adequately described methods of allocation concealment (Dall 2014; Hermann 2011), introducing possible selection bias. Blinding of outcome assessors was also poorly reported; only three studies reported that assessors were blinded to group allocation (Dall 2014; Hermann 2011; Pascoalino 2015). Attrition bias was detected in three studies, with losses to followup greater than 20\% in two studies (Braith 2008; Tegtbur 2003), and another study (Wu 2008) reporting that four participants in the exercise group changed over to the control group after randomisation. Reporting bias was not an issue in any of the studies. Two studies reported that despite randomisation, comparator and intervention groups were not balanced at baseline in terms of participant characteristics (Haykowsky 2009; Wu 2008), and in one study it was unclear if co-interventions were delivered equally across both groups (Hermann 2011). Source of funding was reported in six studies (Braith 2008; Dall 2014; Haykowsky 2009; Hermann 2011; Nytrøen 2012; Pascoalino 2015); however, conflicts of interests were reported in only four studies (Dall 2014; Hermann 2011; Nytrøen 2012; Pascoalino 2015). Notably, reporting of sources of funding and conflicts of interest was better in studies published after 2010 studies.

Where appropriate, we employed the GRADE approach to assess the quality of evidence for the main outcomes (Schünemann 2011). Exercise capacity and health-related quality of life (HRQoL) in both comparisons were assessed using the five GRADE considerations (study limitations, consistency of effect, imprecision, indirectness, and publication bias) (see Summary of findings for the main comparison;Summary of findings 2). The quality of the evidence for exercise capacity and HRQoL were downgraded in the main comparison (exercise versus no exercise) to moderate, due to the risk of selection or detection bias in more than $50 \%$ of the studies contributing data. Both these outcomes were downgraded in the second comparison (high-intensity interval training versus continued moderate-intensity training) because only one study with 16 participants (Dall 2014) contributed data.

Included studies were small in size and designed to assess surrogate measures of treatment outcomes such as exercise capacity or cardiovascular function, and were not powered to assess treatment group differences in mortality and morbidity outcomes.

\section{Potential biases in the review process}

There were some limitations in this review. The specific goal was to create an up-to-date systematic review to update evidence from previous non-Cochrane reviews (Didsbury 2013; Nytrøen 2013c), to determine the effectiveness and safety of exercisebased rehabilitation on the mortality, hospital admissions, morbidity, exercise capacity, $\mathrm{HRQ}$ oL, and return to work of people after heart transplantation. However, only 10 studies met our inclusion criteria; all were small, involved interventions over short durations, and had relatively short follow-up periods. The studies varied in terms of specific research questions, with objectives including the determination of the effects of exercise on exercise 
capacity, HRQoL, cardiovascular control, vascular and endothelial function, skeletal muscle function and strength, ambulatory blood pressure and arterial stiffness and coronary risk factors. Because study sample sizes were small, they were not adequately powered to detect changes in clinical events and HRQoL; these secondary findings must therefore be interpreted with caution. We acknowledge the limitations of including only randomised trials in this review, which may have constrained the collection of important outcome data.

Populations in studies also varied considerably in terms of time since transplant, with the interventions commencing at a median of 12 months (range 0.5 months to 61 months) post-transplant. It has been suggested that the greatest improvement in $\mathrm{VO}_{2 \text { peak }}$ is thought to occur within the first year post-transplant (Osada 1997), with less being understood about the effect of exercise training when initiated in the longer-term ( $\geq 5$ years) after heart transplant when patients are more clinically stable. We found insufficient evidence to investigate this aspect in this review. Neither was it possible to compare different types and intensities of exercise on heart transplant recipients because only one included study compared different types of exercise regimens.

In a sensitivity analysis, which excluded two studies considered to be at high risk of bias (Kobashigawa 1999; Wu 2008), the size of effect for exercise capacity was increased (MD $3.20 \mathrm{~mL} / \mathrm{kg} / \mathrm{min}$, $95 \% \mathrm{Cl} 2.08$ to 4.33 ). While the confidence around the estimate was increased by removing these studies from the analysis, we can be confident that the overall direction of the result was not affected by the inclusion of these higher risk studies in the meta-analysis.

\section{Agreements and disagreements with other studies or reviews}

Our findings agree with a previous non-Cochrane systematic review that reported a significantly higher $\mathrm{VO}_{2 \text { peak }}$ in participants who received exercise-based cardiac rehabilitation compared to those receiving usual care (SMD $0.77,95 \% \mathrm{Cl} 0.10$ to 1.45 ; participants $=175$, studies $=6, P=0.03 ; I^{2}=77 \%$; Didsbury 2013). The smaller effect size found by Didsbury 2013 was driven by inclusion of a study that compared a hospital-supervised exercise programme with a home-based programme in heart transplant recipients (Karapolat 2008). Because Karapolat 2008 compared hospital- with homebased exercise, it was excluded from this current review.

Our review did not include any data from study participants who were followed up for more than one year following completion of their exercise-based cardiac rehabilitation programmes. Dall 2014 reported that the improvements achieved by exercise were not maintained during the five month washout period of a cross-over study. Similarly, unpublished five year follow-up data of a study included in this review (Nytrøen 2012), reveal that participants who completed 12 month high-intensity interval training were unable to maintain their high post-exercise $\mathrm{VO}_{2 \text { peak }}$ levels and muscle capacity in the long-term, with no significant differences in $\mathrm{VO}_{2 \text { peak }}$ levels between the groups at the five year follow-up despite similar levels of activity frequency and intensity being reported by both groups (Yardley 2016). These data suggest that moderate levels of exercise and intensity are insufficient to maintain improved $\mathrm{VO}_{2 \text { peak }}$ levels, and that lifelong participation in exercise may be required to maintain the positive effects on exercise capacity.
However, the authors of a retrospective study conducted in 201 participants who underwent single-organ heart transplantation at the Mayo Clinic, Minnesota, USA between June 2000 and July 2013, claimed demonstration of an association between early exercisebased cardiac rehabilitation and improved long-term survival after heart transplantation, despite the plateauing of $\mathrm{VO}_{2 \text { peak }}$ following completion of cardiac rehabilitation (Rosenbaum 2016). Overall survival was $98 \%, 88 \%$ and $82 \%$ at 1,5 and 10 years respectively. Using multivariate Cox regression (controlling for baseline posttransplant 6 minute walk test and early rejection episodes), the number of cardiac rehabilitation sessions attended in the first 90 days after transplant was found to predict survival (HR 0.90, 95\% $\mathrm{Cl} 0.82$ to $0.97 ; \mathrm{P}=0.007$ ). One obvious confounder in this study was that the participants who were most motivated and with the highest degree of adherence early after transplantation continued to have higher adherence to exercise in the long-term compared to those with low adherence early after transplantation. Similarly, patients who have complications and higher morbidity would be less likely to be able to adhere to an exercise intervention. It is therefore not clear if the enhanced survival in participants in this study were associated with the early exercise intervention or the continued motivation and adherence to exercise (Rosenbaum 2016).

\section{AUTHORS' CONCLUSIONS}

\section{Implications for practice}

The short-term gains in exercise capacity with exercise-based cardiac rehabilitation in this review support current clinical guideline recommendations for providing cardiac rehabilitation for heart transplant recipients. However, this review highlights some differences between every day clinical practice and research protocols used in the included trials. For example, routine cardiopulmonary testing undertaken across trials may not be available in many cardiac rehabilitation services, resulting in reliance on other measures of exercise intensity prescription, such as rate of perceived exertion and heart rate. While we were unable to demonstrate consistent improvements in health-elated quality of life (HRQoL), it is plausible that less clinically stable and de novo heart recipients may demonstrate greater improvements in quality of life following exercise than more clinically stable participants included in this review. Uncertainty remains about the longerterm benefits of exercise programmes and if high-intensity interval training should be used in routine cardiac rehabilitation settings.

\section{Implications for research}

Further good quality, well reported researchis needed to confirm if the short-term benefits of exercise-based cardiac rehabilitation on exercise capacity in heart transplant recipients seen in this review can be maintained in the longer-term. Ideally, future studies should (i) be powered to measure the effects of exercise on clinical outcomes and mortality, (ii) follow participants for a minimum of six months post cardiac rehabilitation, and (iii) report patientrelated outcomes including validated HRQoL outcome measures and return to work, and report adherence to exercise programmes and healthcare costs. To better inform healthcare decision making, future research should also consider the use of resistance training as well as high-intensity interval training, and determine the optimum time post-transplant to start training, as well as the optimum frequency and total duration of exercise training. We suggest that studies consider incorporating rate of perceived 
exertion (RPE) scales and the suitability of training heart rate calculations for the denervated heart in study designs. To deliver optimum exercise regimens to future heart transplant recipients, further comparative studies are needed that assess the benefits of different types and intensity of exercise and address the ethical issue of omitting exercise from control group participants' posttransplant care.

\section{A C K N OWLEDGEMENTS}

The authors acknowledge the support of the Cochrane Heart Group editorial team and the template protocol they made available. We would also like to thank Nicole Martin of the Cochrane Heart Group for updating the search strategy. Finally, we would like to thank $\mathrm{Dr}$ Felix Gradinger for his translation services and all the authors who provided additional information about their trials. 


\section{REFERE N C E S}

\section{References to studies included in this review}

Bernardi 2007 \{published data only\}

Bernardi L, Radaelli A, Passino C, Falcone C, Auguadro C, Martinelli $L$, et al. Effects of physical training on cardiovascular control after heart transplantation. International Journal of Cardiology 2007;118(3):356-62.

\section{Braith 2008 \{published data only\}}

Braith RW, Schofield RS, Hill J A, Casey DP, Pierce GL. Exercise training attenuates progressive decline in brachial artery reactivity in heart transplant recipients. Journal of Heart and Lung Transplantation 2008;27(1):52-9.

\section{Dall 2014 \{published data only\}}

Dall C, Snoer MS, Christensen SB, Monk-Hanen T, Frederiksen M, Langberg H, et al. Superior effect of high intensity interval training vs. continued moderate training on oxygen consumption and chronotropic response in heart transplant recipients. European Journal of Heart Failure. 2014; Vol. 16:106-7.

Dall CH, Gustafsson F, Christensen SB, Dela F, Langberg H, Prescott $\mathrm{E}$. Effect of moderate- versus high-intensity exercise on vascular function, biomarkers and quality of life in heart transplant recipients: A randomized, crossover trial. Journal of Heart and Lung Transplantation 2015;34(8):1033-41.

* Dall CH, Snoer M, Christensen S, Monk-Hansen T, Frederiksen M, Gustafsson F, et al. Effect of high-intensity training versus moderate training on peak oxygen uptake and chronotropic response in heart transplant recipients: a randomized crossover trial. American Journal of Transplantation 2014;14(10):2391-9.

NCT01914406. High-intensity interval training versus moderate continuous training in heart transplant recipients [Highintensity interval training versus moderate continuous training in heart transplant recipients with impaired chronotropic response: A randomized controlled crossover trial]. clinicaltrials.gov/ct2/show/NCT01914406 (first received 25 July 2013).

\section{Haykowsky 2009 \{published data only\}}

Haykowsky M, Taylor D, Kim D, Tymchak W. Exercise training improves aerobic capacity and skeletal muscle function in heart transplant recipients. American Journal of Transplantation 2009;9(4):734-9.

\section{Hermann 2011 \{published data only\}}

Christensen SB, Dall CH, Hermann T, Prescott E, Gustafsson F. A high-intensity exercise program decreases self-reported anxiety in cardiac transplant recipients: A randomized study. Journal of Heart and Lung Transplantation 2010;1(2 Suppl):S34.

Christensen SB, Dall CH, Prescott E, Pedersen SS, Gustafsson F. A high-intensity exercise program improves exercise capacity, self-perceived health, anxiety and depression in heart transplant recipients: a randomized, controlled trial. Journal of Heart and Lung Transplantation 2012;31(1):106-7.
Dall C, Christensen SB, Hermann TS, Prescott E, Gustafsson F. A high-intensity exercise program improves peak $\mathrm{VO}_{2}$ and reduces markers of systemic inflammation in cardiac transplant recipients: A randomized study. European Journal of Cardiovascular Prevention and Rehabilitation 2010;29(2 Suppl):S75.

Dall C, Snoer M, Frederiksen M, Langberg H, Gustafsson F, Prescott $\mathrm{E}$. Intensive interval training is superior to moderate aerobic training in heart transplant recipients. European Journal of Preventive Cardiology 2012;19(1 Suppl):S96.

* Hermann TS, Dall CH, Christensen SB, Goetze JP, Prescott E, Gustafsson F. Effect of high intensity exercise on peak oxygen uptake and endothelial function in long-term heart transplant recipients. American Journal of Transplantation 2011;11(3):536-41.

Monk-Hansen T, Dall CH, Christensen SB, Snoer M, Gustafsson F, Rasmusen $\mathrm{H}$, et al. Interval training does not modulate diastolic function in heart transplant recipients. Scandinavian Cardiovascular Journal 2014;48(2):91-8.

NCT01028599. Effect of physical training on oxygen uptake and endothelial function in heart transplant recipients. clinicaltrials.gov/ct2/show/NCT01028599 (first received 8 December 2009).

Kobashigawa 1999 \{published data only\}

Kobashigawa JA, Leaf DA, Gleeson MP, Hamilton MA, Chelimskyfallick C, Moriguchi JD, et al. A randomised study of cardiac rehabilitation in heart-transplant recipients. Journal of the American College of Cardiology. 1994; Vol. 655:A356.

* Kobashigawa JA, Leaf DA, Lee N, Gleeson MP, Liu H, Hamilton MA, et al. A controlled trial of exercise rehabilitation after heart transplantation. New England Journal of Medicine 1999;340(4):272-7.

\section{Nytrøen 2012 \{published data only\}}

NCT01091194. Effect of exercise after heart transplantation (TEX) [Effect of high intensity interval-based aerobic exercise 1-8 years after heart transplantation. 1 year follow up]. clinicaltrials.gov/ct2/show/NCT01091194 (first received 18 March 2010).

Nytrøen K, Rustad LA, Aukrust P, Ueland T, Hallén I, Holm I, et al. Effect of high intensity interval training in heart transplant recipients - a randomized controlled trial. Circulation 2012;126(Suppl 21):2.

* Nytrøen K, Rustad LA, Aukrust P, Ueland T, Hallén J, Holm I, et al. High-intensity interval training improves peak oxygen uptake and muscular exercise capacity in heart transplant recipients. American Journal of Transplantation 2012;12(11):3134-42.

Nytrøen K, Rustad LA, Erikstad I, Aukrust P, Ueland T, Gude E, et al. High intensity interval training decreases progression of cardiac allograft vasculopathy in heart transplant recipients - A randomized controlled trial. European Heart Journal. 2013; Vol. 34 suppl 1:3747. 
Nytrøen K, Rustad LA, Erikstad I, Aukrust P, Ueland T, Lekva T, et al. Effect of high-intensity interval training on progression of cardiac allograft vasculopathy. Journal of Heart and Lung Transplantation 2013;32(11):1073-80.

Nytrøen K, Rustad LA, Erikstad I, Aukrust P, Ueland T, Lekva T, et al. High intensity interval training reduces progression of cardiac allograft vasculopathy among heart transplant recipients - Results from a randomized controlled trial. Journal of Heart and Lung Transplantation 2013;32(4 Suppl):S27.

Nytrøen K, Rustad LA, Holm I, Aakhus S, Gullestad L. High intensity interval training improves muscle strength and $\mathrm{VO}_{2}$ peak in heart transplant recipients. Journal of Heart and Lung Transplantation 2012;31(4):S96-7.

Rustad LA, Nytrøen K, Amundsen BH, Gullestad L, Aakhus S. One year of high-intensity interval training improves exercise capacity, but not left ventricular function in stable heart transplant recipients: a randomised controlled trial. European Journal of Preventive Cardiology 2014;21(2):181-91.

Yardley M, Gullestad L, Bendz B, Bjørkelund E, Rolid K, Arora S, et al. The long term effects of high intensity exercise; a 5 years follow-up of a randomized controlled trial in heart transplant recipients. European Journal of Heart Failure. 2016; Vol. 18 Suppl 1:260.

\section{Pascoalino 2015 \{published data only\}}

Pascoalino LN, Ciolac EG, Tavares AC, Castro RE, AyubFerreira SM, Bacal F, et al. Exercise training improves ambulatory blood pressure but not arterial stiffness in heart transplant recipients. Journal of Heart and Lung Transplantation 2015;34(5):693-700.

\section{Tegtbur 2003 \{published data only\}}

Tegtbur U, Busse M W, Jung K, Markofsky A, Machold H, Brinkmeier $U$, et al. Phase III rehabilitation after heart transplantation [Phase III Rehabilitation nach Herztransplantation]. Zeitschrift fur Kardiologie 2003;92(11):908-15.

\section{Wu 2008 \{published data only\}}

Wu YT, Chien CL, Chou NK, Wang SS, Lai JS, Wu YW. Efficacy of a home-based exercise program for orthotopic heart transplant recipients. Cardiology 2008;111(2):87-93.

\section{References to studies excluded from this review}

\section{Anonymous 2014 \{published data only\}}

Anonymous. Clinical digest. Stable heart transplant patients benefit from high-intensity interval training. Nursing Standard 2014;28(52):17.

\section{Belardinelli 2006 \{published data only\}}

Belardinelli R, Agostoni P. Physical exercise in patients with chronic heart failure and in patients with cardiac transplantation. Medicina Dello Sport 2006;59:237-45.

\section{Christensen 2012 \{published data only\}}

Christensen SB, Dall CH, Prescott E, Pedersen SS, Gustafsson F. A high-intensity exercise program improves exercise capacity, self-perceived health, anxiety and depression in heart transplant recipients: A randomized, controlled trial. Journal of Heart and Lung Transplantation 2012;31(1):106-7.

\section{Karapolat 2007 \{published data only\}}

Karapolat H, Eyigör S, Zoghi M, Yagdi T, Nalbangil S, Durmaz B. Comparison of hospital-supervised exercise versus home-based exercise in patients after orthotopic heart transplantation: effects on functional capacity, quality of life, and psychological symptoms. Transplantation Proceedings 2007;39(5):1586-8.

Kawauchi 2013 \{published data only\}

Kawauchi TS, Almeida PO, Lucy KR, Bocchi EA, Feltrim MI, Nozawa E. Randomized and comparative study between two intra-hospital exercise programs for heart transplant patients. Revista Brasileira de Cirurgia Cardiovascular 2013;28(3):338-46.

\section{Kugler 2008 \{published data only\}}

Kugler C, Tegtbur U, Malehsa D, Bara C, Strueber M, Haverich A, et al. Randomized rehabilitation to improve exercise capacity and HRQoL after heart transplantation. Journal of Heart and Lung Transplantation 2008;27(2 Suppl):S114-5.

\section{Nytrøen 2014 \{published data only\}}

Nytrøen K, Rustad LA, Gude E, Hallén J, Fiane AE, Rolid K, et al. Muscular exercise capacity and body fat predict $\mathrm{VO} 2$ peak in heart transplant recipients. European Journal of Preventive Cardiology 2014;21(1):21-9.

Pierce 2008 \{published data only\}

Pierce GL, Schofield RS, Casey DP, Hamlin SA, Hill JA, Braith RW. Effects of exercise training on forearm and calf vasodilation and proinflammatory markers in recent heart transplant recipients: a pilot study. European Journal of Cardiovascular Prevention and Rehabilitation 2008;15(1):10-8.

\section{Pokan 2004 \{published data only\}}

Pokan R, Von Duvillard SP, Ludwig J, Rohrer A, Hofmann P, Wonisch $\mathrm{M}$, et al. Effect of high-volume and -intensity endurance training in heart transplant recipients. Medicine and Science in Sports and Exercise 2004;36(12):2011-6.

\section{Stevinson 1999 \{published data only\}}

Stevinson C. Exercise helps restore physical work capacity following heart transplantation. Focus on Alternative and Complementary Therapies 1999; Vol. 4, issue 3:145-6.

\section{References to studies awaiting assessment}

Braith 2005 \{published data only\}

Braith RW, Magyari PM, Pierce GL, Edwards DG, Hill JA, White LJ, et al. Effect of resistance exercise on skeletal muscle myopathy in heart transplant recipients. American Journal of Cardiology 2005;95(10):1192-8.

\section{Emmanuel 2015 \{published data only\}}

Emmanuel Ciolac EG, Castro RE, Bocchi EA, Guimaraes GV. Effects of exercise training on heart rate response to exercise in heart transplant recipients. European Journal of Preventive Cardiology. 2015; Vol. 22, issue 1 Suppl:S48. 
Tegtbur 2005 \{published data only\}

Tegtbur U, Busse MW, Jung K, Pethig K, Haverich A. Time course of physical reconditioning during exercise rehabilitation late after heart transplantation. Journal of Heart and Lung Transplantation 2005;24(3):270-4.

\section{References to ongoing studies}

NCT01760538 \{unpublished data only\}

Study on Heart Rate Variability in Cardiac Transplant Recipients with Exercise and After Exercise Training. Ongoing study August 2001.

NCT02602834 \{unpublished data only\}

Imminently Effect of Interval Training With High Intensity (HIT) After Heart Transplantation. Ongoing study May 2015.

Nytrøen 2016 \{published and unpublished data\}

Nytrøen K, Yardley M, Rolid K, Bjørkelund E, Karason K, Wigh JP, et al. Design and rationale of the HITTS randomized controlled trial: Effect of high-intensity interval training in de novo heart transplant recipients in Scandinavia. American Heart Journal 2016;172:95-105.

Rolid K, Gullestad L, Nytroen K. High-intensity interval training in de novo heart transplant recipients-description of a study design. European Journal of Cardiovascular Nursing 2014;13:S51.

\section{Additional references}

\section{ACSM 2017}

American College of Sports Medicine. ACSM's Guidelines for Exercise Testing and Prescription. 10th Edition. Philadelphia: Wolters Kluwer Health, 2017.

\section{Anderson 2016}

Anderson L, Thompson DR, Oldridge N, Zwisler AD, Rees K, Martin N, et al. Exercise-based cardiac rehabilitation for coronary heart disease. Cochrane Database of Systematic Reviews 2016, Issue 1. [DOI: 10.1002/14651858.CD001800.pub3]

\section{Anderson 2016a}

Anderson L, Dall CH, Nguyen TT, Burgess L, Taylor RS. Exercisebased cardiac rehabilitation in heart transplant recipients. Cochrane Database of Systematic Reviews 2016, Issue 6. [DOI: 10.1002/14651858.CD012264]

\section{BACPR 2012}

British Association for Cardiovascular Prevention and Rehabilitation. The BACPR standards and core components for cardiovascular disease prevention and rehabilitation, 2nd edition. www.bacpr.com/resources/46C_BACPR_Standards_ and_Core_Components_2012.pdf (accessed 20 April 2016).

\section{Bengel 2001}

Bengel FM, Ueberfuhr P, Schiepel N, Nekolla SG, Reichart B, Schwaiger M. Effect of sympathetic reinnervation on cardiac performance after heart transplantation. New England Journal of Medicine 2001;345(10):731-8.

\section{Bethell 2008}

Bethell H, Lewin R, Evans J, Turner S, Allender S, Petersen S. Outpatient cardiac rehabilitation attendance in England: variability by region and clinical characteristics. Journal of Cardiopulmonary Rehabilitation and Prevention 2008;28(6):386-91.

\section{Blair 1996}

Blair SN, Kampert JB, Kohl HW, Harold W, Barlow CE, Macera CA, et al. Influences of cardiorespiratory fitness and other precursors on cardiovascular disease and all-cause mortality in men and women. Journal of the American Medical Association 1996;276(3):205-10.

\section{Braith 2000}

Braith RW, Edwards DG. Exercise following heart transplantation. Sports Medicine 2000;30(3):171-92.

\section{Brown 2011}

Brown JPR, Clark AM, Dalal H, Welch K, Taylor RS. Patient education in the management of coronary heart disease. Cochrane Database of Systematic Reviews 2011, Issue 12. [DOI: 10.1002/14651858.CD008895]

\section{Butler 2004}

Butler J, Khadim G, Paul KM, Davis SF, Kronenberg MW, Chomsky DB, et al. Selection of patients for heart transplantation in the current era of heart failure therapy. Journal of the American College of Cardiology 2004;43(5):787-93.

\section{Colvin 2015}

Colvin MM, Cook JL, Chang P, Francis G, Hsu DT, Kiernan MS, et al. Antibody-mediated rejection in cardiac transplantation: emerging knowledge in diagnosis and management: a scientific statement from the American Heart Association. Circulation 2015;131(18):1608-39.

\section{Colvin-Adams 2014}

Colvin-Adams M, Smithy JM, Heubner BM, Skeans MA, Edwards LB, Waller C, et al. OPTN/SRTR 2012 Annual Data Report: heart. American Journal of Transplantation 2014;14(Suppl 1):113-38.

\section{Colvin-Adams 2015}

Colvin-Adams M, Smith JM, Heubner BM, Skeans MA, Edwards LB, Waller CD, et al. OPTN/SRTR 2013 Annual Data Report: heart. American Journal of Transplantation 2015;15(Suppl 2):1-28.

\section{Corra 2005}

Corra U, Giannuzzi P, Adamopoulos S, Bjornstad H, BjarnasonWeherns B, Cohen-Solal A, et al. Executive summary of the position paper of the Working Group on Cardiac Rehabilitation and Exercise Physiology of the European Society of Cardiology (ESC): core components of cardiac rehabilitation in chronic heart failure. European Journal of Cardiovascular Prevention and Rehabilitation 2005;12(4):321-5.

\section{Costanzo 2010}

Costanzo MR, Dipchand A, Starling R, Anderson A, Chan M, Desai $S$, et al. The International Society of Heart and Lung 
Transplantation Guidelines for the care of heart transplant recipients. Journal of Heart and Lung Transplantation 2010;29(8):914-56.

\section{Dalal 2012}

Dalal HM, Wingham J, Palmer J, Taylor R, Petre C, Lewin R, et al. Why do so few patients with heart failure participate in cardiac rehabilitation? A cross-sectional survey from England, Wales and Northern Ireland. BMJ Open 2012;2(2):e000787.

\section{Didsbury 2013}

Didsbury M, McGee RG, Tong A, Craig JC, Chapman JR, Chadban $\mathrm{S}$, et al. Exercise training in solid organ transplant recipients: a systematic review and meta-analysis. Transplantation 2013;95(5):679-87.

\section{Douard 1997}

Douard H, Parrens E, Billes MA, Labbe L, Baudet E, Broustet JP. Predictive factors of maximal aerobic capacity after cardiac transplantation. European Heart Journal 1997;18(11):1823-8.

\section{Egger 1997}

Egger M, Davey Smith G, Schneider M, Minder C. Bias in metaanalysis detected by a simple, graphical test. British Medical Journal 1997;315(7109):629-34.

\section{Fleg 2005}

Fleg JL, Morrell CH, Bos AG, Brant LJ, Talbot LA, Wright JG, et al. Accelerated longitudinal decline of aerobic capacity in healthy older adults. Circulation 2005;112(5):674-82.

\section{GRADEpro GDT 2015 [Computer program]}

GRADE Working Group, McMaster University. GRADEpro GDT. Available from www. gradepro.org. Version accessed prior to 3 March 2017. Hamiltion (ON): GRADE Working Group, McMaster University, 2015.

\section{Gulati 2003}

Gulati M, Pandey DK, Arnsdorf MF, Lauderdale DS, Thisted RA, Wicklund $\mathrm{RH}$, et al. Exercise capacity and the risk of death in women: the St James Women Take Heart Project. Circulation 2003;108(13):1554-9.

\section{Haykowsky 2005}

Haykowsky M, Eves N, Figgures L, McLean A, Koller M, Taylor D, et al. Effect of exercise training on VO2 peak and left ventricular systolic function in recent cardiac transplant recipients. American Journal of Cardiology 2005;95(8):1002-4.

\section{Heran 2011}

Heran BS, Chen JM, Ebrahim S, Moxham T, Oldridge N, Rees K, et al. Exercise-based cardiac rehabilitation for coronary heart disease. Cochrane Database of Systematic Reviews 2011, Issue 7. [DOI: 10.1002/14651858.CD001800.pub2]

\section{Higgins 2011}

Higgins JPT, Green S (editors). Cochrane Handbook for Systematic Reviews of Interventions Version 5.1.0 [updated March 2011]. The Cochrane Collaboration, 2011. Available from www.cochrane-handbook.org.

\section{Hollenberg 2004}

Hollenberg SM, Klein LW, Parrillo JE, Scherer M, Burns D, Tamburro P, et al. Changes in coronary endothelial function predict progression of allograft vasculopathy after heart transplantation. Journal of Heart and Lung Transplantation 2004;23(3):265-71.

\section{Hsieh 2011}

Hsieh PL, Wu YT, Chao WJ. Effects of exercise training in heart transplant recipients: a meta-analysis. Cardiology 2011;120(1):27-35.

\section{ISHLT 2015}

International Society for Heart and Lung Transplantation. Transplant registry quarterly reports. www.ishlt.org/registries/ quarterlyDataReportStep3.asp (accessed 20 April 2016).

\section{Jendzjowsky 2007}

Jendzjowsky NG, Tomczak CR, Lawrance R, Taylor DA, Tymchak WJ, Riess KJ, et al. Impaired pulmonary oxygen uptake kinetics and reduced peak aerobic power during small muscle mass exercise in heart transplant recipients. Journal of Applied Physiology 2007;103(5):1722-7.

\section{Kao 1994}

Kao AC, Van Trigt P 3rd, Shaeffer-McCall GS, Shaw JP, Kuzil BB, Page RD, et al. Central and peripheral limitations to upright exercise in untrained cardiac transplant recipients. Circulation 1994;89(6):2605-15.

\section{Kao 1995}

Kao AC, Van Trigt P 3rd, Shaeffer-McCall GS, Shaw JP, Kuzil BB, Page RD, et al. Allograft diastolic dysfunction and chronotropic incompetence limit cardiac output response to exercise two to six years after heart transplantation. Journal of Heart and Lung Transplantation 1995;14:11-22.

\section{Karapolat 2008}

Karapolat H, Eyigor S, Zoghi M, Yagdi T, Nalbantgil S, Durmaz B, et al. Effects of cardiac rehabilitation program on exercise capacity and chronotropic variables in patients with orthotopic heart transplant. Clinical Research in Cardiology 2008;97(7):449-56.

\section{Keteyian 1991}

Keteyian S, Shepard R, Ehrman J, Fedel F, Glick C, Rhoads K, et al. Cardiovascular responses of heart transplant patients to exercise training. Journal of Applied Physiology 1991;70(6):2627-31.

\section{Kobashigawa 1999a}

Kobashigawa JA. Postoperative management following heart transplantation. Transplant Proceedings 1999;31(5):2038-46.

\section{Kobashigawa 2012}

Kobashigawa JA. The future of heart transplantation. American Journal of Transplantation 2012;12(11):2875-91. 


\section{Kokkinos 2008}

Kokkinos P, Myers J, Kokkinos JP, Pittaras A, Narayan P, Manolis A, et al. Exercise capacity and mortality in black and white men. Circulation 2008;117(5):614-22.

\section{Kokkinos 2010a}

Kokkinos P, Myers J. Exercise and physical activity: clinical outcomes and applications. Circululation 2010;122(16):1637-48.

\section{Kokkinos 2010b}

Kokkinos P, Myers J, Faselis C, Panagiotakos DB, Doumas M, Pittaras A, et al. Exercise capacity and mortality in older men: a 20-year follow-up study. Circulation 2010;122(8):790-7.

\section{Lampert 1996}

Lampert E, Mettauer B, Hoppeler H, Charloux A, Charpentier A, Lonsdorfer J. Structure of skeletal muscle in heart transplant recipients. Journal of American College of Cardiology 1996;28(4):980-4.

\section{Lefebvre 2011}

Lefebvre C, Manheimer E, Glanville J. Chapter 6: Searching for studies. In: Higgins JPT, Green S (editors). Cochrane Handbook for Systematic Reviews of Interventions Version 5.1.0 [updated March 2011]. The Cochrane Collaboration, 2011. Available from www.cochrane-handbook.org.

\section{Lietz 2007}

Lietz K, Miller LW. Improved survival of patients with end-stage heart failure listed for heart transplantation: analysis of organ procurement and transplantation network/US United Network of Organ Sharing data, 1990 to 2005. Journal of American College of Cardiology 2007;50(13):1282-90.

\section{Lund 2013}

Lund LH, Edwards LB, Kucheryavaya AY, Dipchand AI, Benden C, Christie JD, et al. The Registry of the International Society for Heart and Lung Transplantation: Thirtieth Official Adult Heart Transplant Report - 2013; focus theme: age. Journal of Heart and Lung Transplantation 2013;32(10):951-64.

\section{Mandak 1995}

Mandak JS, Aaronson KD, Mancini DM. Serial assessment of exercise capacity after heart transplantation. Journal of Heart and Lung Transplantation 1995;14(3):468-78.

\section{Manson 2002}

Manson JE, Greenland P, LaCroix AZ, Stefanick ML, Mouton CP, Oberman $\mathrm{A}$, et al. Walking compared with vigorous exercise for the prevention of cardiovascular events in women. New England Journal of Medicine 2002;347(10):716-25.

\section{Marconi 2003}

Marconi C, Marzorati M. Exercise after heart transplantation. European Journal of Applied Physiology 2003;90(3-4):250-9.

\section{McMurray 2012}

McMurray JJ, Adamopoulos S, Anker SD, Auricchio A, Bohm M, Dickstein $\mathrm{K}$, et al. ESC Guidelines for the diagnosis and treatment of acute and chronic heart failure 2012: The Task Force for the Diagnosis and Treatment of Acute and Chronic
Heart Failure 2012 of the European Society of Cardiology. Developed in collaboration with the Heart Failure Association (HFA) of the ESC. European heart Journal 2012;33(14):1787-847.

\section{Myers 2002}

Myers J, Prakash M, Froelicher V, Do D, Partington S, Atwood JE. Exercise capacity and mortality among men referred for exercise testing. New England Journal of Medicine 2002;346(11):793-801.

\section{Nair 2011}

Nair N, Ball T, Uber PA, Mehra MR. Current and future challenges in therapy for antibody-mediated rejection. Journal of Heart and Lung Transplantation 2011;30(6):612-7.

\section{NICE 2013}

National Institute for Health and Care Excellence. MI -

Secondary Prevention: Secondary Prevention in Primary and Secondary Care for Patients Following a Myocardial Infarction: Partial Update of NICE CG48. www.nice.org.uk/guidance/cg172 (accessed 20 April 2016).

\section{Nytrøen 2013c}

Nytrøen K, Gullestad L. Exercise after heart transplantation: an overview. World Journal of Transplantation 2013;3(4):78-90.

\section{Osada 1997}

Osada N, Chaitman BR, Donohue TJ, Wolford TL, Stelken AM, Miller LW. Long-term cardiopulmonary exercise performance after heart transplantation. American Journal of Cardiology 1997;79(4):451-6.

\section{Paffenbarger 1993}

Paffenbarger RS Jr, Hyde RT, Wing AL, Lee IM, Jung DL, Kampert JB. The association of changes in physical-activity level and other lifestyle characteristics with mortality among men. New England Journal of Medicine 1993;328(8):538-45.

\section{Paulus 1992}

Paulus WJ, Bronzwaer JG, Felice H, Kishan N, Wellens F. Deficient acceleration of left ventricular relaxation during exercise after heart transplantation. Circulation 1992;86(4):1175-85.

\section{Piepoli 2010}

Piepoli MF, Corrà U, Benzer W, Bjarnason-Wehrens B, Dendale $P$, Gaita D, et al. Secondary prevention through cardiac rehabilitation: from knowledge to implementation. A position paper from the Cardiac Rehabilitation Section of the European Association of Cardiovascular Prevention and Rehabilitation. European Journal of Cardiovascular Prevention and Rehabilitation 2010;17(1):1-17.

\section{RevMan 2014 [Computer program]}

The Cochrane Collaboration. Review Manager (RevMan). Version 5.3. Copenhagen: The Nordic Cochrane Centre: The Cochrane Collaboration, 2014.

\section{Rosenbaum 2016}

Rosenbaum AN, Kremers WK, Schirger JA, Thomas RJ, Squires RW, Allison TG, et al. Association between early cardiac 
rehabilitation and long-term survival in cardiac transplant recipients. Mayo Clinic Proceedings 2016;91(2):149-56.

\section{Sandvik 1993}

Sandvik L, Erikssen J, Thaulow E, Erikssen G, Mundal R, Rodahl K. Physical fitness as a predictor of mortality among healthy, middle-aged Norwegian men. New England Journal of Medicine 1993;328(8):533-537.

\section{Schünemann 2011}

Schünemann HJ, Oxman AD, Vist GE, Higgins JPT, Deeks JJ, Glasziou P, Guyatt GH. Chapter 12: Interpreting results and drawing conclusions. In: Higgins JPT, Green S (editors), Cochrane Handbook for Systematic Reviews of Interventions. Available from www.cochrane-handbook.org.

\section{Shah 2012}

Shah MR, Starling RC, Schwartz Longacre L, Mehra MR, Working Group Participants. Heart transplantation research in the next decade - a goal to achieving evidence-based outcomes: National Heart, Lung, and Blood Institute Working Group. Journal of American College of Cardiology 2012;59(14):1263-9.

\section{Sibilitz 2016}

Sibilitz KL, Berg SK, Tang LH, Risom SS, Gluud C, Lindschou J, et al. Exercise-based cardiac rehabilitation for adults after heart valve surgery. Cochrane Database of Systematic Reviews 2016, Issue 3. [DOI: 10.1002/14651858.CD010876]

\section{StataCorp 2013 [Computer program]}

StataCorp. Stata Statistical Software: Release 13. College Station, TX: StataCorp, 2013.

\section{Stehlik 2012}

Stehlik J, Edwards LB, Kucheryavaya AY, Benden C, Christie JD, Dipchand Al, et al. The Registry of the International Society for Heart and Lung Transplantation: 29th official adult heart transplant report. Journal of Heart and Lung Transplantation 2012;31(10):1052-64.

\section{Stehlik 2014}

Stehlik J, Stevenson LW, Edwards LB, Crespo-Leiro MG, Delgado JF, Dorent R, et al. Organ allocation around the world: insights from the ISHLT International Registry for Heart and Lung Transplantation. Journal of Heart and Lung Transplantation 2014;33(10):975-84.

\section{Taylor 2007}

Taylor DO, Edwards LB, Boucek MM, Trulock EP, Aurora P, Christie J, et al. Registry of the International Society for

\section{CHARACTERISTICS OF STUDIES}

Characteristics of included studies [ordered by study ID]
Heart and Lung Transplantation: twenty-fourth official adult heart transplant report - 2007. Journal of Heart and Lung Transplantation 2007;26(8):769-81.

\section{Taylor 2014}

Taylor RS, Sagar VA, Davies EJ, Briscoe S, Coats AJS, Dalal $\mathrm{H}$, et al. Exercise-based rehabilitation for heart failure. Cochrane Database of Systematic Reviews 2014, Issue 4. [DOI: 10.1002/14651858.CD003331.pub4]

\section{Taylor 2015}

Taylor RS, Dalal H, Jolly K, Zawada A, Dean SG, Cowie A, et al. Home-based versus centre-based cardiac rehabilitation. Cochrane Database of Systematic Reviews 2015, Issue 8. [DOI: 10.1002/14651858.CD007130]

\section{Tierney 2011}

Tierney S, Mamas M, Skelton D, Woods S, Rutter MK, Gibson M, et al. What can we learn from patients with heart failure about exercise adherence? A systematic review of qualitative papers. Health Psychology 2011;30(4):401.

\section{Tjang 2008}

Tjang YS, van der Heijden GJ, Tenderich G, Grobbee DE, Korfer R. Survival analysis in heart transplantation: results from an analysis of 1290 cases in a single center. European Journal of Cardiothoracic Surgery 2008;33(5):856-61.

\section{Tonsho 2014}

Tonsho M, Michel S, Ahmed Z, Alessandrini A, Madsen JC. Heart transplantation: challenges facing the field. Cold Spring Harbor Perspectives in Medicine 2014;4(5):a015636.

\section{Yancy 2013}

Yancy CW, Jessup M, Bozkurt B, Butler J, Casey DE Jr, Drazner MH, et al. 2013 ACCF/AHA guideline for the management of heart failure: a report of the American College of Cardiology Foundation/American Heart Association Task Force on Practice Guidelines. Journal of American College of Cardiology 2013;62(16):e147-239.

\section{Yardley 2016}

Yardley M, Gullestad L, Nytrøen K. The long term effects of high intensity exercise; a 5 years follow-up of a randomized controlled trial in heart transplant recipients. European Journal of Heart Failure. 2016; Vol. 18:260.

* Indicates the major publication for the study

\section{Bernardi 2007}

$\begin{array}{ll}\text { Methods } & \text { Study design: RCT } \\ & \text { Country: Italy } \\ & \text { Dates participants recruited: NR }\end{array}$


Bernardi 2007 (Continued)

Maximum follow up: 6 months

Participants Inclusion criteria: 6 months after heart transplantation. No signs or symptoms of active cardiorespiratory disease (apart from controlled hypertension)

Exclusion criteria: NR

N randomised: total: 24 ; intervention: 13 ; comparator: 11

Age (mean \pm SD): intervention: $50 \pm 3$ years; comparator: $53 \pm 4$ years

Percentage male: NR

Ethnicity: NR

Interventions

Interventions: Exercising on a training bicycle at $50 \mathrm{rpm}$ for 30 minutes, 5 days a week, at $60 \%$ to $70 \%$ of their peak oxygen consumption (first exercise session measured the peak oxygen consumption and familiarised the patients with the intervention). Exercise test to exhaustion performed after 3 months. A new training load was calculated.

Components: Exercise only

Setting: Home

Aerobic exercise: Cycling

Time of start after transplant: Randomised 6 months post-transplantation

Length of session: 30 minutes

Frequency: 5 days a week

Intensity: $50 \mathrm{rpm} 60 \%$ to $70 \%$ of their peak oxygen consumption. (measured at first exercise session)

Resistance training included? No

Total duration: 6 months (a new exercise test to exhaustion was performed at 3 months)

Co-interventions: Medication

Comparator: Patients were told to "avoid exercise above their normal pre-study routine and specifi-

cally to avoid exercise that would lead to feelings of dyspnoea or exhaustion"

Co-interventions: Medication

\begin{tabular}{ll}
\hline Outcomes & Exercise capacity $\left(\mathrm{VO}_{2 \text { peak }}\right)$ \\
\hline Notes & \\
\hline
\end{tabular}

\section{Risk of bias}

\begin{tabular}{lll}
\hline Bias & Authors' judgement & Support for judgement \\
\hline $\begin{array}{l}\text { Random sequence genera- } \\
\text { tion (selection bias) }\end{array}$ & Unclear risk & $\begin{array}{l}\text { Method of random sequence generation was not described. "The subjects } \\
\text { were randomly assigned to the training or to the control group" }\end{array}$ \\
\hline $\begin{array}{l}\text { Allocation concealment } \\
\text { (selection bias) }\end{array}$ & Unclear risk & Allocation concealment was not described \\
\hline $\begin{array}{l}\text { Blinding of outcome as- } \\
\text { sessment (detection bias) } \\
\text { All outcomes }\end{array}$ & Unclear risk & Blinding of outcome assessment was not described \\
\hline $\begin{array}{l}\text { Incomplete outcome data } \\
\text { (attrition bias) }\end{array}$ & Low risk & $\begin{array}{l}\text { No patients were reported as being lost to follow-up in either group } \\
\text { All outcomes }\end{array}$ \\
\hline $\begin{array}{l}\text { Selective reporting (re- } \\
\text { porting bias) }\end{array}$ & Low risk & $\begin{array}{l}\text { All variables described in the methods section were reported in the results sec- } \\
\text { tion }\end{array}$ \\
\hline $\begin{array}{l}\text { Were groups balanced at } \\
\text { baseline? }\end{array}$ & Low risk & $\begin{array}{l}\text { The groups were balanced at baseline; no significant differences found in any } \\
\text { participants' characteristics at the time of their first observation }\end{array}$ \\
\hline $\begin{array}{l}\text { Did both groups receive } \\
\text { comparable care? }\end{array}$ & Low risk & $\begin{array}{l}\text { All participants in both groups received the same co-intervention (drug thera- } \\
\text { py) }\end{array}$ \\
\hline
\end{tabular}


Bernardi 2007 (Continued)

\begin{tabular}{lll} 
Source of funding & Unclear risk & NR \\
\hline $\begin{array}{l}\text { Declared conflicts of Inter- } \\
\text { est }\end{array}$ & Unclear risk & NR \\
\hline
\end{tabular}

Braith 2008

\begin{tabular}{ll}
\hline Methods & Study design: RCT \\
Country: USA \\
Dates participants recruited: Participants were randomised before their heart transplantation. Exer- \\
cise was initiated 8 weeks after transplantation \\
Maximum follow up: 12 weeks \\
\hline Participants & $\begin{array}{l}\text { Inclusion criteria: NR (participants were recruited while on the waiting list for a heart transplant) } \\
\text { Exclusion criteria: NR } \\
\text { N randomised: Total: } 20 \text {; intervention: } 10 ; \text { comparator: } 10 \\
\text { Age (mean } \pm \text { SD): intervention: } 54.4 \pm 13.1 \text { years; comparator: } 54.3 \pm 9.5 \text { years } \\
\text { Percentage male: intervention: } 78 \% ; \text { comparator: } 86 \% \\
\text { Ethnicity: NR }\end{array}$ \\
\hline
\end{tabular}

Interventions: Each session consisted of a 5 minute warm up, 30 minutes of continuous treadmill walking and a 5 minute cool down. Exercised progressed to 35 to 40 minutes as tolerated. Intensity was measured using a Borg RPE scale to maintain intensity in the range of 11 and 13 , and progressed to 12 to 14 range.

Components: Exercise only

Setting: The Living Well Centre at the University of Gainesville, Florida

Aerobic exercise: walking on a treadmill

Time of start after transplant: 8 weeks

Length of session: 40 minutes (progressed to 45 to 50 minutes after 4 weeks if exercise was well tolerated)

Frequency: 3 days a week

Intensity: Range 11 to 13 on Borg RPE scale, and progressed to 12 to 14 range

Total duration: 12 weeks

Resistance training included?: No

Co-interventions: Medication - immunosuppressive therapy

Comparator: The control group received the usual post-transplant medical care but did not participate in any supervised exercise

Co-interventions: "Continue to receive standard medical care for HTRs from their transplant physician, including encouragement to engage in regular walking, but did not participate in supervised exercise"

Outcomes $\quad$ Exercise capacity $\left(\mathrm{VO}_{2 \text { peak }}\right)$

Notes

\section{Risk of bias}

\begin{tabular}{lll}
\hline Bias & Authors' judgement & Support for judgement \\
\hline $\begin{array}{l}\text { Random sequence genera- } \\
\text { tion (selection bias) }\end{array}$ & Unclear risk & Randomisation method not described \\
\hline $\begin{array}{l}\text { Allocation concealment } \\
\text { (selection bias) }\end{array}$ & Unclear risk & Allocation concealment not described \\
\hline
\end{tabular}


Braith 2008 (Continued)

Blinding of outcome as- Unclear risk "All FMD procedures were performed by the same blinded technician". Howevsessment (detection bias) er, blinding was not described for assessment of other outcomes

All outcomes

\begin{tabular}{lll}
$\begin{array}{l}\text { Incomplete outcome data } \\
\text { (attrition bias) } \\
\text { All outcomes }\end{array}$ & High risk & Intervention: 1/10 (10\%) lost to follow-up; control: 3/10 (30\%) lost to follow-up \\
\hline $\begin{array}{l}\text { Selective reporting (re- } \\
\text { porting bias) }\end{array}$ & Low risk & All outcomes described in the methods were reported in the results \\
\hline $\begin{array}{l}\text { Were groups balanced at } \\
\text { baseline? }\end{array}$ & Low risk & $\begin{array}{l}\text { No significant difference was found in the baseline characteristics between } \\
\text { both groups }\end{array}$ \\
\hline $\begin{array}{l}\text { Did both groups receive } \\
\text { comparable care? }\end{array}$ & Low risk & $\begin{array}{l}\text { All participants within the groups received the same co-intervention (drug } \\
\text { therapy) }\end{array}$ \\
\hline $\begin{array}{l}\text { Source of funding } \\
\text { Declared conflicts of Inter- }\end{array}$ & Unclear risk & American Heart Association \\
\hline est & NR
\end{tabular}

Dall 2014

\begin{tabular}{ll}
\hline Methods & Study design: Cross-over RCT \\
& Country: Denmark \\
& Dates participants recruited: NR \\
& Maximum follow up: 12 weeks
\end{tabular}

Participants

Inclusion criteria: Clinically stable heart transplant recipients (12 months or more after transplantation) aged $>18$ years. From the Heart Centre, Rigshospitalet, University of Copenhagen, physically capable of participating in high-intensity interval training.

Exclusion criteria: Unstable condition defined as recent moderate or severe rejection episodes (> H1R $<3$ months); severe coronary allograft vasculopathy or malignant disease; and retransplantation or multi-organ transplantation

N randomised: Total: 17 (only 16 completed the study and whom the analysis was based on); intervention: 9; comparator: 8

(Note: As this was a cross-over study, both groups swapped after the 5 months washout period)

Age (mean \pm SD): Mean $=51.9$ years (range: 33 years to 70 years)

Percentage male: $75 \%$

Ethnicity: NR

Interventions

Interventions: High-intensity training session consisted of 16 minutes interval training of 4-, 2 and 1minute duration at $>80 \%$ of $\mathrm{VO}_{2 \text { peak }}$, separated by a 2 -min active rest period (approximately $60 \%$ of $\mathrm{VO}_{2 \text { peak }}$. Each session lasted 32 minutes

The $>80 \%$ of $\mathrm{VO}_{2 \text { peak }}$ was used as a minimum exercise effort in the 4-, 2-, and 1-min interval blocks. If the heart transplant recipients were able to work at an even higher exercise intensity in the shorter time frames (e.g. in the 2- or 1-min interval blocks) they were told to do so. high-intensity interval training protocol (10-minute warm up, 16-minutes of high-intensity interval training + recovery and 10minute cool down)

Components: Exercise only

Setting: Heart Centre

Aerobic exercise: Cycling

Time of start after transplant: Minimum of 12 months

Length of session: 32 minutes

Frequency: 3 times a week 
Dall 2014 (Continued)

Intensity: 16 minutes interval training of 4-,2 and 1-minute duration at $>80 \%$ of $\mathrm{VO}_{2 \text { peak }}$, separated by

a 2-minute active rest period (approximately $60 \%$ of $\mathrm{VO}_{2 \text { peak }}$ ).

$>80 \%$ of $\mathrm{VO}_{2 \text { peak }}$ was used as a minimum exercise effort in the 4-, 2-, and 1-min interval blocks

Total duration: 12 weeks

Resistance training included?: No

Co-interventions: Medication

Comparator: Continued moderate exercise

Co-interventions: Supervised sessions three times a week for 12 weeks.

"The CON sessions consisted of biking for $45 \mathrm{~min}$ with an intensity corresponding to $60-70 \%$ of

$\mathrm{VO}_{2 \text { peak. }}$ All sessions began with a 10- min warm-up and ended with a 10-min cool down".

\begin{tabular}{ll}
\hline Outcomes & Exercise capacity $\left(\mathrm{VO}_{2 \text { peak }}\right)$ \\
\hline Notes & $\begin{array}{l}\text { Data were analysed as a } 2 \times 2 \text { cross-over design using the pkcross command in STATA with a formal test } \\
\text { for period and carryover effects. }\end{array}$
\end{tabular}

\section{Risk of bias}

\begin{tabular}{|c|c|c|}
\hline Bias & Authors' judgement & Support for judgement \\
\hline $\begin{array}{l}\text { Random sequence genera- } \\
\text { tion (selection bias) }\end{array}$ & Low risk & $\begin{array}{l}\text { "After baseline testing, a person not involved in the study randomised pa- } \\
\text { tients (envelope randomisation) into two groups: high-intensity interval train- } \\
\text { ing-washout-CON or CON-washout-high-intensity interval training" }\end{array}$ \\
\hline $\begin{array}{l}\text { Allocation concealment } \\
\text { (selection bias) }\end{array}$ & Low risk & $\begin{array}{l}\text { "After baseline testing, a person not involved in the study randomised pa- } \\
\text { tients" }\end{array}$ \\
\hline $\begin{array}{l}\text { Blinding of outcome as- } \\
\text { sessment (detection bias) } \\
\text { All outcomes }\end{array}$ & Low risk & $\begin{array}{l}\text { "The outcome assessors were blinded to the intervention allocation, and the } \\
\text { patients were asked not to discuss exercise habits with the test staff". }\end{array}$ \\
\hline $\begin{array}{l}\text { Incomplete outcome data } \\
\text { (attrition bias) } \\
\text { All outcomes }\end{array}$ & Low risk & $1 / 17$ total $(6 \%)$ drop-out \\
\hline $\begin{array}{l}\text { Selective reporting (re- } \\
\text { porting bias) }\end{array}$ & Low risk & All outcomes stated that were going to be recorded were reported \\
\hline $\begin{array}{l}\text { Were groups balanced at } \\
\text { baseline? }\end{array}$ & Low risk & $\begin{array}{l}\text { As it was a cross-over study, baseline characteristics given were for all partici- } \\
\text { pants recruited }\end{array}$ \\
\hline $\begin{array}{l}\text { Did both groups receive } \\
\text { comparable care? }\end{array}$ & Low risk & $\begin{array}{l}\text { In this cross-over trial, each group either received high-intensity interval train- } \\
\text { ing or continued moderate-intensity exercise for } 12 \text { weeks, and then after a } \\
\text { month washout period, the group was allocated to the alternative intervention }\end{array}$ \\
\hline Source of funding & Low risk & Danish Physiotherapy Research Foundation and the Danish Health Foundation \\
\hline $\begin{array}{l}\text { Declared conflicts of Inter- } \\
\text { est }\end{array}$ & Low risk & $\begin{array}{l}\text { "The authors of this manuscript have no conflicts of interest to disclose as de- } \\
\text { scribed by the American Journal of Transplantation". }\end{array}$ \\
\hline
\end{tabular}

Haykowsky 2009

\begin{tabular}{ll}
\hline Methods & $\begin{array}{l}\text { Study design: RCT } \\
\text { Country: Canada }\end{array}$
\end{tabular}


Haykowsky 2009 (Continued)

Dates participants recruited: NR

Maximum follow up: 12 weeks

Inclusion criteria: Clinically stable HTR $>0.5$ years post surgery
Exclusion criteria: NR
N randomised: Total: 43 ; intervention: 22 ; comparator: 21
Age (mean \pm SD): intervention: $57 \pm 10$ years; comparator: $59 \pm 11$ years
Percentage male: intervention: $77 \%$; comparator: $86 \%$
Ethnicity: NR

Interventions

Interventions: The supervised aerobic and strength training (SET) program consisted of aerobic training ( 5 days/week) and strength training ( 2 days/week). During the first 8 weeks, treadmill and cycle exercise were performed at a heart rate equal to $60 \%$ to $80 \% \mathrm{VO}_{2 \text { peak }}$ for 30 to 45 minutes. In the final 4 weeks, continuous aerobic training was performed 3 days/week ( $45 \mathrm{~min} / \mathrm{session}$ at a heart rate equal to $80 \% \mathrm{VO}_{2 \text { peak }}$ ) and interval training was performed 2 days/week. Specifically, participants cycled for 30 seconds at $90 \%$ to $100 \%$ of baseline peak power output followed by 60 seconds rest. Ten repetitions ( 1 rep $=30$ sec exercise followed by 60 seconds rest) were initially performed and gradually increased until 25 repetitions were completed. Upper extremity (chest press, latissimus dorsi pull down, arm curls) and lower extremity (leg press) strength training ( 1 to 2 sets of 10 to 15 repetitions) was performed 2 days/week at $50 \%$ of maximal strength.

Components: Exercise only

Setting: Centre (No details reported)

Aerobic exercise: Running (treadmill) and cycling

Time of start after transplant: 6 months

Length of session: First 8 weeks: 30 to 45 minutes; final 4 weeks: 45 minutes; interval training: 15 minutes ( 30 seconds followed by 60 seconds rest $x 10$ )

Frequency: First 8 weeks: 5 days a week; final 4 weeks: 3 days a week; interval training: 2 days a week Intensity: First 8 weeks: $60 \%$ to $80 \% \mathrm{VO}_{2 \text { peak }}$; Final 4 weeks: $80 \% \mathrm{VO}_{2 \text { peak }}$; interval training: $90 \%$ to $100 \%$ of baseline peak power output

Total duration: 12 weeks

Resistance training included?: Yes

"Ten repetitions (1 rep = 30 sec exercise followed by $60 \mathrm{sec}$ rest) were initially performed and gradually increased until 25 repetitions were completed. Upper extremity (chest press, latissimus dorsi pull down, arm curls) and lower extremity (leg press) strength training (1-2 sets of 10-15 repetitions) was performed 2 days/week at $50 \%$ of maximal strength".

Strength training $=$ ( 1 to 2 sets of 10 to 15 repetitions $)$ performed 2 days/week at $50 \%$ of maximal strength

Co-interventions: Medication

Comparator: No training (NT) control

Co-interventions: "Not provided with exercise guidelines and continued with their usual activities of daily living"

Outcomes Exercise capacity $\left(\mathrm{VO}_{2 \text { peak }}\right)$

Notes

\section{Risk of bias}

\begin{tabular}{lll}
\hline Bias & Authors' judgement & Support for judgement \\
\hline $\begin{array}{l}\text { Random sequence genera- } \\
\text { tion (selection bias) }\end{array}$ & Low risk & $\begin{array}{l}\text { "Randomly assigned, using computer generated randomisation sequences } \\
\text { (blocks of 8 with variable blocks of 2 and 4; www.epicore.ualberta.ca)" }\end{array}$ \\
\hline $\begin{array}{l}\text { Allocation concealment } \\
\text { (selection bias) }\end{array}$ & Unclear risk & Allocation concealment not described \\
\hline
\end{tabular}


Haykowsky 2009 (Continued)
Blinding of outcome as-
Unclear risk
Blinding of outcome assessment not described sessment (detection bias) All outcomes

\begin{tabular}{|c|c|c|}
\hline $\begin{array}{l}\text { Incomplete outcome data } \\
\text { (attrition bias) }\end{array}$ & Low risk & $\begin{array}{l}\text { Intervention: } 2 / 21 \text { (10\%) lost to follow-up; comparator: } 1 / 22(5 \%) \text { lost to fol- } \\
\text { low-up }\end{array}$ \\
\hline
\end{tabular}

All outcomes

Selective reporting (re- Low risk $\quad$ All selected measurements were reported in the results
porting bias)

\begin{tabular}{lll}
\hline $\begin{array}{l}\text { Were groups balanced at } \\
\text { baseline? }\end{array}$ & High risk & $\begin{array}{l}\text { "A lower number of participants in the SET group had a pretransplant diagno- } \\
\text { sis of ischemic heart failure (SET: 45\% vs. NT: 76\%, } \mathrm{P}=0.04) . \text { Body mass was } \\
\text { lower in the SET ( } 80 \pm 22 \mathrm{~kg}) \text { compared to the NT group (93 } \pm 14 \mathrm{~kg}, \mathrm{P}=0.03) . "\end{array}$ \\
\hline $\begin{array}{l}\text { Did both groups receive } \\
\text { comparable care? }\end{array}$ & Low risk & $\begin{array}{l}\text { All participants within the groups received the same co-intervention (drug } \\
\text { therapy) }\end{array}$ \\
\hline $\begin{array}{l}\text { Source of funding } \\
\text { Declared conflicts of Inter- }\end{array}$ & Lnclear risk & Heart and Stroke Foundation of Alberta, NWT \& Nunavut \\
\hline est & &
\end{tabular}

Hermann 2011

$\begin{array}{ll}\text { Methods } & \text { Study design: } \mathrm{RCT} \\ & \text { Country: Denmark } \\ & \text { Dates participants recruited: At least } 12 \text { months after transplantation } \\ & \text { Maximum follow up: } 8 \text { weeks }\end{array}$

Participants Inclusion criteria: "Above 18 years of age, and were included at least 12 months after transplantation. All subjects were capable of performing aerobic exercise training".

Exclusion criteria: "Subjects were excluded if they had plasma creatinine greater than $2.3 \mathrm{mg} / \mathrm{dL}$ or were on dialysis treatment, or if they had significant rejection (greater than grade $1 \mathrm{R}$ ) in the previous 3 months, severe coronary allograft vasculopathy or malignant disease. Patients who had undergone retransplantation or multi-organ transplantation were also excluded".

N randomised: Total: 30; intervention: 15 ; comparator: 15

Age (mean \pm SD): intervention: $53 \pm 11$ years; comparator: $47 \pm 18$ years

Percentage male: intervention: $86 \%$; comparator: $77 \%$

Ethnicity: NR

Interventions

Interventions: All completed an 8-week training period with three supervised sessions weekly. The exercise intervention protocol was designed as aerobic interval training on bicycles and staircase running, with interval blocks, approximately $80 \%$ of $\mathrm{VO}_{2 \text { peak }}$ which equals approximately $85 \%$ of maximal heart rate. Each exercise session was introduced by a warming up period above $50 \%$ of $\mathrm{VO}_{2}$ peak. After initial warming up, a 42 minute high-intensity exercise program followed, with interval blocks of 4 minutes/ 2 minutes/30 seconds according to $80 \%, 85 \%$ and $90 \%$ of $\mathrm{VO}_{2 \text { peak }}$ and recovery periods of half a minute. Finally 10 minutes of staircase running up corresponding to $80 \%$ of peak $\mathrm{VO}_{2}$ and recovery walking down according to $50 \%$ peak $\mathrm{VO}_{2}$. The intensity of the interval blocks was kept above $80 \%$ of $\mathrm{VO}_{2 \text { peak }}$ corresponding to level 18 to 19 on the Borg scale.

Components: Exercise plus education (education about the benefits of exercise training together with information on nutrition generally and especially before and after training sessions)

Setting: Cardiac Rehabilitation Clinic

Aerobic exercise: Cycling and staircase running

Time of start after transplant: 12 months 
Hermann 2011 (Continued)

Length of session: 42 minutes

Frequency: 3 times a week

Intensity: Each exercise session was introduced by a warming period above $50 \%$ of $\mathrm{VO}_{2 \text { peak. }}$. Each ses-

sion's intensity was set at $80 \%$ of $\mathrm{VO}_{2 \text { peak }}$ (approximately $85 \%$ of maximal heart rate)

Total duration: 8 weeks

Resistance training included?: No

Co-interventions: Medication and education

Comparator: No exercise

Co-interventions: Medication

\begin{tabular}{ll}
\hline Outcomes & Exercise capacity $\left(\mathrm{VO}_{2 \text { peak }}\right)$ \\
\hline Notes & $\begin{array}{l}\text { Specific intervention for the control group was not mentioned. The only thing mentioned was that they } \\
\text { were the "no exercise" group. }\end{array}$
\end{tabular}

\section{Risk of bias}

\begin{tabular}{|c|c|c|}
\hline Bias & Authors' judgement & Support for judgement \\
\hline $\begin{array}{l}\text { Random sequence genera- } \\
\text { tion (selection bias) }\end{array}$ & Low risk & $\begin{array}{l}\text { "Randomisation was performed as an envelope randomisation after stratifica- } \\
\text { tion by gender". }\end{array}$ \\
\hline $\begin{array}{l}\text { Allocation concealment } \\
\text { (selection bias) }\end{array}$ & Low risk & $\begin{array}{l}\text { An impartial person drew the envelopes to the exercise group or the control } \\
\text { group }\end{array}$ \\
\hline $\begin{array}{l}\text { Blinding of outcome as- } \\
\text { sessment (detection bias) } \\
\text { All outcomes }\end{array}$ & Low risk & $\begin{array}{l}\text { "All measurements were performed with the operator blinded to the interven- } \\
\text { tion group allocation" }\end{array}$ \\
\hline $\begin{array}{l}\text { Incomplete outcome data } \\
\text { (attrition bias) } \\
\text { All outcomes }\end{array}$ & Low risk & $\begin{array}{l}\text { Intervention: } 1 / 15 \text { (7\%) lost to follow-up; comparator: } 2 / 15 \text { (13\%) lost to fol- } \\
\text { low-up }\end{array}$ \\
\hline $\begin{array}{l}\text { Selective reporting (re- } \\
\text { porting bias) }\end{array}$ & Low risk & All data stated to be recorded was presented in the results \\
\hline $\begin{array}{l}\text { Were groups balanced at } \\
\text { baseline? }\end{array}$ & Low risk & There were no differences in between groups at baseline \\
\hline $\begin{array}{l}\text { Did both groups receive } \\
\text { comparable care? }\end{array}$ & Unclear risk & $\begin{array}{l}\text { Unsure if the comparator group received education as well as the exercise } \\
\text { group }\end{array}$ \\
\hline Source of funding & Low risk & $\begin{array}{l}\text { Research Fund for the Danish Physiotherapists Organisation and the Danish } \\
\text { Medical Association Research Fund }\end{array}$ \\
\hline $\begin{array}{l}\text { Declared conflicts of Inter- } \\
\text { est }\end{array}$ & Low risk & $\begin{array}{l}\text { "The authors of this article have no conflict of interest to disclose as described } \\
\text { by the American Journal of Transplantation" }\end{array}$ \\
\hline
\end{tabular}

Kobashigawa 1999

\begin{tabular}{ll}
\hline Methods & Study design: RCT \\
& Country: USA \\
& Dates participants recruited: August 1992 to June 1993 \\
& Maximum follow up: 6 months
\end{tabular}


Kobashigawa 1999 (Continued)

Participants

Inclusion criteria: Patients who underwent heart transplantation by the mid atrial-cuff technique between August 1992 and June 1993

Exclusion criteria: Multiple medical limitations after prolonged hospitalisation

N randomised: Total: 27; intervention: 14; comparator: 13

Age (mean \pm SD): intervention: $55 \pm 8$ years; comparator: $50 \pm 12$ years

Percentage male: intervention: $79 \%$; comparator: $62 \%$

Ethnicity (percentage white): intervention: $71 \%$; comparator: $85 \%$

Interventions

Interventions: At the time of entry, participants were evaluated for overall muscle strength, joint flexibility, and aerobic endurance. A supervised program of exercise was developed according to each participant's specific needs, including strengthening, flexibility and aerobic exercises. The duration and intensity of aerobic exercise sessions were increased to meet the participant's tolerance, with a goal of at least 30 minutes of continuous exercise at a moderate intensity. The frequency of cardiac rehabilitation sessions was gradually reduced to once every two weeks as participants became more independently involved in their home exercise programs.

Components: Exercise only

Setting: Cardiac Rehabilitation Clinic, but some participants were given specific instructions for exercising at home due to transport difficulties

Aerobic exercise: Walking on a treadmill or pedaling on a bicycle ergometer

Time of start after transplant: Within two weeks after transplantation

Length of session: 30 minutes

Frequency: Supervised specialised training: 1 to 3 times a week. Then reduced to once every 2 weeks; Cardiopulmonary exercise training: 1 month after transplantation and again 6 months after transplantation

Intensity: Supervised specialised training: increased to meet the patients tolerance; Cardiopulmonary exercise training: 50 to $70 \mathrm{rpm}$

Total duration: 6 months

Resistance training included?: Yes. "Strengthening exercises consisted primarily of closed-chain resistive activities (e.g. bridging half-squats, and toe raises) and abdominal exercises (curl-ups and pelvic tilts)"

Co-interventions: Medication. "Before discharge from the hospital, patients in both groups received written guidelines with specific instructions to follow certain exercises at home".

Comparator: "The control group received written guidelines for exercise but participated in no formal, supervised exercise sessions after discharge from the hospital"

Co-interventions: Medication. "Before discharge from the hospital, patients in both groups received written guidelines with specific instructions to follow certain exercises at home"

Outcomes Exercise capacity $\left(\mathrm{VO}_{2 \text { peak }}\right)$

Notes

\section{Risk of bias}

\begin{tabular}{lll}
\hline Bias & Authors' judgement & Support for judgement \\
\hline $\begin{array}{l}\text { Random sequence genera- } \\
\text { tion (selection bias) }\end{array}$ & Low risk & "Randomly assigned (by selection of sealed envelopes)" \\
\hline $\begin{array}{l}\text { Allocation concealment } \\
\text { (selection bias) }\end{array}$ & Unclear risk & Allocation concealment not described \\
\hline
\end{tabular}

Blinding of outcome as- Unclear risk Blinding of outcome assessment not described

sessment (detection bias)

All outcomes

Incomplete outcome data Low risk

(attrition bias)

No participants were reported as being lost to follow-up in either group

All outcomes 
Kobashigawa 1999 (Continued)
Selective reporting (re-
Low risk
All selected measurements were reported in the results porting bias)

Were groups balanced at Low risk baseline?
Both groups were balanced at baseline, with no significant differences reported

\begin{tabular}{lll}
\hline $\begin{array}{l}\text { Did both groups receive } \\
\text { comparable care? }\end{array}$ & Low risk & $\begin{array}{l}\text { Participants in both groups received written guidance on exercise, but the } \\
\text { control group not participate in any formal exercise training }\end{array}$ \\
\hline Source of funding & Unclear risk & NR \\
\hline $\begin{array}{l}\text { Declared conflicts of Inter- } \\
\text { est }\end{array}$ & Unclear risk & NR \\
\hline
\end{tabular}

\section{Nytrøen 2012}

\begin{tabular}{ll}
\hline Methods & Study design: RCT \\
& Country: Norway \\
& Dates participants recruited: Between 2009 and 2010 \\
& Maximum follow up: 12 months
\end{tabular}

Participants Inclusion criteria: "Age > 18 years; $1-8$ years after HT; optimal medical treatment; stable clinical condition; ability to perform maximal exercise test on a tread- mill; willingness and ability to perform a 1year high-intensity interval training-program; and provision of written informed consent."

Exclusion criteria: "Unstable condition; need for revascularization or other intervention; infection; physical disability preventing participation and exercise capacity limited by other disease or illness". N randomised: Total: 52; intervention: 26; comparator: 26

Age (mean \pm SD): intervention: $48 \pm 17$ years; comparator: $53 \pm 14$ years

Percentage male: intervention: $67 \%$; comparator: $71 \%$

Ethnicity: NR

Interventions

Interventions: High-intensity interval training was performed on a treadmill. Each participant was assigned to a local, co-operating physiotherapist for individual supervision of high-intensity interval training-sessions. The intervention was divided into three 8-week periods of exercise with three sessions every week. Participants were also encouraged to continue any physical activity on their own.

"The HIIT-sessions consisted of 10 min warm-up, followed by four 4 min exercise bouts at $85-95 \%$ of maximum heart rate (HRmax), interposed by 3 min active recovery periods corresponding to $\sim 11-13$ on the Borg, 6-20 rated perceived exertion (RPE), scale. HRmax, recorded during the maximal exercise test at baseline, was used to determine each patient's training zone. Speed and/or increased inclination of the treadmill were adjusted individually to reach the desired HR."

Components: Exercise only

Setting: Both (participants were assigned to a local physiotherapist and were also encouraged to continue any physical activity on their own)

Aerobic exercise: Running on a treadmill

Time of start after transplant: 1 to 8 years

Length of session: 10 minute warm ups, followed by four 4-minute exercise bouts, interposed by 3minute active recovery periods

Frequency: 3 sessions weekly in 3 different 8-week periods

Intensity: $85 \%$ to $95 \%$ of maximum heart rate

Total duration: 3 different 8 week periods over a year

Resistance training included?: No

Co-interventions: Medication

Comparator: "No intervention was given to the control group other than basic, general care given to all HT [heart transplant] patients".

Co-interventions: Medication 
Nytrøen 2012 (Continued)

Outcomes Exercise capacity $\left(\mathrm{VO}_{2 \text { peak }}\right)$

Notes

\section{Risk of bias}

\begin{tabular}{|c|c|c|}
\hline Bias & Authors' judgement & Support for judgement \\
\hline $\begin{array}{l}\text { Random sequence genera- } \\
\text { tion (selection bias) }\end{array}$ & Low risk & $\begin{array}{l}\text { "patients...were randomised, using computer generated randomisation se- } \\
\text { quences, to either intervention group (HIIT) or control group (usual care)". }\end{array}$ \\
\hline $\begin{array}{l}\text { Allocation concealment } \\
\text { (selection bias) }\end{array}$ & Unclear risk & Allocation concealment not described \\
\hline $\begin{array}{l}\text { Blinding of outcome as- } \\
\text { sessment (detection bias) } \\
\text { All outcomes }\end{array}$ & Unclear risk & Blinding of outcome assessment not described \\
\hline $\begin{array}{l}\text { Incomplete outcome data } \\
\text { (attrition bias) } \\
\text { All outcomes }\end{array}$ & Low risk & $\begin{array}{l}\text { Intervention: } 2 / 26 \text { (7.7\%) lost to follow-up; control: } 2 / 26 \text { (7.7\%) lost to fol- } \\
\text { low-up }\end{array}$ \\
\hline $\begin{array}{l}\text { Selective reporting (re- } \\
\text { porting bias) }\end{array}$ & Low risk & All outcomes described in the methods were reported on in the results \\
\hline $\begin{array}{l}\text { Were groups balanced at } \\
\text { baseline? }\end{array}$ & Low risk & $\begin{array}{l}\text { "Baseline characteristics are given in Table } 1 \text { with no significant differences } \\
\text { between the exercise group (EG) and the control group (CG)". }\end{array}$ \\
\hline $\begin{array}{l}\text { Did both groups receive } \\
\text { comparable care? }\end{array}$ & Low risk & $\begin{array}{l}\text { "No intervention was given to the control group other than basic, general care } \\
\text { given to all HT [heart transplant] patients." }\end{array}$ \\
\hline Source of funding & Low risk & South-East Health Region in Norway (Helse Sør-Øst) \\
\hline $\begin{array}{l}\text { Declared conflicts of Inter- } \\
\text { est }\end{array}$ & Low risk & $\begin{array}{l}\text { "The authors of this manuscript have no conflicts of interest to disclose as de- } \\
\text { scribed by the American Journal of Transplantation" }\end{array}$ \\
\hline
\end{tabular}

Pascoalino 2015

Study design: RCT
Country: Brazil
Dates participants recruited: 2 May 2008 to 30 August 2010
Maximum follow up: 12 weeks

Participants

Inclusion criteria: Heart transplant $\mathrm{T}=$ recipients aged 20 to 60 years. Heart transplant at least 12 months prior "sedentary lifestyle (noninvolvement in regular physical activity or exercise training during the previous 6 months), optimised and unchanged therapy during the previous 6 months, office BP $\leq 140 / 90 \mathrm{mmHg}$, and no musculoskeletal, cardiovascular and metabolic contraindications to training." Exclusion criteria: "Patients with evidence of graft rejection during the previous 6 months, psychological disorders, neuromuscular disease, chronic obstructive pulmonary disease, evidence of target organ damage (i.e. heart, eye, kidney, and brain), complex ventricular arrhythmia, atrial fibrillation, and alcoholism were also not included in the study. Patients who changed their medication during the study were excluded from the final analysis."

N randomised: Total: 42; intervention: 33; comparator: 9

Age (mean \pm SD): intervention: $45 \pm 3$ years; comparator: $45 \pm 6$ years

Percentage male: intervention: $74.2 \%$; comparator: $55.6 \%$ 
Pascoalino 2015 (Continued)

\section{Ethnicity: NR}

Interventions Interventions: Two supervised and one unsupervised sessions a week.

Supervised: 5 minute warm up, 40 minute endurance exercise (walking/jogging on a treadmill) at intensity $80 \%$ of RCP heart rate, and 5 minute cool down. Endurance exercise intensity was adjusted continuously.

Unsupervised: Instructed to follow the same protocol as the supervised session.

Components: Exercise only

Setting: Home and centre (no details reported)

Aerobic exercise: Walking and jogging on a motorised treadmill

Time of start after transplant: At least 12 months

Length of session: 50 minutes

Frequency: 3 times a week

Intensity: $80 \%$ of RCP

Total duration: 12 weeks

Resistance training included?: No

Comparator: "Maintain daily activities without exercise training during the 12 weeks"

Co-interventions: Medication

\begin{tabular}{ll}
\hline Outcomes & Exercise capacity $\left(\mathrm{VO}_{2 \text { peak }}\right), \mathrm{HRQoL}$ \\
\hline Notes &
\end{tabular}

\section{Risk of bias}

\begin{tabular}{|c|c|c|}
\hline Bias & Authors' judgement & Support for judgement \\
\hline $\begin{array}{l}\text { Random sequence genera- } \\
\text { tion (selection bias) }\end{array}$ & Low risk & Computer generated randomisation list generated by statistician \\
\hline $\begin{array}{l}\text { Allocation concealment } \\
\text { (selection bias) }\end{array}$ & Unclear risk & Unclear if the statistician was independent from the study or not \\
\hline $\begin{array}{l}\text { Blinding of outcome as- } \\
\text { sessment (detection bias) } \\
\text { All outcomes }\end{array}$ & Low risk & Outcome assessors were blinded to group assignments \\
\hline $\begin{array}{l}\text { Incomplete outcome data } \\
\text { (attrition bias) } \\
\text { All outcomes }\end{array}$ & Low risk & $\begin{array}{l}\text { Intervention: } 2 / 33(6 \%) \text { lost to follow-up; comparator: 0/9 (0\%) lost to fol- } \\
\text { low-up }\end{array}$ \\
\hline $\begin{array}{l}\text { Selective reporting (re- } \\
\text { porting bias) }\end{array}$ & Low risk & All outcomes recorded are reported on \\
\hline $\begin{array}{l}\text { Were groups balanced at } \\
\text { baseline? }\end{array}$ & Low risk & There was no significant difference between the groups at baseline \\
\hline $\begin{array}{l}\text { Did both groups receive } \\
\text { comparable care? }\end{array}$ & Low risk & $\begin{array}{l}\text { All participants with the groups received the same co-intervention (drug thera- } \\
\text { py) }\end{array}$ \\
\hline Source of funding & Low risk & Fundação de Amparo à Pesquisa do Estado de São Paulo \\
\hline $\begin{array}{l}\text { Declared conflicts of Inter- } \\
\text { est }\end{array}$ & Low risk & "No conflicts to declare" \\
\hline
\end{tabular}


Tegtbur 2003

\begin{tabular}{ll}
\hline Methods & $\begin{array}{l}\text { Study design: RCT } \\
\text { Country: Germany } \\
\text { Dates participants recruited: NR } \\
\text { Maximum follow up: } 12 \text { months }\end{array}$ \\
\hline Participants & Inclusion criteria: Heart transplant patients in the follow-up program at Hannover Medical School \\
& Exclusion criteria: NR \\
& N randomised: Total: 31 ; intervention: $16 ;$ comparator: 15 \\
& Age (mean \pm SD): intervention: $55 \pm 7$ years; comparator: $54 \pm 8$ years \\
Percentage male: intervention: $95 \%$; comparator: $91.6 \%$ \\
Ethnicity: NR
\end{tabular}

Interventions

Interventions: Every 2 days home training on bicycle ergometer at an intensity of $10 \%$ below the anaerobic threshold.

Total session around $28 \mathrm{~min}$ ( $6 \mathrm{~min}$ warm up and $2 \mathrm{~min}$ cool down) programmed as a preset workout on a smart card.

Data from each home exercise (heart rate, performance and rating of perceived exertion) were stored on the chip card and analysed at the clinic appointment when they also underwent a supervised ergometer endurance test with ECG,

Components: Exercise only

Setting: Home

Aerobic exercise: Cycling on an ergometer

Time of start after transplant: Mean $5.1 \pm 2.2$ years after transplantation

Length of session: 28 minutes ( 6 minute warm up and 2 minute cool down)

Frequency: Every 2 days

Intensity: $10 \%$ below the anaerobic threshold

Total duration: 12 months

Resistance training included?: No

Comparator: Usual medical care given to heart transplant recipients

Co-interventions: Medication and standard medical follow-up

\begin{tabular}{ll}
\hline Outcomes & Exercise capacity $\left(\mathrm{VO}_{2 \text { peak }}\right), \mathrm{HRQoL}$ \\
\hline Notes &
\end{tabular}

\section{Risk of bias}

\begin{tabular}{|c|c|c|}
\hline Bias & Authors' judgement & Support for judgement \\
\hline $\begin{array}{l}\text { Random sequence genera- } \\
\text { tion (selection bias) }\end{array}$ & Unclear risk & Unclear how participants were randomised \\
\hline $\begin{array}{l}\text { Allocation concealment } \\
\text { (selection bias) }\end{array}$ & Unclear risk & Allocation concealment was not described \\
\hline $\begin{array}{l}\text { Blinding of outcome as- } \\
\text { sessment (detection bias) } \\
\text { All outcomes }\end{array}$ & Unclear risk & Blinding of outcomes was not described \\
\hline $\begin{array}{l}\text { Incomplete outcome data } \\
\text { (attrition bias) } \\
\text { All outcomes }\end{array}$ & High risk & Intervention: $8 / 20$ (40\%) lost to follow-up; control: $7 / 15$ (47\%) lost to follow-up \\
\hline $\begin{array}{l}\text { Selective reporting (re- } \\
\text { porting bias) }\end{array}$ & Low risk & All outcomes described in the methods section were reported in the results \\
\hline $\begin{array}{l}\text { Were groups balanced at } \\
\text { baseline? }\end{array}$ & Low risk & There were no differences between the intervention and control group \\
\hline
\end{tabular}


Tegtbur 2003 (Continued)

\begin{tabular}{|c|c|c|}
\hline $\begin{array}{l}\text { Did both groups receive } \\
\text { comparable care? }\end{array}$ & Low risk & $\begin{array}{l}\text { "The control group received the established aftercare program". No other co } \\
\text { interventions were described }\end{array}$ \\
\hline
\end{tabular}

\begin{tabular}{lll}
\hline Source of funding & Unclear risk & NR \\
\hline $\begin{array}{l}\text { Declared conflicts of Inter- } \\
\text { est }\end{array}$ & Unclear risk & NR \\
\hline
\end{tabular}

\title{
Wu 2008
}

\begin{tabular}{ll}
\hline Methods & Study design: RCT \\
& Country: Taiwan \\
& Dates participants recruited: July 2005 to July 2006 \\
& Maximum follow up: 8 weeks
\end{tabular}

\begin{abstract}
Participants
Inclusion criteria: "All subjects were clinically stable and free from acute rejection detected from endomyocardial biopsy and allograft vasculopathy on coronary angiography in the recent 2 months, infection or any other major illnesses that could have interfered with the assessment or participation in the study. Medical clearance was con- firmed by the transplantation team of the National Taiwan University Hospital".
\end{abstract}

Exclusion criteria: NR

N randomised: Total: 37 ; intervention: 14; comparator: 23

Age (mean \pm SD): Intervention: $60.6 \pm 6.2$ years; comparator: $51.6 \pm 12.8$ years

Percentage male: intervention: $78.5 \%$; comparator: $78.2 \%$

Ethnicity: NR

\section{Interventions}

Interventions: "Exercise group subjects were instructed to conduct an 8-week structured home-based exercise program that included a 5-min warm-up, upper and lower extremity light-weight strengthening exercises, $15-20$ min walking at a prescribed intensity with $60-70 \%$ peak $\mathrm{VO}_{2}, 10$ min of stepping exercise with a stool and a $5 \mathrm{~min}$ cool down at least 3 times a week. Exercises for the upper and lower extremities included arms curls, triceps extension in shoulder elevation, chest press and standing shoulder press, as well as half squats, toe raises, bridging exercise and bridging exercise with 1 straight leg rising. The speed of walking was $60-70 \%$ peak $\mathrm{VO}_{2}$ of the baseline measurements".

Components: Exercise only

Setting: Home

Aerobic exercise: Walking, stepping exercises and stationary bike training

Time of start after transplant: Minimum of 12 months

Length of session: 30 minutes

Frequency: 3 times a week

Intensity: Speed walking was $60 \%$ to $70 \%$ peak $\mathrm{VO}_{2 \text { peak }}$

Total duration: 8 weeks

Resistance training included?: No

Comparator: Control group "was asked to keep the usual activity lifestyle during the study period."

Co-interventions: Medical therapy

\section{Outcomes}

Exercise capacity $\left(\mathrm{VO}_{2 \text { peak }}\right)$, Brief version of the World Health Organization Questionnaire on Quality of Life (WHOQoL-BREF)

\section{Risk of bias}

\section{Bias}

\section{Authors' judgement Support for judgement}


Wu 2008 (Continued) $\begin{array}{ll}\begin{array}{l}\text { Random sequence genera- } \\ \text { tion (selection bias) }\end{array} & \begin{array}{l}\text { Method of randomisation was not described. Also } 4 \text { patients "chose" to change } \\ \text { from the intervention to the control group due to time restraints }\end{array}\end{array}$

Allocation concealment Unclear risk The allocation concealment was not described

(selection bias)

\begin{tabular}{lll}
\hline Blinding of outcome as- & Unclear risk & The blinding of outcomes was not described \\
sessment (detection bias) &
\end{tabular}

All outcomes

\begin{tabular}{|c|c|c|}
\hline $\begin{array}{l}\text { Incomplete outcome data } \\
\text { (attrition bias) } \\
\text { All outcomes }\end{array}$ & High risk & $\begin{array}{l}\text { Intervention: } 2 / 14 \text { (14.3\%) lost to follow-up; control: } 4 / 23 \text { (17.4\%) lost to fol- } \\
\text { low-up } \\
\text { In addition } 4 \text { participants in the exercise group changed over to the control } \\
\text { group after randomisation. Analyses were done using the latter group alloca- } \\
\text { tion and not original randomised groups }\end{array}$ \\
\hline
\end{tabular}

\begin{tabular}{|c|c|c|}
\hline $\begin{array}{l}\text { Selective reporting (re- } \\
\text { porting bias) }\end{array}$ & Low risk & All outcomes described in the methods are reported in the results section \\
\hline $\begin{array}{l}\text { Were groups balanced at } \\
\text { baseline? }\end{array}$ & High risk & The exercise group was significantly older than the control group \\
\hline $\begin{array}{l}\text { Did both groups receive } \\
\text { comparable care? }\end{array}$ & Low risk & Both groups received the same co-interventions (medical therapy) \\
\hline Source of funding & Unclear risk & NR \\
\hline $\begin{array}{l}\text { Declared conflicts of Inter- } \\
\text { est }\end{array}$ & Unclear risk & NR \\
\hline
\end{tabular}

BP - blood pressure; CON - continued moderate exercise; ECG - electrocardiogram; HIIT - high-intensity interval training; HR - heart rate; $\mathrm{HRQoL}$ - health-related quality of life; HT - heart transplant; NR - not reported; RCP - respiratory compensation point; RCT - randomised controlled trial; RPE - rated perceived exertion; $\mathrm{rpm}$ - revolutions per minute; $\mathrm{VO}_{2 \text { peak }} / \mathrm{VO}_{2 \text { max }}$ - peak/maximal oxygen uptake

Characteristics of excluded studies [ordered by study ID]

\begin{tabular}{ll}
\hline Study & Reason for exclusion \\
\hline Anonymous 2014 & Not an RCT \\
\hline Belardinelli 2006 & Not an RCT \\
\hline Christensen 2012 & Not an RCT \\
\hline Karapolat 2007 & Home- versus centre-based rehabilitation \\
\hline Kawauchi 2013 & Comparison of two different training regimes of same exercise intensity \\
\hline Kugler 2008 & Authors contacted but full paper was not published and no data were available \\
\hline Nytroen 2014 & Not an RCT \\
\hline Pierce 2008 & Authors were contacted but no data on outcomes of interest was received. \\
\hline
\end{tabular}




\begin{tabular}{ll}
\hline Study & Reason for exclusion \\
\hline Pokan 2004 & Not an RCT \\
\hline Stevinson 1999 & Not an RCT \\
\hline
\end{tabular}

$\mathrm{RCT}$ - randomised controlled trial

Characteristics of studies awaiting assessment [ordered by study ID]

Braith 2005

Methods The purpose of this study was to determine the efficacy of resistance exercise in reversing skeletal
muscle myopathy in heart transplant recipients.

\begin{tabular}{ll}
\hline Participants & $\begin{array}{l}\text { Heart transplant recipients } \\
\text { Intervention group: } \mathrm{N}=8 \\
\text { Comparator group: } \mathrm{N}=7\end{array}$ \\
\hline Interventions & 6 months of resistance exercise \\
\hline Outcomes & Exercise capacity $\left(\mathrm{VO}_{2 \text { peak }}\right)$ \\
\hline Notes & $\mathrm{VO}_{2 \text { peak }}$ is reported graphically for individual patients. The authors were contacted and asked to \\
supply a mean \pm SD. Despite initial positive reply, no data were supplied
\end{tabular}

Emmanuel 2015

\begin{tabular}{ll}
\hline Methods & $\begin{array}{l}\text { The purpose of present study was to analyse the effect of ET on HR response to exercise in HT pa- } \\
\text { tients. }\end{array}$ \\
\hline Participants & $\begin{array}{l}48 \text { sedentary heart transplant recipients (age }=47 \pm 3 \text { years) } \\
\text { Randomised in a 2:1 ratio to exercise training and control }\end{array}$ \\
\hline Interventions & $\begin{array}{l}3 \times \text { weekly aerobic ( } 30 \text { min) and resistance training program (5 exercises) at intensity between } 11 \text { to } \\
13 \text { on the } 6 \text { to } 20 \text { rating of perceived effort scale }\end{array}$ \\
\hline Outcomes & No outcomes of interest were reported in the abstract \\
\hline Notes & Every effort was made to find full text, but no further publications were found \\
\hline
\end{tabular}

\section{Tegtbur 2005}

\begin{tabular}{ll}
\hline Methods & $\begin{array}{l}\text { To determine the time course of physical reconditioning and skeletal muscle adaptation late after } \\
\text { transplantation. }\end{array}$ \\
& "We analysed time course of physical reconditioning data for each home-training session ( $\mathrm{N}=$ \\
& 2396). Constant-load tests with consistent blood lactate concentrations were performed quarter- \\
ly $(\mathrm{n}=105)$ to estimate the time course of skeletal muscle adaptation. Nine heart transplant recipi- \\
ents served as a control group (CG)"
\end{tabular}


Tegtbur 2005 (Continued)

Interventions $\quad 1$ year of an individually tailored home ergometer-training program $(2.1 \pm 0.7$ sessions weekly with matched heart rates, intensity at $10 \%$ below anaerobic threshold)

\begin{tabular}{ll}
\hline Outcomes & Exercise capacity $\left(\mathrm{VO}_{2 p e a k}\right)$ \\
\hline Notes & $\begin{array}{l}\text { Identified from Nytrøen } 2013 \mathrm{c} \text {. Author was emailed (twice) to ask if participants were randomised } \\
\text { ("Nine of } 15 \mathrm{HT} \text { recipients, who were assigned prospectively to the control group (CG)" }\end{array}$ \\
\hline
\end{tabular}

Characteristics of ongoing studies [ordered by study ID]

\section{NCT01760538}

\begin{tabular}{ll}
\hline Trial name or title & Study on Heart Rate Variability in Cardiac Transplant Recipients with Exercise and After Exercise \\
& Training
\end{tabular}

Methods RCT

Enrolment: 30
Inclusion criteria:
- Heart transplant recipients with stable post operation condition
- Age between $20-70$ years
- No acute or severe chronic rejection

\section{Exclusion criteria:}

- Any condition that might affect exercise performance

\begin{tabular}{ll}
\hline Interventions & Exercise training versus usual care \\
\hline Outcomes & Primary outcome measures: \\
& - Heart rate variability \\
& Secondary outcome measures: \\
& - Exercise capacity \\
& Oxygen consumption \\
\hline Starting date & Auguality of life \\
\hline Contact information 2001 \\
\hline Notes & Ying-Tai Wu, National Taiwan University Hospital \\
\hline
\end{tabular}

\section{NCT02602834}

\begin{tabular}{ll}
\hline Trial name or title & Imminently Effect of Interval Training With High Intensity (HIT) After Heart Transplantation \\
\hline Methods & Randomised cross-over assignment, open label \\
\hline Participants & Enrolment: 19 \\
\hline
\end{tabular}


NCT02602834 (Continued)

\section{Inclusion criteria (heart transplant):}

- 1to 10 years after heart transplantation

- Lives in or near Oslo

- Stable health condition

- Optimal medical treatment/medication

- No limiting physical handicap

- Written consent

Inclusion healthy control:

- No verified heart disease

- Willing to perform the study

- Over 18 years

- Written consent

\section{Exclusion criteria:}

- Under 1 year or over 10 year since heart transplant

- Lives far from Oslo

- Unstable health condition

- Not optimal medical treatment and/ or medication

- Limiting physical handicap

- Under 18 years

- Not written consent

\begin{tabular}{ll}
\hline Interventions & Interval training vs moderate exercise \\
\hline Outcomes & Primary outcome measures: \\
- Changes in CRP with interval training compared to moderate training \\
- Changes in interleukin levels with interval training compared to moderate training \\
- Changes in ICAM levels with interval training compared to moderate training \\
Secondary outcome measures: \\
- HRQoL \\
- Oxygen uptake \\
- VO \\
- Questionnaire of physical activity
\end{tabular}

\begin{tabular}{ll}
\hline Starting date & May 2015 \\
\hline Contact information & Lars LG Gullestad, Professor OUS-Oslo University Hospital Rikshospitalet, Cardiology Department \\
\hline Notes & \\
\hline
\end{tabular}

\section{Nytrøen 2016}

\begin{tabular}{ll}
\hline Trial name or title & High Intensity Training in de Novo Heart Transplant Recipients in Scandinavia (HITTS) \\
\hline Methods & Open label RCT \\
\hline Participants & Estimated enrolment: 120 \\
\hline
\end{tabular}


Nytrøen 2016 (Continued)

Inclusion criteria:

- Clinically stable HT recipients approximately 8 to 12 weeks after HT.

- Age > 18 years, both sexes

- Received immunosuppressive therapy as per local protocol.

- Patient willing and capable of giving written informed consent for study participation and anticipated to be able to participate in the study for 9 to 12 months.

Exclusion criteria:

- Unstable condition or postoperative complications

- Recent severe rejection episodes

- Physical disabilities which prevent participation

- Other diseases or disabilities that contradict/refrain from exercise.

\begin{tabular}{ll}
\hline Interventions & Intervention: High-intensity interval training \\
& 9 months of high intensity interval based aerobic exercise (3 times/week) \\
& Comparator: Moderate training \\
& Regular exercise training offered to all heart transplant recipients \\
\hline Outcomes & Exercise capacity $\left(\mathrm{VO}_{2 \text { peak }}\right), \mathrm{HRQ}$ L \\
\hline Starting date & February 18,2013 \\
\hline Contact information & $\begin{array}{l}\text { Kari Nytrøen, PhD, Sahlgrenska University Hospital, Gothenburg, Sweden kari.nytroen@me- } \\
\text { disin.uio.no }\end{array}$ \\
\hline Notes & ClinicalTrials.gov Identifier: NCT01796379 \\
\hline
\end{tabular}

\section{DATA AND ANALYSES}

\section{Comparison 1. Exercise versus no-exercise}

\begin{tabular}{|c|c|c|c|c|}
\hline Outcome or subgroup title & No. of studies & $\begin{array}{l}\text { No. of partici- } \\
\text { pants }\end{array}$ & Statistical method & Effect size \\
\hline 1 Exercise capacity $\left(\mathrm{VO}_{2 \text { peak }}\right)$ & 9 & 284 & $\begin{array}{l}\text { Mean Difference (IV, Fixed, } \\
95 \% \mathrm{Cl} \text { ) }\end{array}$ & $2.49[1.63,3.36]$ \\
\hline $\begin{array}{l}2 \text { Sensitivity analysis (excluding } \\
\text { Kobashigawa 1999) }\end{array}$ & 8 & 257 & $\begin{array}{l}\text { Mean Difference (IV, Fixed, } \\
95 \% \mathrm{Cl} \text { ) }\end{array}$ & $2.59[1.69,3.49]$ \\
\hline $\begin{array}{l}3 \text { Sensitivity analysis (excluding Wu } \\
\text { 2008) }\end{array}$ & 8 & 247 & $\begin{array}{l}\text { Mean Difference (IV, Fixed, } \\
95 \% \mathrm{CI})\end{array}$ & $2.99[1.93,4.05]$ \\
\hline $\begin{array}{l}4 \text { Sensitivity analysis (excluding } \\
\text { Kobashigawa } 1999 \text { and Wu 2008) }\end{array}$ & 7 & 220 & $\begin{array}{l}\text { Mean Difference (IV, Fixed, } \\
95 \% \mathrm{CI})\end{array}$ & $3.20[2.08,4.33]$ \\
\hline
\end{tabular}


Analysis 1.1. Comparison 1 Exercise versus no-exercise, Outcome 1 Exercise capacity $\left(\mathrm{VO}_{2 \text { peak }}\right)$.

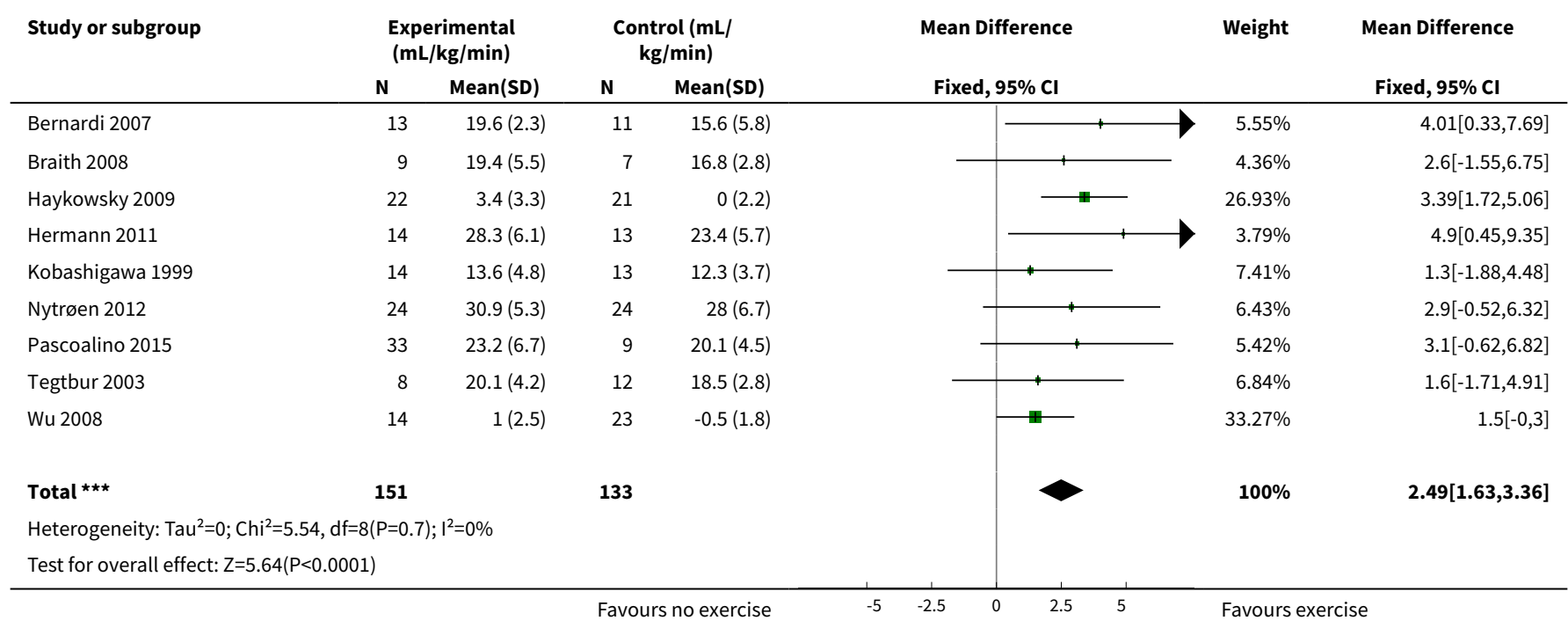

Analysis 1.2. Comparison 1 Exercise versus no-exercise, Outcome 2 Sensitivity analysis (excluding Kobashigawa 1999).

\begin{tabular}{|c|c|c|c|c|c|c|c|}
\hline \multirow[t]{2}{*}{ Study or subgroup } & \multicolumn{2}{|c|}{$\begin{array}{c}\text { Experimental } \\
(\mathrm{mL} / \mathrm{kg} / \mathrm{min})\end{array}$} & \multicolumn{2}{|c|}{$\begin{array}{c}\text { Control (mL/ } \\
\mathrm{kg} / \mathrm{min})\end{array}$} & \multirow{2}{*}{$\begin{array}{c}\text { Mean Difference } \\
\text { Fixed, } 95 \% \mathrm{Cl} \\
\end{array}$} & \multirow[t]{2}{*}{ Weight } & \multirow{2}{*}{$\begin{array}{c}\text { Mean Difference } \\
\text { Fixed, } 95 \% \mathrm{Cl} \\
\end{array}$} \\
\hline & $\mathbf{N}$ & Mean(SD) & $\mathbf{N}$ & Mean(SD) & & & \\
\hline Bernardi 2007 & 13 & $19.6(2.3)$ & 11 & $15.6(5.8)$ & + & $5.99 \%$ & $4.01[0.33,7.69]$ \\
\hline Braith 2008 & 9 & $19.4(5.5)$ & 7 & $16.8(2.8)$ & + & $4.71 \%$ & $2.6[-1.55,6.75]$ \\
\hline Haykowsky 2009 & 22 & $3.4(3.3)$ & 21 & $0(2.2)$ & 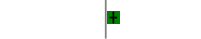 & $29.09 \%$ & $3.39[1.72,5.06]$ \\
\hline Hermann 2011 & 14 & $28.3(6.1)$ & 13 & $23.4(5.7)$ & + & $4.09 \%$ & $4.9[0.45,9.35]$ \\
\hline Pascoalino 2015 & 33 & $23.2(6.7)$ & 9 & $20.1(4.5)$ & + & $5.86 \%$ & $3.1[-0.62,6.82]$ \\
\hline Tegtbur 2003 & 8 & $20.1(4.2)$ & 12 & $18.5(2.8)$ & + & $7.38 \%$ & $1.6[-1.71,4.91]$ \\
\hline Wu 2008 & 14 & $1(2.5)$ & 23 & $-0.5(1.8)$ & $\Phi$ & $35.93 \%$ & $1.5[-0,3]$ \\
\hline 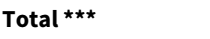 & 137 & & 120 & & 1 & $100 \%$ & $2.59[1.69,3.49]$ \\
\hline \multicolumn{8}{|c|}{ Heterogeneity: $\mathrm{Tau}^{2}=0 ; \mathrm{Chi}^{2}=4.96, \mathrm{df}=7(\mathrm{P}=0.66) ; \mathrm{I}^{2}=0 \%$} \\
\hline
\end{tabular}

Analysis 1.3. Comparison 1 Exercise versus no-exercise, Outcome 3 Sensitivity analysis (excluding Wu 2008).

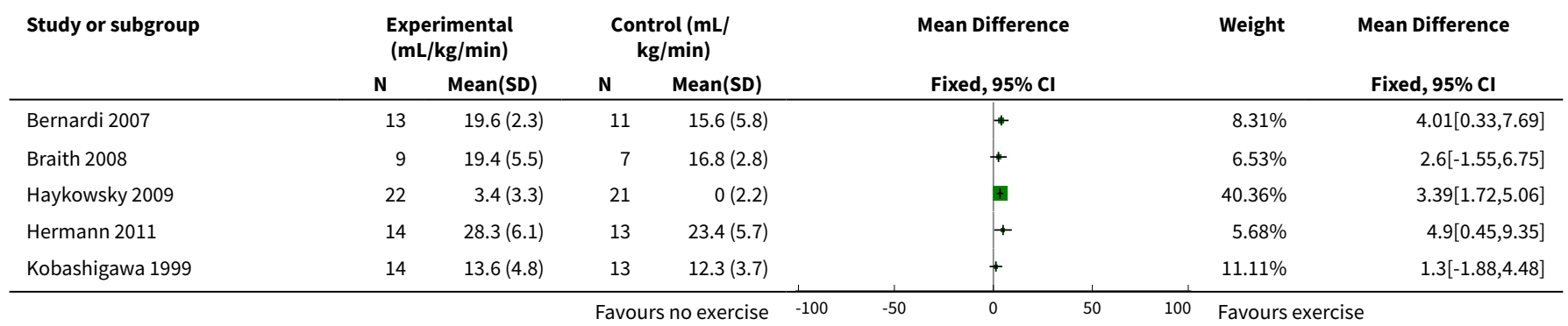




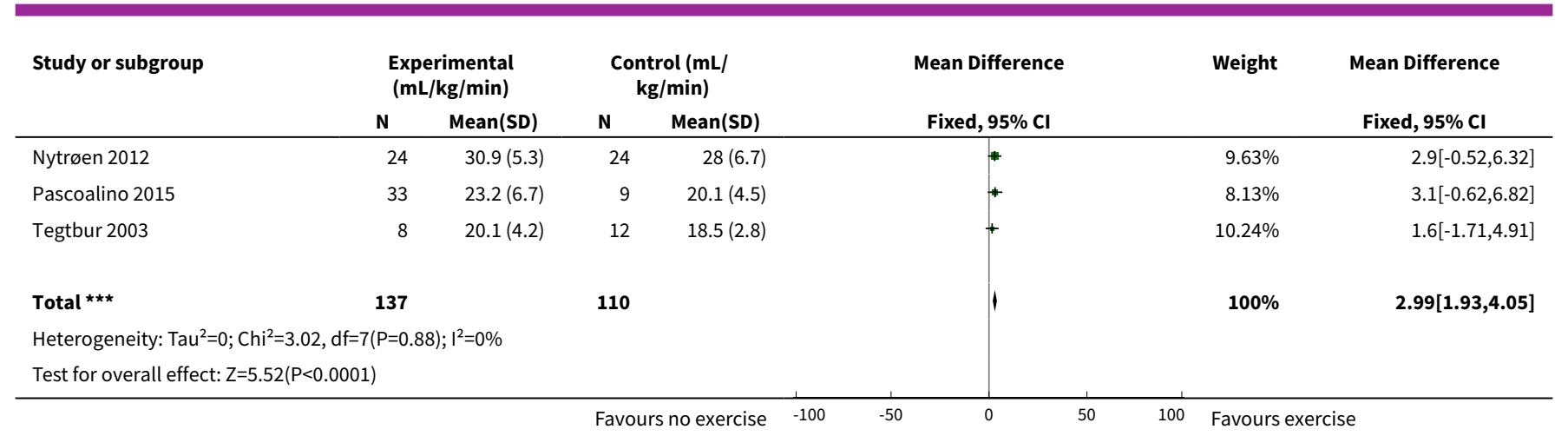

Analysis 1.4. Comparison 1 Exercise versus no-exercise, Outcome 4 Sensitivity analysis (excluding Kobashigawa 1999 and Wu 2008).

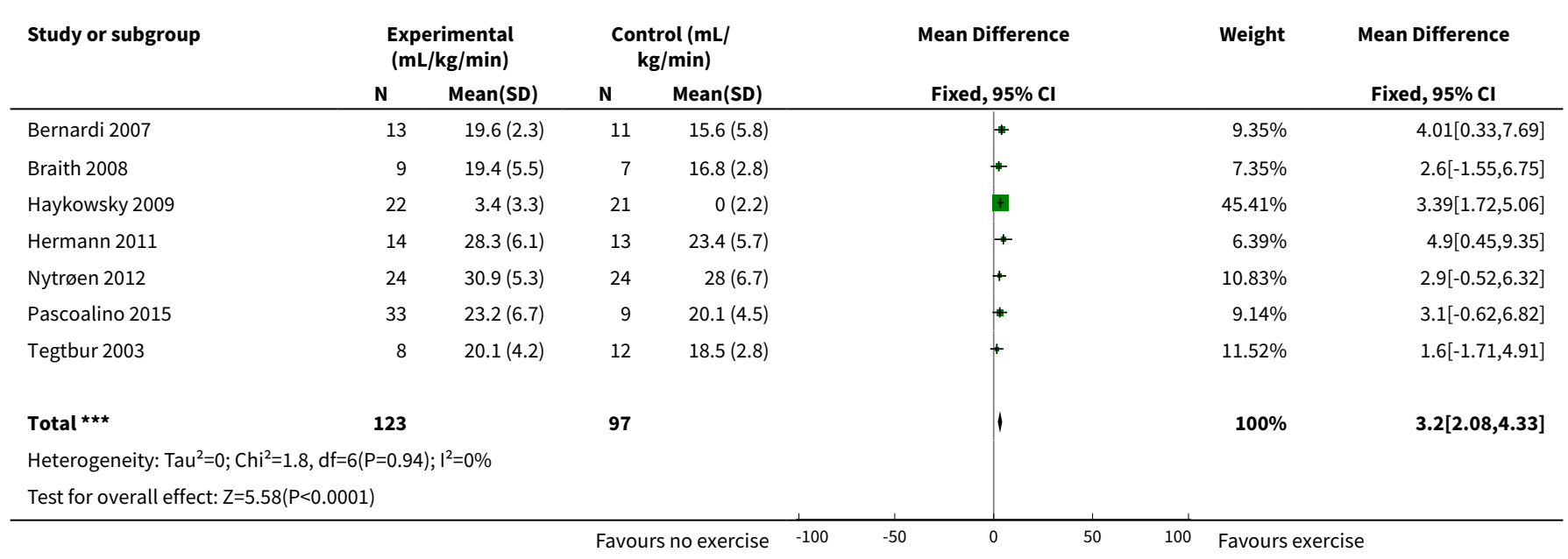

Comparison 2. High-intensity interval training versus continued moderate-intensity exercise

\begin{tabular}{lllll}
\hline Outcome or subgroup title & No. of studies & $\begin{array}{l}\text { No. of partici- } \\
\text { pants }\end{array}$ & Statistical method & Effect size \\
\hline 1 Exercise capacity $\left(\mathrm{VO}_{2 \text { peak }}\right)$ & 1 & 32 & $\begin{array}{l}\text { Mean Difference (IV, Fixed, 95\% } \\
\mathrm{Cl})\end{array}$ & $2.30[0.59,4.01]$ \\
\hline
\end{tabular}

Analysis 2.1. Comparison 2 High-intensity interval training versus continued moderate-intensity exercise, Outcome 1 Exercise capacity $\left(\mathrm{VO}_{2 \text { peak }}\right)$.

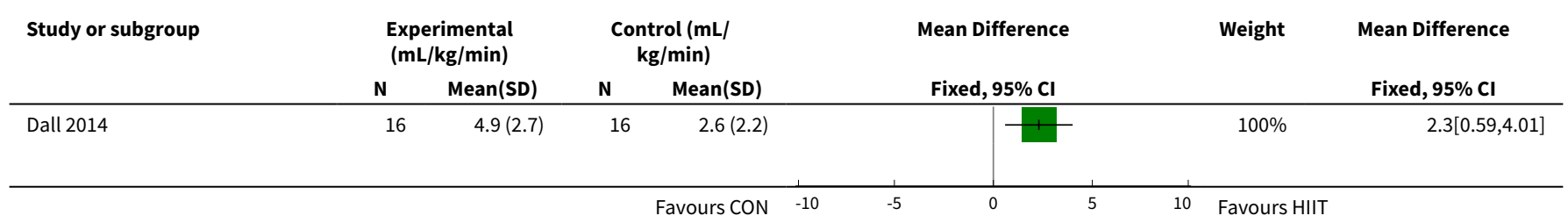




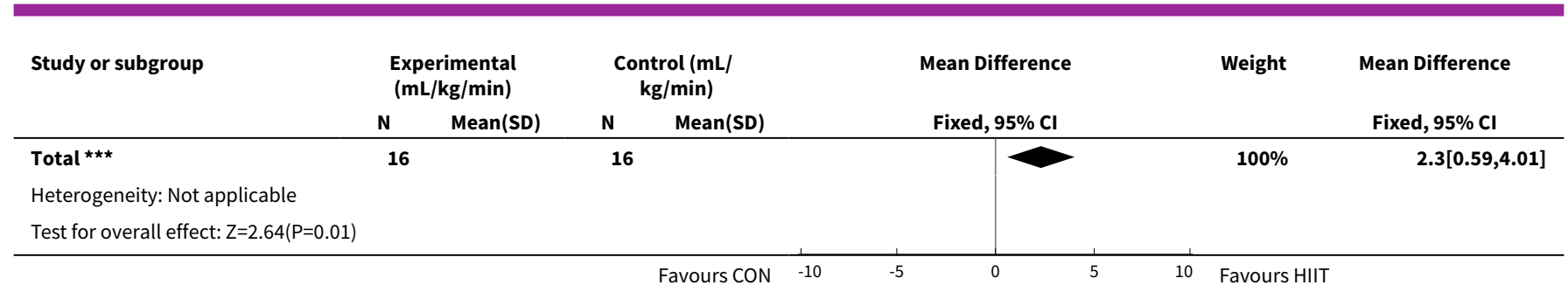

\section{ADDITIONAL TABLES}

Table 1. All-cause withdrawal/drops out at follow-up

\begin{tabular}{|c|c|c|c|c|}
\hline Study & & $\begin{array}{l}\text { Number ran- } \\
\text { domised }\end{array}$ & $\begin{array}{l}\text { Number lost at } \\
\text { follow-up }\end{array}$ & Notes \\
\hline \multirow[t]{2}{*}{ Bernardi 2007} & Intervention & 13 & NR & NR \\
\hline & Control & 11 & NR & NR \\
\hline \multirow[t]{2}{*}{ Braith 2008} & Intervention & 10 & 1 & 1 withdrew due to illness \\
\hline & Control & 10 & 3 & $\begin{array}{l}3 \text { participants not included in the final analysis due } \\
\text { to non-compliance with testing regimen }\end{array}$ \\
\hline \multirow[t]{2}{*}{ Dall 2014} & Intervention & 17 & 1 & \multirow{2}{*}{$\begin{array}{l}1 \text { participant had insufficient exercise testing (res- } \\
\text { piratory exchange ratio }(\mathrm{RER})<0.85 \text { ) and was an } \\
\text { outlier on several parameters, and thus excluded } \\
\text { from the main analyses (cross-over design) }\end{array}$} \\
\hline & Control & 17 & 1 & \\
\hline \multirow{2}{*}{$\begin{array}{l}\text { Haykowsky } \\
2009\end{array}$} & Intervention & 22 & 1 & 1 participant withdrew due to illness \\
\hline & Control & 21 & 2 & $\begin{array}{l}2 \text { participants requested not to perform the post- } \\
\text { intervention assessments }\end{array}$ \\
\hline \multirow[t]{2}{*}{ Hermann 2011} & Intervention & 15 & 1 & $\begin{array}{l}1 \text { participant withdrew due to illness ( } 1 \text { additional } \\
\text { participant lost to echo follow-up) }\end{array}$ \\
\hline & Control & 15 & 2 & $\begin{array}{l}1 \text { participant withdrew due to illness; } 1 \text { withdrew } \\
\text { consent ( } 3 \text { additional participants lost to echo fol- } \\
\text { low-up) }\end{array}$ \\
\hline \multirow{2}{*}{$\begin{array}{l}\text { Kobashigawa } \\
1999\end{array}$} & Intervention & 14 & NR & NR \\
\hline & Control & 13 & NR & NR \\
\hline \multirow[t]{2}{*}{ Nytrøen 2012} & Intervention & 26 & 2 & 2 participants withdrew due to illness \\
\hline & Control & 26 & 2 & $\begin{array}{l}1 \text { participant withdrew due to illness; } 1 \text { lost to fol- } \\
\text { low-up (missing exercise capacity test) }\end{array}$ \\
\hline \multirow[t]{2}{*}{ Pascoalino 2015} & Intervention & 33 & 2 & 1 participant withdrew consent; 1 lost to follow-up \\
\hline & Control & 9 & 0 & 0 participants were lost to follow-up \\
\hline
\end{tabular}


Table 1. All-cause withdrawal/drops out at follow-up (Continued)

\begin{tabular}{|c|c|c|c|c|}
\hline \multirow[t]{2}{*}{ Tegtbur 2003} & Intervention & 16 & 8 & $\begin{array}{l}2 \text { participants declined participation due to per- } \\
\text { sonal reasons; } 2 \text { were excluded due to illness; } 4 \\
\text { dropped out during the intervention due to person- } \\
\text { al reasons }(\mathrm{N}=3 \text { ) or orthopaedic impairment ( } \mathrm{N}= \\
\text { 1) }\end{array}$ \\
\hline & Control & 15 & 3 & $\begin{array}{l}2 \text { participants declined participation due to per- } \\
\text { sonal reasons; } 1 \text { excluded due to illness }\end{array}$ \\
\hline \multirow[t]{2}{*}{ Wu 2008} & Intervention & 14 & 2 & $\begin{array}{l}2 \text { participants dropped out after evaluation. In ad- } \\
\text { dition, } 4 \text { participants in the exercise group changed } \\
\text { over to the control group after randomisation. } \\
\text { Analyses conducted using the latter group alloca- } \\
\text { tion and not original randomised groups }\end{array}$ \\
\hline & Control & 23 & 4 & $\begin{array}{l}4 \text { participants dropped out: } 2 \text { due to renal prob- } \\
\text { lem/anaemia; } 2 \text { for personal reasons }\end{array}$ \\
\hline \multirow{2}{*}{$\begin{array}{l}\text { Combined re- } \\
\text { sults }\end{array}$} & Intervention & 180 & 18 & $10.0 \%$ \\
\hline & Control & 160 & 17 & $10.6 \%$ \\
\hline
\end{tabular}

* All causes of drop out from follow-up included (including mortality)

$\mathrm{NR}=$ not reported

Table 2. Summary of health-related quality of life (HRQOL) scores at follow-up

\begin{tabular}{|c|c|c|c|c|}
\hline \multirow[t]{2}{*}{ Measure of HRQOL } & \multicolumn{2}{|c|}{$\begin{array}{l}\text { Mean (SD) outcome values at fol- } \\
\text { low-up }\end{array}$} & \multirow[t]{2}{*}{$P$ value } & \multirow[t]{2}{*}{ Difference between groups } \\
\hline & $\begin{array}{l}\text { High-intensity } \\
\text { interval training }\end{array}$ & $\begin{array}{l}\text { Continued mod- } \\
\text { erate-intensity } \\
\text { training }\end{array}$ & & \\
\hline \multicolumn{5}{|l|}{ Dall 2014} \\
\hline \multicolumn{5}{|c|}{ SF-36 at 3 months follow-up } \\
\hline Physical functioning & $83.1(15.9)$ & $83.1(15.5)$ & NS & $\mathrm{HIIT}=\mathrm{CON}$ \\
\hline Physical performance & $84.4(25.6)$ & $83.1(15.5)$ & NS & $\mathrm{HIIT}=\mathrm{CON}$ \\
\hline Bodily pain & $85.2(17.0)$ & $83.1(18.2)$ & NS & $\mathrm{HIIT}=\mathrm{CON}$ \\
\hline General health & $65.6(16.4)$ & $65.5(12.7)$ & NS & $\mathrm{HIIT}=\mathrm{CON}$ \\
\hline Vitality & $77.2(15.5)$ & $78.4(12.6)$ & NS & $\mathrm{HIIT}=\mathrm{CON}$ \\
\hline Social functioning & $95.3(11.1)$ & $96.1(7.5)$ & NS & $\mathrm{HIIT}=\mathrm{CON}$ \\
\hline Emotional performance & $89.6(20.1)$ & $91.7(22.8)$ & NS & $\mathrm{HIIT}=\mathrm{CON}$ \\
\hline Mental health & $89.3(7.4)$ & $89.3(5.8)$ & NS & $\mathrm{HIIT}=\mathrm{CON}$ \\
\hline Mental component & $89.3(7.4)$ & $90.0(6.6)$ & NS & $\mathrm{HIIT}=\mathrm{CON}$ \\
\hline
\end{tabular}


Table 2. Summary of health-related quality of life (HRQOL) scores at follow-up (Continued)

\begin{tabular}{|c|c|c|c|c|}
\hline Physical component & $76.4(11.8)$ & $77.5(8.9)$ & NS & $\mathrm{HIIT}=\mathrm{CON}$ \\
\hline \multirow[t]{2}{*}{ Measure of HRQOL } & \multicolumn{2}{|c|}{$\begin{array}{l}\text { Mean (SD) outcome values at fol- } \\
\text { low-up }\end{array}$} & $P$ value & Difference between groups \\
\hline & Exercise & Usual care & & \\
\hline \multicolumn{5}{|l|}{ Nytrøen 2012} \\
\hline \multicolumn{5}{|c|}{ SF-36 at 6 months follow-up } \\
\hline Physical functioning & NR & NR & ${ }^{*} \mathrm{NS}$ & Exercise $=$ Comparator \\
\hline Physical performance & NR & NR & ${ }^{*} \mathrm{NS}$ & Exercise $=$ Comparator \\
\hline Bodily pain & NR & NR & ${ }^{*} \mathrm{NS}$ & Exercise $=$ Comparator \\
\hline General health & 54 & 49 & $\mathrm{P}<0.05$ & Exercise $>$ Comparator \\
\hline Vitality & NR & NR & ${ }^{\star} \mathrm{NS}$ & Exercise $=$ Comparator \\
\hline Social functioning & NR & NR & ${ }^{*} \mathrm{NS}$ & Exercise $=$ Comparator \\
\hline Emotional performance & NR & NR & ${ }^{\star} \mathrm{NS}$ & Exercise $=$ Comparator \\
\hline Mental health & NR & NR & ${ }^{\star} \mathrm{NS}$ & Exercise $=$ Comparator \\
\hline Mental component & NR & NR & ${ }^{*} \mathrm{NS}$ & Exercise $=$ Comparator \\
\hline Physical component & NR & NR & ${ }^{*} \mathrm{NS}$ & Exercise $=$ Comparator \\
\hline
\end{tabular}

Tegtbur 2003

**Profile of quality of life in the chronically ill (PLC)

\begin{tabular}{lllll}
\hline Physical function & NR & NR & $\mathrm{P}<0.05$ & Exercise $>$ Comparator \\
\hline Psychological function & NR & NR & NS & Exercise = Comparator \\
\hline Positive mood & NR & NR & NS & Exercise = Comparator \\
\hline Negative mood & NR & NR & ES & NS \\
\hline Social function & NR & NR & Comparator \\
\hline Social well being & NR & NR & NS & Exercise $=$ Comparator \\
\hline Physical well being & NR & NR & $\mathrm{P}<0.01$ & Exercise $>$ Comparator
\end{tabular}

Wu 2008

\section{World Health Organization Quality of Life (WHOQOL) - BREF}

\begin{tabular}{lllll}
\hline Physical domain & $13.84(1.78)$ & $13.64(2.11)$ & NS & Exercise $=$ Usual care \\
\hline Psychological domain & $13.33(1.85)$ & $14.00(2.45)$ & NS & Exercise $=$ Usual care \\
\hline
\end{tabular}


Table 2. Summary of health-related quality of life (HRQOL) scores at follow-up (Continued)

\begin{tabular}{lllll} 
Social relationship domain & $13.90(2.49)$ & $14.55(1.88)$ & NS & Exercise = Usual care \\
\hline Environment domain & $14.00(2.30)$ & $14.30(2.10)$ & NS & Exercise = Usual care \\
\hline
\end{tabular}

CON = continued moderate-intensity exercise

HIIT = high-intensity interval training

$\mathrm{NR}=$ not reported

NS = Not significant

* There were no significant changes in any of the sum-scores (data not shown)

${ }^{\star *}$ Values reported graphically, with higher values indicating a better self-assessment of quality of life

\section{AP P E N DICES}

\section{Appendix 1. Search strategies}

\section{Cochrane Library}

\#1 MeSH descriptor: [Exercise Therapy] explode all trees

\#2 MeSH descriptor: [Sports] explode all trees

\#3 MeSH descriptor: [Physical Exertion] explode all trees

\#4 rehabilitat ${ }^{\star}$

\#5 (physical ${ }^{\star}$ near (fit* or train ${ }^{\star}$ or therap ${ }^{\star}$ or activit $\left.{ }^{\star}\right)$ )

\#6 MeSH descriptor: [Exercise] explode all trees

\#7 (train*) near (strength* or aerobic ${ }^{\star}$ or exercise ${ }^{\star}$ )

\#8 ((exercise* or fitness) near/3 (treatment or intervent* or program $\left.^{\star}\right)$ )

\#9 MeSH descriptor: [Rehabilitation] explode all trees

\#10 kinesiotherap*

\#11 MeSH descriptor: [Physical Education and Training] explode all trees

\#12 (run* or walk* or jog* or danc ${ }^{\star}$ )

\#13 ((lifestyle or life-style) near/5 (interven* or program* or treatment $\left.{ }^{\star}\right)$ )

\#14 MeSH descriptor: [Dance Therapy] this term only

\#15 MeSH descriptor: [Patient Education as Topic] this term only

\#16 (patient* near/5 educat ${ }^{\star}$ )

\#17 ((lifestyle or life-style) near/5 (interven ${ }^{\star}$ or program* or treatment $\left.{ }^{\star}\right)$ )

\#18 MeSH descriptor: [Self Care] this term only

\#19 (self near/5 (manag* or care or motivate*))

\#20 MeSH descriptor: [Psychotherapy] explode all trees

\#21 psychotherap*

\#22 (psycholog* near/5 intervent*)

\#23 MeSH descriptor: [Counseling] this term only 
\#24 (counselling or counseling)

\#25 ((behavior* or behaviour ${ }^{\star}$ ) near/5 (modify or modificat* or therap* or change))

\#26 (psycho-educat* or psychoeducat ${ }^{\star}$ )

\#27 (motivat* near/5 (intervention or interv*))

\#28 MeSH descriptor: [Health Education] this term only

\#29 (health near/5 educat ${ }^{\star}$ )

\#30 (psychosocial or psycho-social)

\#31 (cognitive near/2 behav*)

$\# 32 \# 1$ or \#2 or \#3 or \#4 or \#5 or \#6 or \#7 or \#8 or \#9 or \#10 or \#11 or \#15 or \#16 or \#17 or \#18 or \#19 or \#20 or \#21 or \#22 or \#23 or \#24 or $\# 25$ or \#26 or \#27 or \#28 or \#29 or \#30 or \#31

\#33 MeSH descriptor: [Heart Transplantation] explode all trees

\#34 (heart near/2 transplant ${ }^{\star}$ )

\#35 (cardiac near/2 transplant ${ }^{\star}$ )

\#36 heart next graft ${ }^{\star}$

\#37 \#33 or \#34 or \#35 or \#36

$\# 38 \# 32$ and \#37

\section{MEDLINE Ovid}

1. exp Exercise Therapy/

2. Sports/

3. Physical Exertion/

4. rehabilitat*.mp.

5. (physical ${ }^{\star}$ adj5 (fit* or train ${ }^{\star}$ or therap ${ }^{\star}$ or activit $\left.\left.{ }^{\star}\right)\right) \cdot \mathrm{mp}$.

6. exp Exercise/

7. (train ${ }^{\star} \operatorname{adj} 5$ (strength ${ }^{\star}$ or aerobic ${ }^{\star}$ or exercise $\left.\left.{ }^{\star}\right)\right)$. tw.

8. ((exercise* or fitness) adj3 (treatment or intervent ${ }^{\star}$ or program $\left.\left.{ }^{\star}\right)\right)$.tw.

9. exp Rehabilitation/

10. kinesiotherap*.tw.

11. "Physical Education and Training"/

12. $\left(\right.$ run $^{\star}$ or walk ${ }^{\star}$ or jog ${ }^{\star}$ or danc $\left.{ }^{\star}\right)$.tw.

13. (("lifestyle" or life-style) adj5 (physical* or activ*)).tw.

14. Dance Therapy/

15. Patient Education as Topic/

16. patient $^{\star}$ adj5 educat $\left.{ }^{\star}\right)$.tw.

17. ((lifestyle or life-style) adj5 (interven* or program* or treatment $\left.\left.{ }^{\star}\right)\right) . t w$.

18. Self Care/ 
19. (self adj5 (manag* or care or motivate $\left.{ }^{\star}\right)$ ).tw.

20. exp Psychotherapy/

21. psychotherap*.tw.

22. $\left(\right.$ psycholog $^{\star}$ adj5 intervent $\left.{ }^{\star}\right)$.tw.

23. Counseling/

24. (counselling or counseling).tw.

25. ((behavior* or behaviour $^{\star}$ ) adj5 (modify or modificat ${ }^{\star}$ or therap ${ }^{\star}$ or change)).tw.

26. (psycho-educat* ${ }^{\star}$ or psychoeducat $\left.{ }^{\star}\right)$.tw.

27. (motivat* ${ }^{\star}$ adj5 (intervention or interv $\left.{ }^{\star}\right)$ ).tw.

28. Health Education/

29. (health adj5 educat*).tw.

30. (psychosocial or psycho-social).tw.

31. (cognitive adj2 behav ${ }^{\star}$ ).tw.

32. or/1-31

33. exp Heart Transplantation/

34. (heart adj2 transplant $\left.{ }^{\star}\right)$.tw.

35. (cardiac adj2 transplant ${ }^{\star}$ ).tw.

36. heart graft ${ }^{\star} . t w$.

37. or/33-36

38. 32 and 37

39. randomized controlled trial.pt.

40. controlled clinical trial.pt.

41. randomized.ab.

42. placebo.ab.

43. drug therapy.fs.

44. randomly.ab.

45. trial.ab.

46. groups.ab.

47.39 or 40 or 41 or 42 or 43 or 44 or 45 or 46

48. exp animals/ not humans.sh.

49. 47 not 48

50. 38 and 49

\section{Embase Ovid}

1. exp kinesiotherapy/

2. exp sport/ 
3. exp exercise/

4. rehabilitat ${ }^{\star}$. tw.

5. (physical ${ }^{\star}$ adj5 ( fit $^{\star}$ or train ${ }^{\star}$ or therap ${ }^{\star}$ or activit $\left.\left.{ }^{\star}\right)\right)$. tw.

6. (train* adj5 (strength* or aerobic ${ }^{\star}$ or exercise*)).tw.

7. ((exercise* or fitness) adj3 (treatment or intervent ${ }^{\star}$ or program $\left.\left.{ }^{\star}\right)\right)$. tw.

8. exp rehabilitation/

9. kinesiotherap^.tw.

10. (run* or walk* or jog* or danc $\left.{ }^{\star}\right)$.tw.

11. (("lifestyle" or life-style) adj5 (physical* or activ*)).tw.

12. dance therapy/

13. patient education/

14. patient $^{\star}$ adj5 educat*).tw.

15. ((lifestyle or life-style) adj5 (interven* or program* or treatment $\left.\left.{ }^{\star}\right)\right) . t w$.

16. self care/

17. (self adj5 (manag* or care or motivate $\left.{ }^{\star}\right)$ ).tw.

18. exp psychotherapy/

19. psychotherap ${ }^{\star}$. tw.

20. (psycholog* adj5 intervent $\left.{ }^{\star}\right)$.tw.

21. counseling/

22. (counselling or counseling).tw.

23. ((behavior ${ }^{\star}$ or behaviour $\left.{ }^{\star}\right)$ adj5 (modify or modificat ${ }^{\star}$ or therap ${ }^{\star}$ or change)).tw.

24. (psycho-educat* ${ }^{\star}$ or psychoeducat $\left.{ }^{\star}\right)$.tw.

25. (motivat* adj5 (intervention or interv*)).tw.

26. health education/

27. (health adj5 educat $\left.{ }^{\star}\right)$.tw.

28. (psychosocial or psycho-social).tw.

29. (cognitive adj2 behav ${ }^{\star}$ ).tw.

30. or/1-29

31. exp heart transplantation/

32. (heart adj2 transplant $\left.{ }^{\star}\right) . t w$.

33. (cardiac adj2 transplant $\left.{ }^{\star}\right)$.tw.

34. heart graft ${ }^{\star}$. tw.

35. or $/ 31-34$

36. 30 and 35

37. random\$.tw.

Exercise-based cardiac rehabilitation in heart transplant recipients (Review) 
38. factorial\$s.tw.

39. crossover\$.tw.

40. cross over\$.tw.

41. cross-over\$.tw.

42. placebo\$.tw.

43. (doubl\$ adj blind\$).tw.

44. (singl\$ adj blind\$).tw.

45. assign\$.tw.

46. allocat\$.tw.

47. volunteer\$.tw.

48. crossover procedure/

49. double blind procedure/

50. randomized controlled trial/

51. single blind procedure/

52.37 or 38 or 39 or 40 or 41 or 42 or 43 or 44 or 45 or 46 or 47 or 48 or 49 or 50 or 51

53. (animal/ or nonhuman/) not human/

54.52 not 53

55. 36 and 54

\section{CINAHL}

S55 S36 AND S54

$\mathrm{S} 54 \mathrm{~S} 37$ or S38 or S39 or S40 or S41 or S42 or S43 or S44 or S45 or S46 or S47 or S48 or S49 or S50 or S51 or S52 or S53

S53 TX cross-over ${ }^{\star}$

S52 TX crossover*

S51 TX volunteer*

S50 (MH "Crossover Design")

S49 TX allocat*

S48 TX control*

S47 TX assign*

S46 TX placebo*

S45 (MH "Placebos")

S44 TX random*

S43 TX (doubl* N1 mask*)

S42 TX (singl* N1 mask*)

S41 TX (doubl* N1 blind ${ }^{\star}$ )

S40 TX (singl* N1 blind*) 
S39 TX (clinic* N1 trial?)

S38 PT clinical trial

S37 (MH "Clinical Trials+")

S36 S30 AND S35

S35 S31 OR S32 OR S33 OR S34

S34 "heart graft*"

S33 cardiac N2 transplant*

S32 heart N2 transplant*

S31 (MH "Heart Transplantation+")

S30 S1 OR S2 OR S3 OR S4 OR S5 OR S6 OR S7 OR S8 OR S9 OR S10 OR S11 OR S12 OR S13 OR S14 OR S15 OR S16 OR S17 OR S18 OR S19 OR S20 OR S21 OR S22 OR S23 OR S24 OR S25 OR S26 OR S27 OR S28 OR S29

S29 (cognitive N2 behav ${ }^{\star}$ )

S28 (psychosocial or psycho-social)

S27 (health N5 educat*)

S26 (MH "Health Education")

S25 (motivat ${ }^{\star}$ N5 (intervention or interv $\left.{ }^{\star}\right)$ )

S24 psycho-educat* or psychoeducat*

S23 ((behavior^ or behaviour ${ }^{\star}$ ) N5 (modify or modificat* or therap* or change))

S22 counselling or counseling

S21 (MH "Counseling+")

S20 (psycholog ${ }^{\star}$ N5 intervent ${ }^{\star}$ )

S19 psychotherap*

S18 (MH "Psychotherapy+")

S17 (self N5 (manag* or care or motivate*))

S16 (MH "Self Care+")

S15 ((lifestyle or life-style) N5 (interven* or program* ${ }^{\star}$ or treatment $\left.{ }^{\star}\right)$ )

S14 patient ${ }^{\star}$ N5 educat ${ }^{\star}$

S13 (MH "Dance Therapy")

S12 (("lifestyle" or life-style) N5 (physical* or activ*))

S11 (run* or walk* or jog* or danc*)

S10 kinesiotherap*

S9 (MH "Rehabilitation+")

S8 ((exercise* or fitness) N3 (treatment or intervent ${ }^{\star}$ or program))

S7 (train* N5 (strength* or aerobic ${ }^{\star}$ or exercise $\left.{ }^{\star}\right)$ )

S6 physical* N5 (fit* or train* or therap* or activit*) 
S5 rehabilitat*

S4 (MH "Exertion+")

S3 (MH "Physical Activity")

S2 (MH "Sports+")

S1 (MH "Therapeutic Exercise+")

\section{Web of Science}

\# 8 \#7 AND \#6

\# 7 TS $=\left(\right.$ random $^{\star}$ or blind ${ }^{\star}$ or allocat ${ }^{\star}$ or assign ${ }^{\star}$ or trial ${ }^{\star}$ or placebo* or crossover $^{\star}$ or cross-over $\left.^{\star}\right)$

\# 6 \#5 AND \#4

\# 5 TS=("heart transplant*" or "cardiac transplant*" or "heart graft*")

\# 4 \#3 OR \#2 OR \#1

\# 3 TS=(psychotherap* or psycholog* or counselling or counseling or behavior ${ }^{\star}$ or behaviour ${ }^{\star}$ or psycho-educat* or psychoeducat* or motivat $^{\star}$ or psychosocial or psycho-social or cognitive)

\# 2 TS=("self manag*" or "self car*" or "self motivat*")

\# 1 TS=(rehabilitat* or physical ${ }^{\star}$ or fit* or train* or exercise* or fitness or kinesiotherap* or run* or walk* or jog* or danc ${ }^{\star}$ or "lifestyle" or life-style or sport*)

\section{WHO ICTRP}

exercise AND "heart transplant"

training AND "heart transplant"

\section{Clinicaltrials.gov}

exercise AND "heart transplant"

training AND "heart transplant"

\section{CONTRIBUTIONS OF AUTHORS}

LA undertook study selection, data extraction and risk of bias assessment, led the writing of the review and approved the final manuscript.

TN undertook study selection, data extraction and risk of bias assessment, assisted in the writing of the review and approved the final manuscript.

$\mathrm{CD}$ assisted in writing the protocol, provided clinical expertise, edited the review and approved the final manuscript.

LB provided clinical expertise, edited the review and approved the final manuscript.

RST led the statistical analysis, edited the review and approved the final manuscript.

\section{DECLARATIONSOF INTEREST}

LA is an author on a number of other Cochrane cardiac rehabilitation reviews.

$C D$ is an author of several publications on exercise in heart transplant recipients.

TN declares she has no conflicts of interest.

LB declares she has no conflicts of interest.

CB declares she has no conflicts of interest. 
RST is an author on a number of other Cochrane cardiac rehabilitation reviews and is currently the co-chief investigator on the programme of research with the overarching aims of developing and evaluating a home-based cardiac rehabilitation intervention for people with heart failure and their carers (PGFAR RP-PG-0611-12004).

\section{SOURCES OF SUPPORT}

\section{Internal sources}

- University of Exeter Medical School, UK.

\section{External sources}

- NIHR, UK.

This project was supported by the National Institute for Health Research, via Cochrane Infrastructure funding to the Heart Group. The views and opinions expressed therein are those of the authors and do not necessarily reflect those of the Systematic Reviews Programme, NIHR, NHS, or the Department of Health, UK.

\section{DIFFERENCES BETWEEN PROTOCOLANDREVIEW}

We conducted this systematic review according to the published protocol (Anderson 2016a).

However, the objectives of this review differ from those described in the protocol. In the review 'morbidity' was replaced by 'adverse events' and 'costs' was added, in order to better reflect the outcome measures being collected.

Also, due to the small number of included studies, we were unable to stratify meta-analysis of outcomes according to the length of trial duration, or to undertake univariate meta-regression to explore heterogeneity and examine potential treatment effect modifiers.

In addition to searching CPCI-S on the Web of Science, as described in the protocol, the search was expanded to the core collection for the purposes of this review.

The protocol states that we would assess the risk of bias of blinding of participants and personnel. However, do to the nature of the intervention, this review assessed blinding of outcome assessors instead.

The protocol states that we would extract data on funding and notable conflicts of interest of trial authors. Instead, we assessed the risk of bias due to funding or conflicts of interest for each study and reported our assessment in the risk of bias tables.

\section{N DEX TERMS}

\section{Medical Subject Headings (MeSH)}

*Exercise; *Exercise Tolerance; Cardiac Rehabilitation [ ${ }^{\star}$ methods]; Heart Transplantation [ ${ }^{\star}$ rehabilitation]; High-Intensity Interval Training; Physical Conditioning, Human [ ${ }^{\star}$ methods]; Quality of Life; Randomized Controlled Trials as Topic

\section{MeSH check words}

Female; Humans; Male; Middle Aged 